\title{
Nutrition economics disease related malnutrition and the economic health care value of medical nutrition
}

Citation for published version (APA):

Freijer, K. (2014). Nutrition economics disease related malnutrition and the economic health care value of medical nutrition. [Doctoral Thesis, Maastricht University]. Maastricht University. https://doi.org/10.26481/dis.20140924kf

Document status and date:

Published: 01/01/2014

DOI:

$10.26481 /$ dis.20140924kf

Document Version:

Publisher's PDF, also known as Version of record

\section{Please check the document version of this publication:}

- A submitted manuscript is the version of the article upon submission and before peer-review. There can be important differences between the submitted version and the official published version of record.

People interested in the research are advised to contact the author for the final version of the publication, or visit the DOI to the publisher's website.

- The final author version and the galley proof are versions of the publication after peer review.

- The final published version features the final layout of the paper including the volume, issue and page numbers.

Link to publication

\footnotetext{
General rights rights.

- You may freely distribute the URL identifying the publication in the public portal. please follow below link for the End User Agreement:

www.umlib.nl/taverne-license

Take down policy

If you believe that this document breaches copyright please contact us at:

repository@maastrichtuniversity.nl

providing details and we will investigate your claim.
}

Copyright and moral rights for the publications made accessible in the public portal are retained by the authors and/or other copyright owners and it is a condition of accessing publications that users recognise and abide by the legal requirements associated with these

- Users may download and print one copy of any publication from the public portal for the purpose of private study or research.

- You may not further distribute the material or use it for any profit-making activity or commercial gain

If the publication is distributed under the terms of Article $25 \mathrm{fa}$ of the Dutch Copyright Act, indicated by the "Taverne" license above, 


\section{Nutrition Economics Disease related malnutrition \& the economic health care value of medical nutrition}


(C) Copyright K. Freijer, Maastricht 2014

Layout: Tiny Wouters \& Karen Freijer

Cover design: Karen Freijer

Printed by: Proefschriftmaken.nl || Uitgeverij BOXPress

ISBN: 978-90-8891-897-1

The research presented in this thesis was conducted at the School for Public Health and Primary Care: CAPHRI, Department of Health Services Research (HSR) at the Faculty of Health, Medicine and Life Sciences, Maastricht University, The Netherlands.

Some of the studies in this thesis have been supported by grants from VNFKD and Nutricia Advanced Medical Nutrition.

Financial support for the publication of this thesis was provided by by the Landelijke Prevalentiemeting Zorgproblemen (LPZ), Nutricia Advanced Medical Nutrition, MediZorg, Ars Accessus Medica, Fresenius-Kabi Netherlands, Nestlé Health Science, Mediq Tefa and Sorgente. 


\title{
Nutrition Economics Disease related malnutrition \& the economic health care value of medical nutrition
}

\author{
PROEFSCHRIFT \\ ter verkrijging van de graad van doctor \\ aan de Universiteit Maastricht, \\ op gezag van de Rector Magnificus, Prof. dr. L.L.G. Soete, \\ volgens het besluit van het College van Decanen, \\ in het openbaar te verdedigen \\ op woensdag 24 september 2014 om 16:00 uur
}

door

KAREN FREIJER 
Promotor

Prof. dr. J.M.G.A. Schols

\title{
Copromotores
}

\author{
Dr. R.J.G. Halfens \\ Dr. J.M.M. Meijers \\ Dr. M.J.C. Nuijten
}

\section{Beoordelingscommissie}

Prof. dr. S.M.A.A. Evers (voorzitter)

Prof. dr. M. Elia (University of Southampton, United Kingdom)

Prof. dr. W.N.J. Groot

Prof. dr. ir. C.P.G.M. de Groot (Wageningen University \&Research centre)

Prof. dr. A.M.W.J. Schols 
$\mathcal{A}$ (tijd daar

Het duurt even voordat je je ontspant.

Langzaam ga je steeds comfortabeler liggen.

En als je dan helemaal op je gemak bent

eindig je ondersteboven, binnenstebuiten.

Volledige overgave.

Soms lijkt het alsof je weet wat je wilt.

Een duidelijk doel, richting en resultaat.

Maar dan blijkt dat je juist niet wilt zijn waar je bent.

Je wilt terug, dan heen, en terug.

zo hoort het.

Geen oordeel, geen dubbele agenda.

Een tikkeltje eigenwijs en opportunistisch.

Niets kan mij meer verwarmen

dan jou op me af zien komen lopen. Elke dag weer.

Onvoorwaardelijke liefde.

Hovannouhi Houniet 



\section{Contents}

$\begin{array}{lll}\text { Chapter } 1 \text { General introduction } & 9\end{array}$

$\begin{array}{lll}\text { Chapter } 2 & \text { The economic costs of disease related malnutrition }\end{array}$

Chapter $3 \quad$ Analysis of the health economic impact of medical nutrition 37

in The Netherlands

Chapter $4 \quad$ The budget impact of oral nutritional supplements for disease $\quad 49$

related malnutrition in elderly in the community setting

Chapter 5 The economic value of enteral medical nutrition in the

67

management of disease related malnutrition: a systematic review

Chapter $6 \quad$ Nutrition economics - The view of international experts

regarding health economics for medical nutrition in disease

related malnutrition

Chapter 7 General discussion

Summary

Samenvatting

Dankwoord

About the author

Publications

Valorisation 

1

General introduction 
Chapter 1 


\section{Motivation for the thesis}

Without nutrition life is not possible. Already in the womb sufficient nutrition is needed for the embryo to evolve. From that time we have to eat and drink every day to provide our body with the nutrients needed to meet the requirements to prevent illness as well as to manage metabolic stress situations. Disease, injury, trauma or surgery are examples of such stress situations in which there is an increased need for specific nutrients to strengthen the functioning of our immune system and recovery among others. Malnutrition, meaning under-nutrition (lack of nutrients) in health care also known as disease related malnutrition (DRM) in this thesis, is leading to health impairment associated with high health care costs. DRM is one of the most important indications for the use of medical nutrition, which is a special food indicated to be used in the total treatment of patients. It comprises parenteral as well as enteral nutrition. The latter was the focus in this thesis and is regulated as "foods for special medical purposes "(FSMP), defined by the European Commission Directive 1999/21/EC independent of the route of application ${ }^{1}$. FSMP products include oral nutritional supplements (ONS) as well as enteral tube feeding (ETF) via nasogastric, naso-enteral, or percutaneous tubes and contain regulated minimum and maximum levels of macro (carbohydrates, protein, fat) and micro (vitamins, minerals, trace-elements) nutrients. These products are not only confined to inpatients, but can also be used by outpatients either as a complete daily nutrition or as a supplement ${ }^{1}$. FSMP has to be used under medical supervision and can be eligible for reimbursement. Evidence on safety, efficacy and effectiveness of this medical nutrition is in place and research continues, however economic evaluations for assessing the cost-effectiveness of medical nutrition are yet scarce and under discussion. Now more than ever evidence on this costs-benefits relationship of a technology is crucial to be applied in health care. In The Netherlands cost-effectiveness is one of the criteria in the reimbursement assessment for years. A recent report of the Dutch Health Care Insurance Board (CVZ) indicated an even more prominent role in health care for this criterion regarding all health technologies and not only for drugs as this criterion was almost exclusively used for ${ }^{2}$. Over the years, evidence of the use of medical nutrition in the management of DRM has demonstrated functional as well as clinical benefits, but economic benefits are still rarely explored. This thesis therefore explores the health economic value as well as the methodological issues in the cost-effectiveness assessment of medical nutrition.

This introduction section consists of two parts. In the first part relevant background information is given about health economics including economic evaluations, medical nutrition and about disease related malnutrition as the most prevalent indication of medical nutrition. The second part describes the aims and the outline of this thesis. 


\section{Background information}

\subsection{Health economics (HE)}

The creation of health economics (HE) dates to 1963, when the leading economist of that time Dr Arrow published his article "Uncertainty and the welfare economics of medical care" in The American Economic Review ${ }^{3}$. This publication is seen as the birth of $\mathrm{HE}$ as a sub-discipline of economics which is the study of scarcity and the means by which this problem is dealt with ${ }^{4}$. The essence in economics is that choices have to be made as there will never be enough resources to do all we might like, so this problem should be rationally addressed by using a framework ${ }^{5}$. HE is described as the application of economic theory, models and empirical techniques to the analysis of decision-making by individuals, health care providers and governments with respect to health and health care ${ }^{6}$. It includes evaluation of the health system and of health policies from an economic perspective, of the demand for and supply of health care, and of medical technologies and interventions. Health system resources planning and organization, consideration and evaluation of the determinants of health, as well as analysis of health system performance in terms of equity and allocative efficiency are also included ${ }^{7}$. The used set of techniques thus attempt to allocate limited health care resources among unlimited wants in need to achieve the maximum health benefit. One of the techniques that can be used is economic evaluations, being "comparative analyses of alternative courses of action in terms of both their costs and consequences $^{\prime 8}$. These economic evaluations have a central role within health technology assessment (HTA) and are nowadays even crucial due to the growing pressure on decision makers and health care providers to obtain the maximum possible benefit, given the resources available ${ }^{9}$. The International Network of Agencies for Health Technology Assessment (INAHTA) has defined HTA as the systematic evaluation of properties, effects, and/or impacts of health care technology. It may address the direct, intended consequences of technologies as well as their indirect, unintended consequences and the main purpose is to inform technology-related policymaking in health care. The medical, organizational, economic as well as the societal consequences of imbedding health technologies within the health system are dealt with. This assessment is conducted by interdisciplinary groups using explicit analytical frameworks based on a variety of methods embedded in the process steps. Drummond et al. ${ }^{10}$ concluded that there are eight major steps in a HTA process: 1 . Selecting topics for appraisal, 2. Defining the decision problem, 3. Searching for all the evidence, 4. Systematic review of the evidence, 5. Economic evaluation, 6. Assessing social, legal and ethical implications, 7. Formulating recommendations and implementation of policies and 8 . Monitoring the impact.

Within health care three main types of economic evaluations are used: a cost-benefit (CBA), cost-effectiveness (CEA) or cost-utility analysis (CUA) depending on whether the consequences are expressed as monetary measures, natural units or preference-based 
measures $^{8,11}$. Such comparisons are most useful when one of the alternatives being considered is standard care, as this allows the decision maker to consider whether an innovation is better than the status quo ${ }^{8}$. In measuring the relationship between costs and benefits, economic analyses typically arrive at a ratio of the extra costs required to achieve one extra unit of clinical outcome (the so-called incremental cost-effectiveness ratio (ICER)). Depending on the term used for the clinical effect, the specific analysis measures the cost-effectiveness ratio (direct clinical term used for the clinical effect, e.g. extended life years or avoided complications), the cost-utility ratio (utility term is used, e.g. Quality Adjusted Life Years (QALY)) or the cost-benefit ratio (monetary terms are used $)^{12}$. The difference in the total cost ( $\Delta$ cost) between two technologies ( $A$ and $B$ ) over the difference in their total effect ( $\Delta$ effect) can then be expressed as an incremental cost-effectiveness, -utility or -benefit ratio (ICR): $\Delta$ total cost / $\Delta$ total effect. A cost-effectiveness ratio of a certain health care program can then be compared with the ratios associated with other programs. This will reveal whether or not the studied treatment is efficient (cost-effective): achieving the maximal incremental (marginal) health benefit for a fixed amount of resources (costs).

For pharmaceuticals and other health technologies including devices HTA is common practice since several years including submission of health economics data to support application for reimbursement. Since that time, reimbursement agencies in different countries have issued evaluation guidelines, resulting in a large number of published research papers on economic evaluation of health technologies. Since 2009 specialists have argued that specific methodological issues in the assessment of the evidence (effectiveness and cost-effectiveness) of medical devices are more challenging than for other pharmaceuticals. These experts concluded that these issues therefore require more attention in conducting reliable evaluations ${ }^{13,14}$. HE evaluations for medical nutrition are not common yet, but due to the earlier described changing health care, the need for these analyses is increasing. As nutrition is not a pharmaceutical product, experts in the field of $\mathrm{HE}$ and nutrition have introduced "nutrition economics" as a novel discipline within $\mathrm{HE}^{15}$. Similar to medical devices these specialists concluded that the methodological concepts and issues in the evaluation of nutrition for non-diseased individuals, requires a range of alternative approaches, e.g. to enrich the basic outcome data by carrying out more pragmatic trials instead of very restrictive phase III-type $\mathrm{RCTs}^{16}$. As medical nutrition is intended for the diseased instead of the non-diseased population, potential specific issues in assessing its evidence as part of nutrition economics have to be explored as well.

\subsection{Medical nutrition}

Medical nutrition comprises parenteral nutrition, regulated in pharmaceutical legislation, as well as all forms of enteral nutritional support that are regulated as "foods for special medical purposes"(FSMP), defined by the European Commission Directive 1999/21/EC independent of the route of application ${ }^{1}$. For the purposes of this 
thesis, the term medical nutrition is used only for FSMP, which is a category of dietary foods for particular nutritional uses, specially processed or formulated and intended for the dietary management of patients and to be used under medical supervision. FSMP products include oral nutritional supplements (ONS) as well as enteral tube feeding (ETF) via nasogastric, naso-enteral, or percutaneous tubes and contain regulated minimum and maximum levels of macro (carbohydrates, protein, fat) and micro (vitamins, minerals, trace-elements) nutrients. These products are not only confined to inpatients, but can also be used by patients in the community setting either as a complete daily nutrition or as a supplement to the daily diet ${ }^{1,17}$.

\subsection{Disease related malnutrition (DRM)}

One of the most prevalent indications for the use of medical nutrition is malnutrition, including both over-nutrition (too many nutrients) and under-nutrition (insufficient nutrition $)^{18-20}$. Although there is no universally accepted definition of malnutrition, the following definition is widely acknowledged, including the members of the European Society for Parenteral and Enteral Nutrition (ESPEN): 'A state of nutrition in which a deficiency, excess or imbalance of energy, protein, and other nutrients causes measurable adverse effects on tissue/body form (body shape, size and composition) function, and clinical outcome ${ }^{21}$. Causes of malnutrition can be due to physical, psychological, medical and social factors or a combination thereof and determine the malnutrition type/syndrome ${ }^{20}$. Before an optimal treatment can be provided, it must be clear which type of malnutrition has to be managed. An International Guideline Committee recently developed a consensus approach to defining malnutrition syndromes for adults in the clinical setting. Consensus was achieved through a series of meetings held at the A.S.P.E.N. and ESPEN Congresses. It was agreed that an etiologybased approach that incorporates a current understanding of inflammatory response would be most appropriate. The Committee proposes the following nomenclature for nutrition diagnosis in adults in the clinical practice setting. "Starvation-related malnutrition", when there is chronic starvation without inflammation, "chronic diseaserelated malnutrition", when inflammation is chronic and of mild to moderate degree, and "acute disease or injury-related malnutrition", when inflammation is acute and of severe degree ${ }^{22}$. For the purposes of this thesis, the term malnutrition is used only for under-nutrition in health care, also known as disease related malnutrition (DRM). Furthermore, as the health care management in children is different from that in adults ( $>18$ years), the thesis is exclusively focussed on the latter.

The causes of DRM are multi-factorial of which the metabolic stress of the body due to acute or chronic diseases resulting in catabolism is an important one ${ }^{23}$. This breakdown state of the body increases the daily nutritional needs, in particular for protein. Patientrelated factors resulting from disease and disability that contribute to low food intake as well as lack of knowledge together with organizational and institutional aspects are other causes of DRM. Malnutrition is not a new problem and with an ageing population 
DRM continues to become a major public health concern, as increasing age is associated with an increased risk of malnutrition ${ }^{24}$. About 33 million patients in Europe are affected by DRM costing governments up to $€ 170$ billion per year ${ }^{25}$. Next to these economic consequences, DRM has also many clinical disadvantages, like an increased morbidity, a prolonged hospitalization, a decreased recovery and an impaired immune system, all decreasing the quality of life ${ }^{20,23}$. Although in some cases improvement of the quality or quantity of food supplied can ameliorate the problem, in many cases the person concerned is simply unable or unwilling to consume sufficient normal food to meet their nutritional requirements to manage the DRM. Particularly in the case of disease, it is literally of vital importance to consider other options to improve nutritional intake, such as FSMP products. Due to the catabolic state combined with insufficient nutrient intake, loss of lean body mass leads to weight loss being an independent risk factor for mortality in chronically ill patients; mortality is four times higher for those with a $5 \%$ unintentional weight loss within one month ${ }^{26,27}$. This correlation has been confirmed in numerous other studies ${ }^{28-30}$ and the most recent study on this topic has shown that an unintentional weight loss of $15 \%$ or more from maximum body weight was associated with increased risk of death from all causes among overweight men and among women regardless of maximum $\mathrm{BMI}^{31}$. A rapid unintentional weight loss ( $5 \%$ or more within 1 month or $10 \%$ or more in 6 months) is due to loss of lean body mass and not to a more desired loss of fat tissue, as muscle mass is weighing far more than fat mass. This is why this weight loss criterion is part of all the different existing screening tools for DRM in adults ${ }^{20}$.

A Delphi study also concluded that involuntary weight loss is one of the important elements in the operationalism of under-nutrition next to body mass index, which are included in just some of the existing screening tools ${ }^{32}$. Without nutritional intake, mortality occurs already after about 28 days in chronically ill patients versus approximately 70 days in healthy persons, caused by a $40 \%$ weight loss ${ }^{26}$. Weight loss can be limited if the daily protein intake together with sufficient calories, vitamins, minerals and trace elements, meet the higher nutritional need in patients with DRM. The body is then using the exogenous protein (nutrition) instead of breaking down the lean body mass as an endogenous source of protein that is needed for the construction of e.g. hormones and enzymes, our defence and transport system, regulating/ monitoring the fluid and acid-base balance and the healing process. This adequate intake of the required nutrients can help breaking the virtuous destructive cycle of catabolism initiated by disease, trauma, injury or surgery (Figure 1.1).

The nutritional status is one of the factors that affect the extent to which the metabolic stress response occurs, next to the size of the injury/disease/trauma/surgery and the degree of the patient's pain sensation ${ }^{33}$. By influencing these factors, the metabolic stress response can thus be influenced. Another essential, often forgotten, aspect in retaining the lean body mass is exercise of the muscles to prevent its atrophy ${ }^{33}$. So breaking the virtuous catabolism cycle through nutrition and exercise is leading to a 
decrease of DRM together with its negative consequences resulting in an improved recovery, decreasing the catabolism cycle etc. (Figure 1.1).

Early screening and treatment of DRM in patients is thus very important. Different screening tools have been developed to estimate the prevalence of (risk of) DRM in patients in all ages and/or in different settings. The issues related to the screening of DRM have been investigated and reported in other publications ${ }^{34,35}$, and are therefore excluded from this thesis.
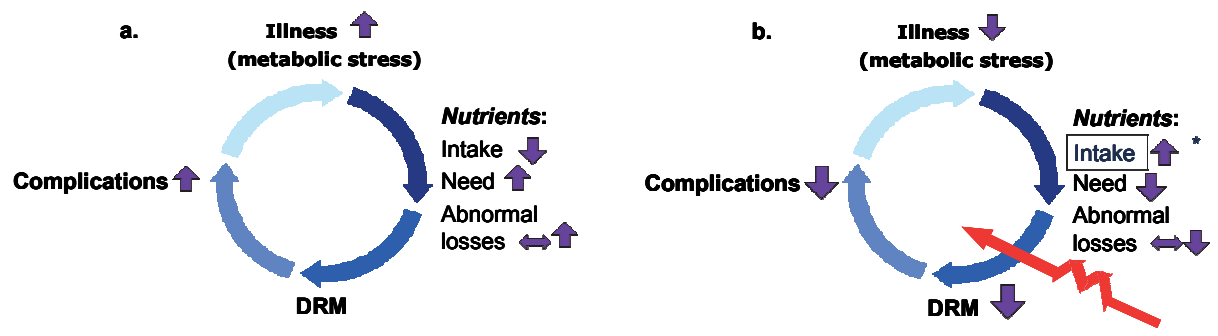

Figure 1.1 The virtuous cycle of catabolism and the breaking by nutrition.

a. Metabolic stress cycle without nutrition intervention: due to e.g. illness, a decreased intake, increased need and/or abnormal losses of nutrients, leading to DRM including increased negative consequences increasing the metabolic stress etc.; $\mathbf{b}$. Metabolic stress cycle broken by nutrition intervention

\subsection{Clinical evidence of medical nutrition for DRM}

There is growing clinical evidence of the benefits of FSMP in different patients suffering from DRM in various settings and in all ages, including weight gain, improvement of muscle function, reduction in mortality, complications and (re-)admission, improvement of wound healing and an increase in quality of life $e^{21,36-40}$. As described earlier, economic evaluations for valuing medical nutrition are scarce but needed. In 2006 the National Institute for Health and Clinical Excellence (NICE) in the United Kingdom has developed a calculation model to estimate the ICER for nutritional screening and management of DRM in the elderly using ONS, resulting in $f 6,800 / Q A L Y$. This outcome means that an extra total investment of $£ 6,800$ for this intervention program is resulting in one extra year lived in perfect health. The additional costs for ONS are partially offset by cost savings elsewhere in the system and a gain in QALYs. As a threshold of $£ 20-30,000 / Q A L Y$ is used by NICE for considering treatments to be costeffective, screening and management of DRM is thus viewed as being value for money based on this model ${ }^{41}$. Evidence has indicated that transferability of economic evaluation data is difficult and complex and therefore country-specific HE analyses are yet preferred ${ }^{42}$. Thus, although these data from NICE are promising, they cannot be used for reimbursement eligibility in other countries. 


\section{Aims and outline of this thesis}

The aims of this thesis are threefold. The first and second aims are to calculate the economic value of medical nutrition in the management of DRM in adults in The Netherlands and to explore the same value in adults on an international level. The third aim is to determine which methodological issues are related to the health economic assessment of medical nutrition in this field.

The following research questions are leading for this thesis:

1. The prevalence of DRM is still considerable in The Netherlands as yearly measured, but what is the economic burden and how do these costs relate to the already known costs of DRM in other European countries?

2. Is using medical nutrition in the management of DRM in The Netherlands costeffective?

3. What is the cost-effectiveness of medical nutrition in the management of DRM on an international level and what is the average quality of the performed economic evaluations?

4. Medical nutrition is not a pharmaceutical product and the existing costeffectiveness evaluation guidelines have initially been developed for pharmaceutical technologies like drugs; what are the issues that have to be taken into account in assessing the health economic value for this specific nutrition?

The first research questions are answered in Chapter 2, in which the additional costs of DRM in The Netherlands have been estimated by performing a cost-of-illness analysis and compared to the estimations in other countries. In Chapter 3, the calculation of the cost-effectiveness of ONS in the management of DRM in Dutch abdominal surgery patients is presented. The estimation of the budget impact together with the costeffectiveness of this same intervention in community dwelling elderly suffering from DRM in The Netherlands are described in Chapter 4. To have a good overview of the international economic value of medical nutrition in the management of DRM, a systematic review was performed of which the results are presented in chapter 5 , answering research question 3. During our thesis research, it became evident that economic evaluations for medical nutrition are not performed in a similar way. Using and comparing the cost-effectiveness results for medical nutrition are therefore difficult. We therefore organized an international expert meeting in which the appropriate health economic assessment methods for medical nutrition in the management of disease related malnutrition (DRM) were explored and discussed. Chapter 6 presents a report of this meeting. The main findings of our studies together with a discussion and recommendations are described in Chapter 7. 
Chapter 1

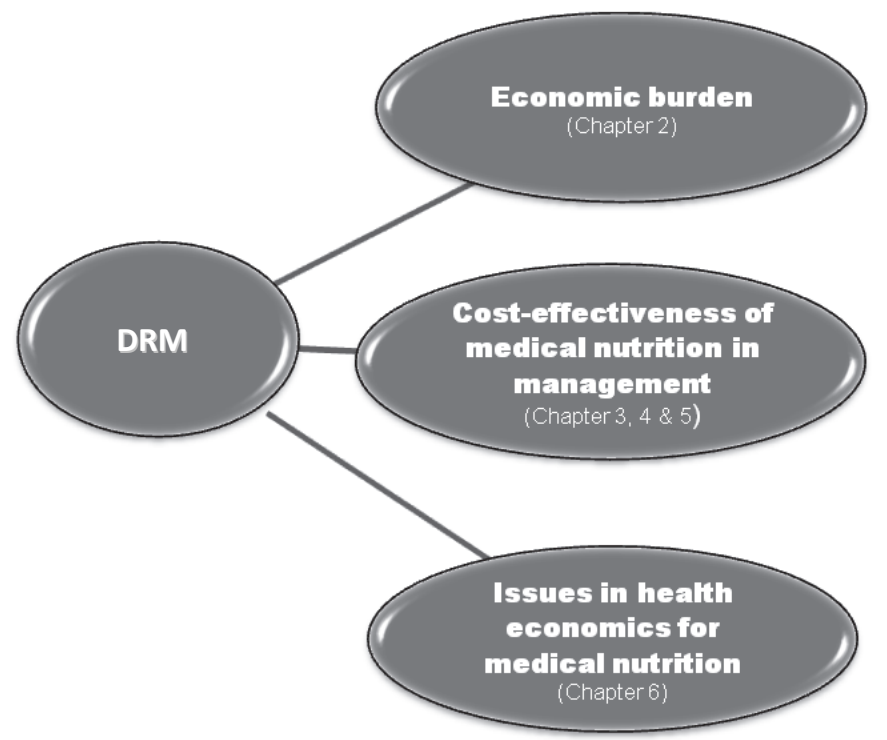

Figure 1.2 Outline of the thesis. 


\section{References}

1. Lochs $\mathrm{H}$, Allison SP, Meier R, et al. Introductory to the ESPEN guidelines on enteral nutrition: terminology, definitions and general topics. Clin Nutr 2006; 25: 180-186.

2. Ligtenberg G, Staal PC, Goettsch WG, et al. Cost-effectiveness in health care. A report of the Dutch Health Care Insurance Board 2013: 1-41. [Dutch].

3. Arrow KJ. Uncertainty and the welfare economics of medical care. Am Econ Rev 1963; 53: 941-973.

4. Savedoff WD. Kenneth Arrow and the birth of health economics. Bull World Health Organ 2004; 82: 139-140.

5. Guiness L, Wiseman V. Introduction to Health Economics. 2nd Ed., McGraw-Hill education Maidenhead, Berkshire, England: Open University Press; 2011: 5-21.

6. Morris S, Devlin N, Parkin D. Introduction to Economic Analysis in Health Care. In: Economic Analysis in Health Care. London: John Wiley \& Sons; 2007: 1-22.

7. Collaboration between International Network of Agencies for Health Technology Assessment (INAHTA), Health Technology Assessment international (HTAi) and other partner organizations. Available at http://htaglossery.net. Accessed on November 5, 2013.

8. Drummond MF, Sculpher MJ, Torrance GW, et al. Basic types of economic evaluation. In: Methods for the economic evaluation of health care programmes, 3rd Ed., New York: Oxford University Press; 2005: 7-26.

9. Organisation for Economic Co-operation and Development (OECD). Health at a Glance 2011: OECD Indicators, OECD Publishing. Available at: http://dx.doi.org/10.1787/health_glance-2011-en. Accessed on November 30, 2013.

10. Drummond MF, Schwartz SJ, Jönssen B, et al. Key principles for the improved conduct of health technology assessments for resource allocation decisions. Int J Technol Assess 2008; 24: 244-256.

11. Robinson R. Economic evaluation and health care. What does it mean? B Med J 1993; 307: 670-673.

12. Detsky AS, Naglie IG. A Clinician's Guide to Cost-Effectiveness Analysis. Ann Intern Med 1990; 113: 147-154.

13. Drummond M, Griffin A, Tarricone R. Economic Evaluation for Devices and Drugs - Same or Different? Value in Health 2009; 12: 402-404.

14. Taylor RS, Iglesias CP. Assessing the Clinical and Cost-Effectiveness of Medical Devices and Drugs: Are They That Different? Value in Health 2009; 12: 404-406.

15. Lenoir-Wijnkoop I, Dapoigny M, Dubois D, et al. Nutrition economics: characterizing the economic and health impact of nutrition. BJN 2011; 105: 157-166.

16. Lenoir-Wijnkoop I, Nuijten MJC, Gutiérrez-lbarluzea I, et al. Workshop Report: concepts and methods in the economics of nutrition - gateways to better economic evaluation of nutrition interventions. BJN 2012; 108: 1714-1720.

17. Commission directive 1999/21/EC of 25 March 1999 on dietary foods for special medical purposes. [Cited Nov 25, 2013] available from URL http://eur-lex.europa.eu/LexUriServ/LexUriServ.do? uri=CELEX: 31999L0021 : EN:NOT.

18. ESPEN Guidelines on adult enteral nutrition. Clin Nutr 2006; 25: 177-360.

19. NAIT (National Alliance for Infusion Therapy) and A.S.P.E.N. (the American Society for Parenteral and Enteral Nutrition) Public Policy Committee and Board of Directors. Disease-related malnutrition and enteral nutrition therapy: a significant problem with a cost-effective solution. Nutr Clin Pract 2010; 25: 548-554.

20. Fight malnutrition. Malnutrition guidelines: Guideline screening and treatment of malnutrition 2012. Available at: http://www.fightmalnutrition.eu. Accessed on November 25, 2013.

21. Stratton RJ, Green CJ, Elia M. Disease-related Malnutrition: An Evidence based Approach to Treatment, 1st Ed., Oxford: UK CABI Publishing; 2003.

22. Jensen GL, Mirtallo J, Compher C, et al. Adult starvation and disease-related malnutrition: A proposal for etiology-based diagnosis in the clinical practice setting from the International Consensus Guideline Committee. JPEN 2010; 34: 156 -159.

23. Norman K, Pichard C, Lochs H, et al. Prognostic impact of disease-related malnutrition. Clin Nutr 2008; 27: 5-15. 
24. Russell CA, Elia M, on behalf of BAPEN and collaborators. Nutrition screening survey in the UK in 2008: hospitals, care homes and mental health units. A report by the British Association for Parenteral and Enteral nutrition (BAPEN). Redditch: BAPEN; 2009.

25. Ljungqvist O, de Man F. Under nutrition - a major health problem in Europe. Nutr Hosp 2009; 24: 368-370.

26. Sauerwein HP, Romijn JA. More consideration to dietary protein in the nutrition of chronically ill adults with tendency to weight loss. Ned Tijdschr Geneeskd 1999: 143; 886-889. [Dutch].

27. Huffman GB. Evaluating and treating unintentional weight loss in the elderly. Am Fam Physician 2002; 65: $640-650$

28. Wallace II, Schwartz RS. Epidemiology of weight loss in humans with special reference to wasting in the elderly. Int J Cardiol 2002; 85: 15-21.

29. Sahyoun NR, Serdula MK, Galuska DA, et al. The Epidemiology of Recent Involuntary Weight Loss in the United States Population. J Nutr Health Aging 2004; 8: 510-517.

30. Alibhai SM, Greenwood C, Payette $\mathrm{H}$. An approach to the management of unintentional weight loss in elderly people. CMAJ 2005; 172: 773-780.

31. Ingram DD, Mussolino ME. Weight loss from maximum body weight and mortality: the Third National Health and Nutrition Examination Survey Linked Mortality File. Int J Obes 2010; 34: 1044-1050.

32. Meijers JMM, van Bokhorst-de van der Schueren MAE, Schols JMG, et al. Defining malnutrition: Mission or mission impossible? Nutrition 2010; 26: 432-440.

33. Gooszen HG, Blankensteijn HD, Borel Rinkes IHM, et al. Voeding. In: Leerboek Chirurgie, 2nd Ed., Houten: Bohn Stafleu van Loghum; 2012: 35-45. [Dutch].

34. Meijers JMM. Awareness of malnutrition in healthcare. The Dutch perspective. Thesis, Maastricht University, the Netherlands July 2009.

35. Health Council of the Netherlands. Undernutrition in the elderly. The Hague: Health Council of the Netherlands; 2011; publication no. 2011/32.

36. Stratton RJ, Ek AC, Engfer M, et al. Enteral nutritional support in prevention and treatment of pressure ulcers: a systematic review and meta-analysis. Ageing Res Rev 2005; 4: 422-450.

37. Elia M, Stratton RJ, Russell C, et al. The Cost of Disease-Related Malnutrition in the UK and Economic Considerations for the use of Oral Nutritional Supplements (ONS) in Adults. Redditch: BAPEN; 2005.

38. Stratton RJ, Elia M. Who benefits from nutritional support: what is the evidence? Eur J Gastroenterol Hepatol 2007; 19: 353-358.

39. Cawood AL, Elia M, Stratton RJ. Systematic review and meta-analysis of the effects of high protein oral nutritional supplements. Ageing Res Rev 2012; 11: 278- 296.

40. Stratton RJ, Hébuterneb X, Elia M. A systematic review and meta-analysis of the impact of oral nutritional supplements on hospital readmissions. Ageing Res Rev 2013; 12: 884-897.

41. NICE Clinical guideline (CG) 32. Nutrition Support in adults: oral nutrition support, enteral tube feeding and parenteral nutrition; 2006. London: National Collaborating Centre for Acute Care, Commissioned by the National Institute for Clinical Excellence. Available at http://www.nice.org.uk/CG32. Accessed on November 26, 2013.

42. Goeree R, Burke N, O'Reilly D, et al. Transferability of economic evaluations: approaches and factors to consider when using results from one geographic area for another. Curr Med Res Opin. 2007; 23: 671-682. 


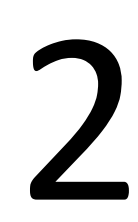

\title{
The economic costs of disease related
}

\section{malnutrition}

\author{
Karen Freijer \\ Siok Swan Tan \\ Marc A Koopmanschap \\ Judith MM Meijers \\ Ruud JG Halfens \\ Mark JC Nuijten
}

Published in: Clin Nutr 2013; 32: 136-141 


\section{Abstract}

\section{Background \& Aims}

Disease related malnutrition (under-nutrition caused by illness) is a worldwide problem in all health care settings with potentially serious consequences on a physical as well as a psycho-social level. In the European Union countries about 20 million patients are affected by disease related malnutrition, costing EU governments up to $€ 120$ billion annually. The aim of this study is to calculate the total additional costs of disease related malnutrition in The Netherlands.

\section{Methods}

A cost-of-illness analysis was used to calculate the additional total costs of disease related malnutrition in adults for The Netherlands in 2011 in the hospital, nursing- and residential home and home care setting, expressed as an absolute monetary value as well as a percentage of the total Dutch national health expenditure and as a percentage of the total costs of the studied health care sectors in The Netherlands.

\section{Results}

The total extra costs of managing adult patients ( $>18$ years of age) with disease related malnutrition was estimated to be $€ 1.9$ billion in 2011 which equals $2.1 \%$ of the total Dutch national health expenditure and $4.9 \%$ of the total costs of the healthcare sectors analysed in this study.

\section{Conclusions}

The results of this study show that the additional costs of disease related malnutrition in adults in The Netherlands are considerable. 


\section{Introduction}

Disease related malnutrition has been an important and under recognized problem in all health care settings for many years and with an ageing population it continues to be a growing major public health concern ${ }^{1,2-4}$. In the European Union countries about 20 million patients are affected by disease related malnutrition (33 million in Europe), costing EU governments up to $€ 120$ billion annually ( $€ 170$ billion in Europe $)^{5,6}$. Comparing prevalence rates in different European countries and settings reveals that disease related malnutrition in general is common, but that there is considerable variance due to no universally accepted definition of disease related malnutrition leading to different prevalence findings. Notwithstanding these differences in definitions, the following definition of malnutrition is widely acknowledged, including the members of the European Society for Parenteral and Enteral Nutrition (ESPEN): 'A state of nutrition in which a deficiency, excess or imbalance of energy, protein, and other nutrients causes measurable adverse effects on tissue/ body form (body shape, size and composition) function, and clinical outcome ${ }^{1}$. Malnutrition thus includes both over-nutrition (overweight and obesity) and under-nutrition (insufficient nutrition). For the purposes of this article the term malnutrition is used only for under-nutrition in health care, also known as disease related malnutrition (DRM). Disease related malnutrition is under-nutrition caused by changes of the body metabolism which increases the daily nutritional needs due to illness. DRM adversely impacts every organ system in the body with potentially serious consequences on a physical and psychosocial level that in turn contribute to increased morbidity and mortality ${ }^{7}$. It is obvious that the consequences of DRM result in increased treatment costs or healthcare utilization and associated costs to the society ${ }^{8,9}$. In Germany, UK and Ireland the annual costs of DRM on a national level have been calculated: $€ 9$ billion (2006), $€ 15$ billion (2007) and $€ 1.5$ billion (2009) respectively ${ }^{10-12}$. For The Netherlands, no reliable and accurate estimates on the total additional costs of disease related malnutrition in all healthcare settings have been published. Therefore, the first objective of the present study was to estimate the additional annual costs of patients with DRM in The Netherlands, also known as a cost-of-illness study. The result is expressed as an absolute monetary value as well as a percentage of the total Dutch national health expenditure and as a percentage of the total costs of the studied health care sectors in The Netherlands. The second objective was to determine how these Dutch costs of DRM relate to the already known costs of DRM in Germany, UK and Ireland. 


\section{Methods}

\subsection{Cost-of-illness analysis}

A cost-of-illness study assesses the total costs per patient group resulting from a disease. Total costs may include direct as well as indirect costs. Due to lack of data on the indirect burden of DRM on health care costs, this study focused on the direct health care costs only. Direct health care costs comprise all costs directly relating to the use of care, i.e. the prevention, diagnostics, therapy, rehabilitation and care of the disease or treatment under consideration, which is not the case for indirect costs like productivity loss due to absence at work ${ }^{13}$.

\subsection{Formula and data sources}

In order to derive an estimate of the additional annual costs of patients with disease related malnutrition, we developed a formula:

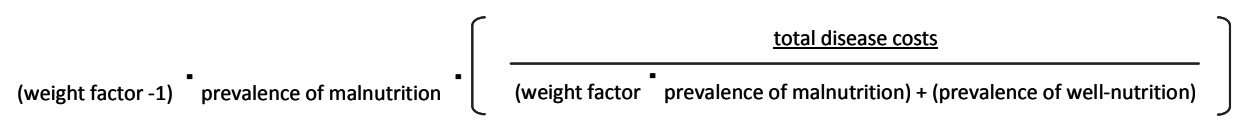

With this formula the total additional annual costs per patient group induced by DRM in The Netherlands were calculated. For example: total disease costs for the disease category oncology $=100$, the prevalence of malnutrition within this category $=20$ malnourished patients and 80 well-nourished patients, then the costs are distributed over these 20-80. If malnourished patients are given a weight of 1.3 (30\% more costs for the management of DRM), the total costs of managing malnourished as well as wellnourished patients within this disease category correspond to $(1.3 \times 20+80)=106$. The total additional costs for the management of the malnourished patients within this disease category oncology is then $(0.3 \times 20 \times(100 / 106)=5.7$.

\subsection{Weight factor}

Being malnourished results in a lower health status, elevating the risk of complications and slowing down the curative process. According to Kruizenga et al. (2005), the mean length of hospital stay for malnourished patients in The Netherlands is $30 \%$ longer than for the well-nourished patients (to be as complete as possible, we used the difference in mean length of hospital stay between both patient groups within the intervention as well as in the control groups in this study of Kruizenga) $)^{14}$. As concrete figures of the increase use of healthcare resources in the non-hospital settings in The Netherlands are not available, but some international studies have shown that use of healthcare resources (e.g. intensity of nursing and medical care, GP visits and (re-)admission) also 
in these settings are increased ${ }^{9,10,15,16}$ we used the same weight factor of 1.3 for these non-hospital sectors.

\subsection{Prevalence of disease related malnutrition}

In The Netherlands the prevalence of DRM is annually measured by an independent measurement within the Dutch National Prevalence Measurement of Care Problems (LPZ-Landelijke Prevalentie Zorgproblemen). Since 2004, the Dutch LPZ has measured the prevalence of DRM across different healthcare settings: hospital, nursing and residential home and home care, using a definition of DRM which is related to the guidelines of ESPEN: BMI (Body Mass Index) $<18,5$ (BMI $\leq 20,0$ for patients of 65 years of age and over) OR a BMI between 18,5 and 20,0 (patients of 65 years of age and over a BMI between 20,0 and 23,0) in combination with three days no/hardly food intake or less food intake than normal during a week OR unintentional weight loss of $6 \mathrm{~kg}$ in the past 6 months or more than $3 \mathrm{~kg}$ in the past month ${ }^{17}$. Results from recent years show that DRM in The Netherlands is a considerable problem in one of every five patients in all participating health care settings ${ }^{4}$. For the hospital, residential- and nursing home setting in this study, we used the LPZ data on DRM for the year 2011 per disease area, age and gender ${ }^{17}$ (Table 1 and 2). To get reliable prevalence estimates for the home care setting in 2011, we used the 2010 LPZ data for home care and corrected the figure for the downward trend in prevalence in recent years by multiplying each prevalence figure per disease area, age and gender with the overall mean prevalence in 2010 $(17.1 \%)$ divided by the overall mean prevalence in earlier years $(22.9 \%)$.

\subsection{Disease costs}

For all sectors, estimates of the total direct costs per disease category were taken from the report of the Dutch National Institute for Public Health and Environment on cost of illness ${ }^{18}$. This report describes the direct costs of Dutch health care categorized for diagnosis group, age and gender in 2007 and the trends in the Dutch health care expenditure in 1999-2010, which is the most recent available data on national expenditures at the time of this analysis. The total health care expenditures are identified and fixed for a given year and divided in costs units per dimension (illness, age, gender, section, finance and care function) based on registration data of health care use or are estimated. A summation of all costs units provides the total amount of the costs per illness ${ }^{18}$. 
The total additional annual costs of disease related malnutrition were analysed separately according to:

- Gender (men and women)

- Age (age $>18$ and $<60$ and age $>60$

- Healthcare sector setting (hospital, nursing- and residential home and home care setting)

- Disease; the framework for the classification of diagnostic groups is the International statistical Classification of Diseases, Injuries and Causes of Death, $9^{\text {th }}$ revision (ICD-9) (WHO, 1977).

Combining the prevalence of the LPZ (Table 2.1 and 2.2$)^{17}$, the total costs by disease ${ }^{18}$ and the weight factor of 1.3, a calculation was made for the annually additional costs of disease related malnutrition in The Netherlands, which is expressed as an absolute monetary value but also as a percentage of the total Dutch health expenditure - $€ 87$ billion in $2010^{18}$ - and as a percentage of the total costs of the four studied health care sectors in The Netherlands - $€ 37.9$ billion in $2010^{18}$. To determine the certainty of the total extra costs of managing patients with disease related malnutrition, a one-way sensitivity analysis was carried out by varying the weight factor between 1.1 and 1.5.

Table 2.1 Prevalence of diseased related malnutrition in 2011 per disease category ${ }^{\mathrm{a}}$, health care setting and gender for the age category of $>18$ and $<60^{b}$.

\begin{tabular}{|c|c|c|c|c|c|c|c|c|c|}
\hline \multirow[t]{2}{*}{ PREVALENCE malnutrition in \% } & \multicolumn{3}{|c|}{ Hospital setting } & \multicolumn{3}{|c|}{$\begin{array}{l}\text { Nursing- and residential } \\
\text { home setting }\end{array}$} & \multicolumn{3}{|c|}{ Home care setting $^{c}$} \\
\hline & Men & Women & Total & Men & Women & Total & Men & Women & Total \\
\hline Inflammatory and parasitic diseases & 27 & 18 & 23 & 33 & 0 & 20 & 15 & 12 & 14 \\
\hline Oncology & 37 & 25 & 30 & 20 & 0 & 11 & 31 & 18 & 23 \\
\hline $\begin{array}{l}\text { Endocrine nutrition system and } \\
\text { metabolic diseases }\end{array}$ & 14 & 26 & 20 & 14 & 20 & 17 & 10 & 11 & 10 \\
\hline Blood en blood producing organs & 44 & 44 & 44 & 29 & 33 & 30 & 25 & 37 & 32 \\
\hline Mental disorders & 18 & 27 & 24 & 16 & 11 & 14 & 0 & 8 & 4 \\
\hline Nerve system and sense organs & 7 & 9 & 8 & 24 & 23 & 23 & 8 & 10 & 9 \\
\hline Cardiovascular system & 15 & 14 & 14 & 12 & 0 & 7 & 20 & 10 & 14 \\
\hline Respiratory system & 31 & 20 & 25 & 33 & 29 & 31 & 21 & 7 & 15 \\
\hline Digestive system & 28 & 32 & 30 & 33 & 50 & 36 & 5 & 28 & 20 \\
\hline Urogenital system & 11 & 9 & 10 & 30 & 0 & 18 & 14 & 16 & 15 \\
\hline Skin and subcutis & 29 & 18 & 22 & 0 & 33 & 13 & 21 & 9 & 14 \\
\hline Motoric system and connective tissue & 7 & 16 & 11 & 13 & 13 & 13 & 7 & 6 & 6 \\
\hline Injuries and intoxications & 5 & 0 & 4 & 28 & 0 & 19 & 12 & 15 & 14 \\
\hline Other & 16 & 5 & 9 & 8 & 18 & 13 & 11 & 12 & 12 \\
\hline
\end{tabular}

[Adapted with permission from ref. 17]. ${ }^{\text {a }}$ Categorization is based on the International Classification of Diseases-9-Clinical Modification (ICD-9-CM) of the WHO; ${ }^{b}$ Data are given in \%; ${ }^{\mathrm{c}}$ Estimate based on the 2010 LPZ data for home care; figure is corrected for the downward trend in prevalence in recent years by multiplying each prevalence figure per disease area, age and gender with the overall mean prevalence in $2010(17,1 \%)$ divided by the overall mean prevalence in earlier years $(22,9 \%)$ 
The weight factor is an important part within the calculation formula because it represents the impact of the use of health care resources on the total additional costs of DRM; in our analysis the use of health care resources is based on length of hospital stay. Studies have shown that the length of hospital stay can be diminished by early recognition and treatment of $\mathrm{DRM}^{14,19}$. To be able to compare our results with those of the few other cost-of-illness studies, we also calculated the costs of DRM per capita for Germany, UK and Ireland by using the outcome of the study divided by the country population of that specific year.

All calculations have been done using Microsoft Office Excel 2007.

Table 2.2 Prevalence of disease related malnutrition in 2011 per disease category ${ }^{\mathrm{a}}$, health care setting and gender for the age category $>60^{\mathrm{b}}$.

\begin{tabular}{|c|c|c|c|c|c|c|c|c|c|}
\hline \multirow[t]{2}{*}{ PREVALENCE malnutrition in \% } & \multicolumn{3}{|c|}{ Hospital setting } & \multicolumn{3}{|c|}{$\begin{array}{l}\text { Nursing- and residential } \\
\text { home setting }\end{array}$} & \multicolumn{3}{|c|}{ Home care setting $^{c}$} \\
\hline & Men & Women & Total & Men & Women & Total & Men & Women & Total \\
\hline $\begin{array}{l}\text { Inflammatory and parasitic } \\
\text { diseases }\end{array}$ & 28 & 36 & 32 & 26 & 21 & 23 & 30 & 19 & 23 \\
\hline Oncology & 39 & 40 & 39 & 19 & 21 & 20 & 27 & 20 & 23 \\
\hline $\begin{array}{l}\text { Endocrine nutrition system and } \\
\text { metabolic diseases }\end{array}$ & 21 & 26 & 23 & 11 & 15 & 14 & 8 & 12 & 11 \\
\hline $\begin{array}{l}\text { Blood en blood producing } \\
\text { organs }\end{array}$ & 33 & 28 & 30 & 15 & 21 & 20 & 15 & 27 & 23 \\
\hline Mental disorders & 33 & 40 & 37 & 17 & 23 & 22 & 13 & 16 & 15 \\
\hline Nerve system and sense organs & 18 & 28 & 23 & 17 & 17 & 17 & 15 & 15 & 15 \\
\hline Cardiovascular system & 21 & 22 & 22 & 13 & 17 & 16 & 13 & 16 & 15 \\
\hline Respiratory system & 30 & 36 & 33 & 23 & 19 & 20 & 16 & 19 & 18 \\
\hline Digestive system & 36 & 40 & 38 & 19 & 16 & 17 & 21 & 22 & 22 \\
\hline Urogenital system & 32 & 34 & 33 & 17 & 19 & 18 & 16 & 15 & 15 \\
\hline Skin and subcutis & 40 & 50 & 45 & 12 & 18 & 16 & 17 & 16 & 16 \\
\hline $\begin{array}{l}\text { Motoric system and connective } \\
\text { tissue }\end{array}$ & 17 & 27 & 23 & 17 & 18 & 18 & 15 & 15 & 15 \\
\hline Injuries and intoxications & 17 & 20 & 19 & 20 & 22 & 21 & 16 & 18 & 17 \\
\hline Other & 34 & 34 & 34 & 16 & 18 & 18 & 14 & 16 & 16 \\
\hline
\end{tabular}

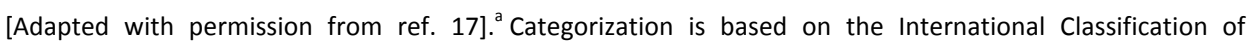
Diseases-9-Clinical Modification (ICD-9-CM) of the WHO; ${ }^{b}$ Data are given in \%; ${ }^{c}$ Estimate based on the 2010 LPZ data for home care; figure is corrected for the downward trend in prevalence in recent years by multiplying each prevalence figure per disease area, age and gender with the overall mean prevalence in 2010 (17.1\%) divided by the overall mean prevalence in earlier years $(22.9 \%)$

\section{Results}

The total extra costs of managing patients with disease related malnutrition was estimated to be $€ 1.9$ billion in 2011 (Table 2.3 and 2.4 ), which equals $2.1 \%$ of the total Dutch national health care expenditure and $4.9 \%$ of the total costs of the health care sectors analysed in this report (hospital, nursing- and residential home, and home care 
setting). Using a weight factor of 1.1 (instead of 1.3) in a one way sensitivity analysis, the total additional costs of managing adult patients with disease related malnutrition was estimated to be $€ 0.7$ billion. Likewise, total additional costs amounted to $€ 1.3$ billion, $€ 2.5$ billion and $€ 3.0$ billion when weight factors of $1.2,1.4$ and 1.5 respectively were chosen (Table 2.5 ). These results indicate that by diminishing the use of health care resources (represented by the weight factor), the total additional costs of DRM can be positively influenced. Total additional costs of DRM were higher for women ( $€ 1.1$ billion) than for men ( $€ 777$ million) and about four times higher for patients of at least 60 years of age ( $€ 1.5$ billion) than for patients in the age category of $>18$ and $<60$ ( $€ 403$ million). Also, $66 \%$ of the total expenditure on DRM was attributable to the hospital setting ( $€ 1.2$ billion). The proportion of the nursing home and residential home setting accounted for $24 \%$ ( $€ 453$ million) and home care setting for $10 \%$ ( $€ 185$ million) of the total expenditure on DRM. Mental disorders, diseases of the cardiovascular system and oncology contributed to the greatest shares of the total costs of DRM (17\%, $16 \%$ and $14 \%$ respectively) due to the fact that these illnesses are the most expensive regarding direct costs within the total Dutch health care expenditure ${ }^{18}$. DRM costs appeared to be particularly present in women with a mental disorder in the nursing and residential home setting (€ 209 million).

Table 2.3 Total additional costs of disease related malnutrition according to gender, age and healthcare sector * 1.000.000 (Euro 2011)

\begin{tabular}{lcrrrrr}
\hline & \multicolumn{2}{c}{ Men } & \multicolumn{2}{c}{ Women } & Total \\
\cline { 2 - 5 } Age & $>18$ and $<60$ & $>60$ & $>18$ and $<60$ & $>60$ & All ages \\
\hline Hospital setting & 188 & 424 & 184 & 437 & 1233 \\
Nursing- and residential home setting & 9 & 107 & 6 & 331 & 453 \\
Home care setting & 6 & 43 & 9 & 126 & 185 \\
\hline Total & 203 & 574 & 200 & 894 & 1871 \\
\hline
\end{tabular}

Comparing the costs of DRM per capita in The Netherlands, Germany, UK and Ireland, these costs in Ireland and the UK in 2007 seem to be higher than those in Germany and The Netherlands. The results of the UK study in $2003^{20}$ are also lower than the calculated costs in the UK study of 2007 and are more in line with the results of Germany and The Netherlands (Table 2.6). 
Table 2.4 Total additional costs of disease related malnutrition according to gender, healthcare sector and disease ${ }^{a} * 1.000 .000$ (Euro 2011)

\begin{tabular}{|c|c|c|c|c|c|c|c|c|c|c|}
\hline \multirow[t]{2}{*}{ COSTS malnutrition } & \multicolumn{3}{|c|}{ Hospital setting } & \multicolumn{3}{|c|}{$\begin{array}{c}\text { Nursing-and residential } \\
\text { home setting }\end{array}$} & \multicolumn{3}{|c|}{ Home care setting } & \multirow[t]{2}{*}{ Total cost } \\
\hline & Men & Women & Total & Men & Women & Total & Men & Women & Total & \\
\hline $\begin{array}{l}\text { Inflammatory and } \\
\text { parasitic diseases }\end{array}$ & 11 & 9 & 19 & 1 & 1 & 2 & 0 & 1 & 1 & 23 \\
\hline Oncology & 123 & 120 & 242 & 3 & 5 & 8 & 7 & 8 & 15 & 265 \\
\hline $\begin{array}{l}\text { Endocrine nutrition } \\
\text { system and metabolic } \\
\text { diseases }\end{array}$ & 8 & 15 & 23 & 1 & 6 & 7 & 1 & 5 & 5 & 36 \\
\hline $\begin{array}{l}\text { Blood en blood } \\
\text { producing organs }\end{array}$ & 7 & 8 & 14 & 0 & 1 & 1 & 0 & 1 & 1 & 16 \\
\hline Mental disorders & 12 & 24 & 36 & 59 & 209 & 269 & 1 & 5 & 6 & 312 \\
\hline $\begin{array}{l}\text { Nerve system and sense } \\
\text { organs }\end{array}$ & 22 & 39 & 60 & 9 & 10 & 19 & 5 & 15 & 20 & 99 \\
\hline Cardiovascular system & 130 & 79 & 209 & 19 & 41 & 60 & 6 & 19 & 25 & 293 \\
\hline Respiratory system & 44 & 35 & 79 & 6 & 7 & 13 & 4 & 7 & 11 & 103 \\
\hline Digestive system & 63 & 67 & 130 & 1 & 3 & 4 & 2 & 7 & 9 & 143 \\
\hline Urogenital system & 31 & 34 & 65 & 1 & 2 & 3 & 2 & 3 & 6 & 73 \\
\hline Skin and subcutis & 12 & 13 & 25 & 0 & 1 & 1 & 1 & 3 & 4 & 31 \\
\hline $\begin{array}{l}\text { Motoric system and } \\
\text { connective tissue }\end{array}$ & 29 & 78 & 107 & 2 & 8 & 10 & 6 & 28 & 34 & 151 \\
\hline $\begin{array}{l}\text { Injuries and } \\
\text { intoxications }\end{array}$ & 21 & 25 & 46 & 5 & 17 & 22 & 1 & 4 & 5 & 73 \\
\hline Other & 101 & 75 & 177 & 9 & 26 & 35 & 12 & 30 & 43 & 255 \\
\hline $\begin{array}{l}\text { TOTAL COSTS } \\
\text { malnourished } \\
\text { population } \\
\end{array}$ & 612 & 621 & 1233 & 116 & 337 & 453 & 49 & 135 & 185 & 1871 \\
\hline
\end{tabular}

${ }^{\text {a }}$ Categorization of the diseases is based on the International Classification of Diseases-9- Clinical Modification (ICD-9-CM) of the WHO

Table 2.5 Results of the base-case ${ }^{a}$ and the one-way sensitivity analysis ${ }^{b}$ (billion Euros).

\begin{tabular}{lccc}
\hline Analysis & & Range $^{c}$ & Additional costs of DRM \\
\hline Base case & Weight factor & 1.3 & $€ 1.9$ \\
Sensitivity analysis & Weight factor & 1.1 & $€ 0.7$ \\
& & 1.2 & $€ 1.3$ \\
& & 1.4 & $€ 2.5$ \\
& 1.5 & $€ 3.0$ \\
\hline
\end{tabular}

\footnotetext{
${ }^{a}$ The overall outcome of the cost-of-illness analysis; ${ }^{b}$ Checking the robustness (sensitivity) of the base case by changing the weight factor in the formula through a range of plausible values; ${ }^{\mathrm{C}}$ The values used in the base case are changed by a range of plausible values
} 
Table 2.6 Costs of disease related malnutrition in adults; total costs and per adult capita.

\begin{tabular}{|c|c|c|c|c|c|}
\hline & $\begin{array}{c}\mathrm{NL}^{\mathrm{a}} \\
(2011) \\
\end{array}$ & $\begin{array}{c}1^{b} \\
(2007)\end{array}$ & $\begin{array}{c}\mathrm{UK}^{\mathrm{c}} \\
(2007)\end{array}$ & $\begin{array}{c}D^{d} \\
(2006) \\
\end{array}$ & $\begin{array}{c}U^{C} \\
(2003) \\
\end{array}$ \\
\hline $\begin{array}{l}\text { Total costs malnutrition in euro }{ }^{e} \\
\text { (>18 years) }\end{array}$ & 1.9 billion & 1.5 billion & 15 billion & 9 billion & 10.5 billion \\
\hline $\begin{array}{l}\text { Adult inhabitants } \\
\text { ( }>18 \text { years) }\end{array}$ & 14 million $^{f}$ & 3 million $^{\mathrm{g}}$ & 49 million $^{\mathrm{h}}$ & 67 million $^{\text {h }}$ & 48 million $^{\mathrm{h}}$ \\
\hline $\begin{array}{l}\text { Costs per adult capita in euro } \\
\text { ( }>18 \text { years) }\end{array}$ & 135 & 500 & 300 & 134 & 219 \\
\hline
\end{tabular}

${ }^{\mathrm{a}}$ The Netherlands; ${ }^{\mathrm{b}}$ Ireland; ${ }^{\mathrm{C}}$ United Kingdom; ${ }^{\mathrm{d}}$ Germany; ${ }^{\mathrm{e}}$ Outcomes of the studies: this study, number 12 , 11, 10 and 20 of the references respectively; ${ }^{f}$ Wobma, E. en W. Portegijs, 2011, Bevolking. In: [Merens, A., van den Brakel, M. Hartgers, B. Hermans (red.)] Emancipatiemonitor 2010.SCP/CBS Den Haag; ${ }^{\mathrm{g}}$ Eurostat database, Population by sex and age on 1January of each year; ${ }^{\text {h }}$ Office for National Statistics; National Assembly for Wales; General Register Office for Scotland; Northern Ireland Statistics and Research Agency (updated Jan 2008).

\section{Discussion}

Our cost-of-illness study is one of the few international studies that calculated the additional costs of DRM on a national level for all health care sectors. Costs of DRM in a specific health care sector were already assessed in The Netherlands for the nursing home setting and for the community setting in the $U K^{15,21}$. One of the striking results is the higher additional costs of disease related malnutrition for women and for patients in the age category of $>60$. The higher costs for women are most probably caused by the fact that the prevalence of DRM for women in the age category of $>60$ is higher than for men, which is probably due to the fact that in this age group the absolute number of women is higher than for men.

Statistically women are getting older than $\operatorname{men}^{22}$ and higher age is associated with an overall increase in disease prevalence ${ }^{23,24}$. Disease and DRM are related, as malnourished patients have a higher mean number of diseases per patient than those who are well nourished ${ }^{24}$. The result that the additional costs of disease related malnutrition are four times higher for patients in the age category of $>60$ than for patients in the age category of $>18$ and $<60$, can be explained by the fact that DRM is particularly a problem in older people: $40 \%$ higher in patients aged 65 years and older than in those younger than 65 years ${ }^{25}$. This age effect may be partly due to the fact that a higher age is associated with an overall increase in disease prevalence ${ }^{23,24}$.

Our cost-of-illness study may have some limitations. The first one is the chosen weight factor of 1.3 used as an indicator for the weight of total burden for malnourished patients in comparison with the burden for well-nourished patients (weight $=1.0$ ). To determine the weight factor, the demonstrated $30 \%$ difference in hospital stay ${ }^{14}$ between the malnourished and well-nourished patients in The Netherlands was used, as this indicates that the extra costs for malnourished patients in hospitals are $30 \%$ of the "normal" costs. For home care, residential- and nursing home care, international 
studies have shown a significantly increased use of healthcare resources and costs by patients identified as malnourished or at risk of DRM compared with non-malnourished patients ${ }^{1,8,10,16}$. Managing DRM in home care, residential- and nursing home care could possibly lead to longer survival, but especially the intensity of nursing and medical care are reduced in patients in better condition due to good nutritional condition ${ }^{10,15,16}$. As concrete figures of the increase use of healthcare resources in these settings in The Netherlands are not available, but some international studies have shown that use of healthcare resources (e.g. intensity of nursing and medical care, GP visits and (re-)admission) also in these settings are increased ${ }^{9,10,15,16}$, we used the same weight factor of 1.3 for these non-hospital sectors. Furthermore our estimate for the weight factor (1.3) is in line with that of a BAPEN report that calculated the additional costs of DRM for the UK in $2003^{26}$. In a similar German study the weight factor was estimated to be $1.43^{27}$. Further research is needed regarding the exact weight factor for DRM in these non-hospital health care settings for The Netherlands.

Another limitation may be the calculated prevalence rate of DRM in the home care setting. Due to small sample size no data for the prevalence of DRM in this setting were available from the LPZ measurement in 2011. To get reliable prevalence estimates however, we used the 2010 LPZ data for the home care setting and corrected the number for the downward trend in prevalence in recent years by multiplying each number per disease area, age and gender with the overall mean prevalence in 2010 (17.1\%) divided by the overall mean prevalence in earlier years (22.9\%). Comparing the calculated costs of DRM per capita for The Netherlands, Germany, UK 2007 and 2003 and Ireland, the costs in Ireland and the UK in 2007 are higher. The outcomes per capita for The Netherlands, Germany and UK in 2003 are comparable. One possible explanation for the differences may be the possible substantial increase of total health care expenditure between the years, in which the various assessments were performed. In 2007 we performed a same cost-of-illness analysis (not published) on DRM in The Netherlands for the year 2006. The total extra costs of managing adult patients with disease related malnutrition were then estimated to be $€ 1.7$ billion in The Netherlands which equalled $2.8 \%$ of the total Dutch national health care expenditure and $5.8 \%$ of the total costs of the healthcare sectors analysed (hospital, nursing home, residential home and home care setting) for that year ${ }^{28}$. The total additional costs of DRM in The Netherlands have thus increased by $€ 0.2$ billion, but decreased as a percentage of the total Dutch national health care expenditure due to a lower prevalence of DRM over the years ${ }^{29,30}$. The increase of the total additional costs can be explained by the substantial increase of total health care expenditure in The Netherlands between 2006 and 2010.

Differences in the methodology of calculation can also be the cause of different outcomes. BAPEN estimated the UK costs of disease related malnutrition in 2007 to be $£ 13$ billion ( $€ 15$ billion) ${ }^{11}$. This study produced relatively high cost estimates as the authors take all treatment costs for individuals with DRM into account like a number of 
services providing support to individuals, e.g. total care at home and total GP visits. Taking all health care costs into account instead of only the additional health care costs due to DRM, obviously leads to very high cost estimates of DRM. The results of our analysis are an estimate of only the additional health care costs of managing patients with DRM. Therefore we provide a more conservative estimate of the costs due to DRM.

Another reason that the amount of $€ 1.9$ billion is a conservative one is that the calculation is done from a health care perspective. This article focuses on the direct health care costs of disease related malnutrition only, due to lack of data on the indirect health care costs. Direct health care costs concern the costs that occur as a result of consumption in the healthcare sector (i.e. prevention, diagnostics, treatment and nursing). A cost estimate from the broader societal perspective would by definition be larger as a disease additionally results in direct non health care costs (e.g. direct costs for the patient and family members like traveling to hospital, various co-payments and expenditure in the home) and in indirect non health care costs that comprise productivity losses due to absence or long-term disability from work, but also costs due to resources consumed in other sectors (e.g. special education). In our calculation the direct costs are based only on an incremental length of stay due to DRM, because of lack of appropriate data on other direct costs (e.g. complications). As DRM is also associated with an increase of complications, the direct costs of DRM would therefore in theory probably be larger.

Finally, the costs of DRM in our cost-of-illness study are based on adult data ( $>18$ years of age) and therefore the actual total costs, including cost of DRM in children, are probably more than the calculated $€ 1.9$ billion. Patients of 18 years of age and younger are not included in this study because health care management of children is not comparable to that of adults, including the method of measurement of DRM. A recent nationwide study in The Netherlands on DRM in children shows that $19 \%$ of children admitted to Dutch hospitals are malnourished at admission and $28 \%$ of children with an underlying disease in hospital are malnourished. Multiple regression analysis showed that children with DRM stayed on average $45 \%$ longer (95\% Cl 7\%-95\%) in the hospital than children without $\mathrm{DRM}^{31}$. This high prevalence of DRM in children and its related clinical consequences, will certainly contribute to the total costs of DRM in The Netherlands. Therefore a cost-of-illness study on DRM in children would be a helpful complement to our analysis.

Although our calculation of the costs of DRM in The Netherlands is a conservative one, the additional annual costs for DRM of $€ 1.9$ billion are still higher than the costs of obesity in The Netherlands, which are $€ 1.2$ billion $^{32}$. DRM in The Netherlands is therefore a costly problem and deserves for that reason the same attention as the economic problem of obesity. In conclusion, the results of our current study show that the additional costs of DRM in adults in The Netherlands are considerable. Early recognition and treatment of DRM can diminish the hospital length of stay and thus 
influence the total additional costs of DRM. More research about the determinants of the related higher health care consumption is necessary. 


\section{References}

1. Stratton RJ, Green CJ, Elia M. Disease-related malnutrition: an evidence based approach to treatment. Wallingford: CABI Publishing; 2003

2. Bristrian $B R, B l a c k b u r n ~ G L$, Cochran $D$, et al. Prevalence of malnutrition in general surgical patients. JAMA 1976; 253: 1567-1570.

3. Isabel M, Correia TD, Waitzberg DL. The impact of malnutrition on morbidity, mortality, length of hospital stay and costs evaluated trough a multivariate model analysis. Clin Nutr 2003; 22: 235-239.

4. Meijers JMM, Halfens RJ, van Bokhorst-de van der Schueren MA, et al. Malnutrition in Dutch health care: prevalence, prevention, treatment, and quality indicators. Nutrition 2009; 25: 512-519.

5. Ljungqvist O, van Gossum A, Sanz M, et al. The European fight against malnutrition. Clin Nutr 2010; 29: 149-150.

6. Ljungqvist O, de Man F. Under nutrition - a major health problem in Europe. Nutr Hosp 2009; 24: 368370.

7. Elia M, Russell C. Combating Malnutrition: Recommendations for action. Report from the Group on Malnutrition, Led by BAPEN. Redditch, BAPEN; 2009.

8. Norman K, Pichard C, Lochs H, et al. Prognostic impact of disease-related malnutrition. Clin Nutr 2008; 27: 5-15.

9. Feldblum I, German L, Bilenko N, et al. Nutritional risk and health care use before and after an acute hospitalization among the elderly. Nutrition 2009; 25: 415-420.

10. Müller MC, Uedelhofen KW, Wiedemann UCH. Mangelernährungkostet 9 Milliarden Euro jährlich. CEPTON; 2007. Available online at http://cepton.eu/ publications/ download/ Pressemitteilung-Studie070621.pdf. [German].

11. Elia M, Stratton RJ. Calculating the cost of disease-related malnutrition in the UK in 2007 (public expenditure only) In: Combating Malnutrition: Recommendations for action. Report from the Advisory Group on Malnutrition, Led by BAPEN. Redditch, BAPEN; 2009. p. 39-52.

12. Gibney M. Nutrition and Health in an Ageing Population. UCD Institute of Food and Health Policy Seminar Series. June 2010. Available from: http://www.ucd.ie/t4cms/UCD_Ageing_Policy_Doc_ June_10.pdf

13. Tan SS, Bouwmans CAM, Rutten FFH, et al. Standardisation of Costs: The Dutch Manual for Costing in Economic Evaluations. Int J Technol Assess Health Care 2012; 28: 152-158.

14. Kruizenga HM, van Tulder MW, Seidell JC, et al. Effectiveness and cost-effectiveness of early screening and treatment of malnourished patients. Am J Clin Nutr 2005; 82: 1082-1089.

15. Meijers JMM, Halfens RJG, Wilson L, et al. Estimating the costs associated with malnutrition in Dutch nursing homes. Clin Nutr 2012; 31: 65-68.

16. Cawood AL, Rust S, Walters E, et al. The impact of malnutrition on health care use in hospital outpatients. Proc Nutr Soc 2010; 69: E149.

17. Halfens RJG, Meijers JMM, Neyens JCL, et al. Ondervoeding. In: Rapportage resultaten. Landelijke prevalentiemeting zorgproblemen 2011. Maastricht, The Netherlands: Universiteit Maastricht, Onderzoeksinstituut Caphri, Department of Health Care and Nursing Sciences; 2011. p. 71-89. [Dutch].

18. Slobbe LCJ, Smit JM, Groen J, et al. Kosten van Ziekten in Nederland 2007; Trends in de Nederlandse zorguitgaven 1999-2010. RIVM Rapport 270751023/2011. Bilthoven, The Netherlands: RIVM; 2007 [Dutch].

19. Tucker HN, Miguel SG. Cost containment through nutrition intervention. Nutr Rev 1996; 54: 111-121.

20. Elia M, Stratton RJ, Russell C, et al. The cost of disease-related malnutrition in the UK and economic considerations for the use of oral nutritional supplements (ONS) in adults. A report by the Health Economic Group of the British Association for Parenteral and Enteral Nutrition (BAPEN). Redditch, BAPEN; 2005.

21. Guest JF, Panca M, Baeyens JP, et al. Health economic impact of managing patients following a community-based diagnosis of malnutrition in the UK. Clin Nutr 2011; 30: 422-429.

22. Centraal Bureau voor de Statistiek (CBS), Levensverwachting; geslacht en leeftijd. Published online Dec 17: http://statline.cbs.nl; 2011. [Dutch]. 
23. Volkert $\mathrm{D}$, Kruse $\mathrm{W}$, Oster $\mathrm{P}$, et al. Malnutrition in geriatric patients: diagnoses and prognostic significance of nutritional parameters. Ann Nutr Metab 1992; 36: 97-112.

24. Meijers JMM, Schols JMGA, Van Bokhorst-de van der Schueren MAE,et al. Malnutrition prevalence in the Netherlands: Results of the annual Dutch National Prevalence Measurement of Care. Br J Nutr 2009; 10: 417-423.

25. Russell CA, Elia M, on behalf of BAPEN and collaborators. Nutrition Screening Survey in the UK in 2008: Hospitals, Care Homes and Mental Health Units. A report by the British Association for Parenteral and Enteral Nutrition (BAPEN). Redditch, BAPEN; 2009.

26. Russell CA. British Association for Parenteral and Enteral Nutrition (BAPEN). The impact of malnutrition on healthcare costs and economic considerations for the use of oral nutritional supplements. Clin Nutr Suppl 2007; 2: 25-32.

27. Pirlich M, Schütz T, Norman K, et al. The German hospital malnutrition study. Clin Nutr 2006; 25: 563-72.

28. Van der Heijden E, Schols JMGA, Van Binsbergen JJ, et al. Behandeling van ondervoeding noodzakelijk en (kosten)effectief onderdeel van het medisch handelen. TSG 2009; 8: 341-345. [Dutch].

29. Halfens RJG, Janssen MAP, Meijers JMM. Ondervoeding in: Rapportage Landelijke Prevalentiemeting Zorgproblemen 2006. Maastricht, The Netherlands: Universiteit Maastricht, Zorgwetenschappen, sectie Verplegingswetenschap; 2006. p. 79-103. [Dutch].

30. Halfens RJG, Meijers JMM, Du Moulin MFMT, et al. Rapportage Landelijke Prevalentiemeting Zorgproblemen 2010. Maastricht, The Netherlands: Universiteit Maastricht, CAPHRI School for Public Health and Primary Care, Department of Health Care and Nursing Science; 2010. p. 65-81. [Dutch].

31. Joosten KF, Zwart H, Hop WC, et al. National malnutrition screening days in hospitalized children in The Netherlands. Arch Dis Child 2010; 95: 141-145.

32. Baal van PHM, Heijink R, Hoogenveen RT, et al. Health care costs of unhealthy behaviour. Zorg voor euro's -3. National Institute for Public Health and the Environment (Rijksinstituut voor Volksgezondheid en Millieu -RIVM). RIVM rapport 270751015. Bilthoven, The Netherlands: RIVM; 2006. p. 1-62. [Dutch]. 


\section{Analysis of the health economic impact of medical nutrition in}

The Netherlands 


\section{Abstract}

\section{Objective}

A health economic analysis was performed to assess the cost-effectiveness of oral nutritional supplements (ONS), being a medical nutrition product, in The Netherlands.

\section{Methods}

This analysis is based on a comparison of the use of ONS versus "no use" of ONS in patients undergoing abdominal surgery. The costs and benefits of the two treatment strategies were assessed using a linear decision analytic model reflecting treatment patterns and outcomes in abdominal surgery. The incremental cost difference was based on costs associated with ONS and hospitalisation. Clinical probabilities and resource utilization were based on clinical trials and published literature; cost data were derived from official price tariffs.

\section{Results}

The use of ONS reduces the costs with a $€ 252$ (7.6\%) cost saving per patient. The hospitalisation costs reduce from $€ 3318$ to $€ 3044$ per patient, which is an $8.3 \%$ cost saving and corresponds with 0.72 days reduction in length of stay. The use of ONS would lead to an annual cost saving of a minimum of $€ 40.4$ million per year. Sensitivity analyses showed that the use of ONS remains cost saving compared with "no use" of ONS. A threshold analysis on the length of stay shows that at 0.64 days, the use of ONS is still cost-effective, which is an unrealistic value.

\section{Conclusions}

This analysis shows that the use of medical nutrition, ONS in this case, is a cost-effective treatment in The Netherlands and is dominant over standard care without medical nutrition: it leads to cost savings and a higher effectiveness. 


\section{Introduction}

Nutritional depletion in Western countries is usually caused by the joint action of an underlying disease, for example, cancer and dietary deficiency ${ }^{1}$, also known as disease related malnutrition (DRM). As a consequence, treatment should be focused not only on the disease but also on nutritional intervention. A Dutch study found that $40 \%$ of the patients in a ward for non-surgical patients were malnourished at admission, and that the risk of subsequent complications was higher in malnourished patients ${ }^{1}$. This frequency of DRM was as high as or higher than that reported in surgical patients $(30 \%)^{1}$. This $40 \%$ percentage of DRM may be an underestimate because patients were excluded if nutritional status could not be assessed within $24 \mathrm{~h}$ after admission. The consequences of malnutrition, if left untreated, are serious, causing a marked decline in physical and psychological health and function ${ }^{2}$. Malnutrition impairs recovery from disease and injury (including surgery), increasing mortality and complications (infections, pressure ulcers, etcetera) and healthcare use (general practitioners visits, length of stay (LOS) $)^{3}$. Recently, also a burden of illness study was performed in The Netherlands ${ }^{4}$. This study shows that the additional costs of DRM in The Netherlands is $€$ 1.683 billion in 2006, which equals $2.8 \%$ of the total Dutch national health expenditures. The majority (49\%) of the total costs on disease-related costs were attributable to the hospital setting (€830 million).

Meta-analyses on treatment of DRM with medical nutrition show a reduction in mortality and complications, for example sepsis, decubitus and pneumonia, improvement of wound healing, and an increase of quality of life ${ }^{5-8}$. Stratton and Elia concluded that nutritional support can be an important part of the management of any patient ${ }^{2}$.

The published literature (meta-analyses and systematic reviews) provide evidence that oral nutritional supplements (ONS) are an effective treatment for patients with malnutrition:

- Mortality rates are significantly lower (odds ratio of $0.61 ; 95 \% \mathrm{Cl} 0.48-0.78)^{2}$. Similar findings were reported in other reviews ${ }^{9}$.

- Complication rates, including infections, are significantly reduced (odds ratio of 0.31 ; $95 \% \mathrm{Cl} 0.17-0.56)^{2,10}$. Another systematic review showed that medical nutrition can significantly reduce the risk ( $25 \%$ risk reduction) of developing pressure ulcers ${ }^{7}$.

In summary, DRM has a high prevalence and its clinical consequences may be severe and costly. Consequently inappropriate management of DRM may have a high economic impact.

\section{Study objectives}

The primary objective of this study was to assess the cost-effectiveness of ONS, being a medical nutrition product, in patients undergoing abdominal surgery in The Netherlands. 


\section{Methods}

A model was constructed using decision analytical techniques ${ }^{11}$. This decision analytic model was developed to estimate the health economic impact of ONS in abdominal surgery from the perspective of the society in 2008 in the Netherlands. Data sources used included published literature, clinical trials and, official Dutch price/tariff lists and national population statistics.

Univariate sensitivity analyses are based on the modification of the basic clinical and economic assumptions in the model in order to test the stability of the conclusions of the analysis over a range of assumptions, probability estimates and value judgments.

- Proportion of malnutrition: the base case analysis (30\%) is based on data for abdominal surgery; the range for the sensitivity analysis also includes data for nonsurgical patients. The sensitivity analysis is based on a range varying from $25 \%$ to $40 \%$.

- Proportion eligible patients: the base-case analysis is based on the assumption that all malnourished patients are treated; a sensitivity analysis is based on a proportion of $50 \%$ of malnourished patients being treated with ONS.

- Cost of ONS: the cost of ONS is varied between $10 \%$ discount of the market price for inpatients ( $€ 2.19$ per bottle) and an outpatient price including VAT ( $€ 2.37$ per bottle).

- Cost of hospitalisation: the base-case analysis is based on a weighted per diem cost for academic and general hospitals. A sensitivity analysis is performed varying the per diem between the per diem of a general hospital ( $€ 357$ ) and the per diem of an academic hospital (€ 504).

- Duration of treatment with ONS: the base-case analysis is based on a mean value of 8.5 days. A sensitivity analysis is performed varying the initiation from 7 to 16 days.

- LOS: a sensitivity analysis is based on a $25 \%$ decrease and increase of LOS for all patients (no risk and risk patients). This range was a subjective choice because of lack of data for the construction of a confidence interval. However, a $25 \%$ decrease and increase reduction of LOS can be considered a very extreme range, and therefore captures the uncertainty in this input variable. A second sensitivity analysis was performed on a $25 \%$ decrease and increase of LOS for risk patients.

\subsection{Model design}

The model calculates and compares the medical costs for a virtual population of abdominal surgery patients with ONS and for a virtual population of abdominal surgery patients without ONS. The health economic impact of ONS is calculated using a decision tree model built in TreeAge Pro 2005/2006 reflecting treatment patterns and outcomes in abdominal surgery. Figure 3.1 shows the structure of the model for treatment with ONS. The first branch point in a tree is called a decision node because it corresponds to 
a choice of treatment - ONS or "no ONS". A decision node is represented as a small square ( $\square$ ). Subsequent to the decision node, the structure of the decision tree is shown, which is identical for both treatment options. The other branch points indicate probabilities. The patient may be at medium to high risk for DRM or at low risk for DRM.

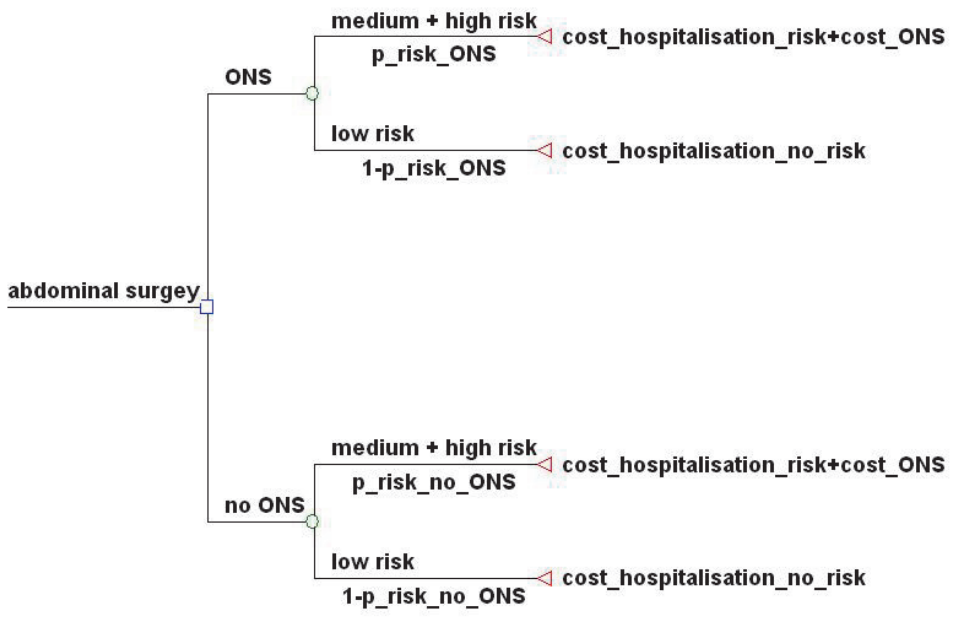

Figure 3.1 Model for the use of ONS in abdominal surgery.

\subsection{Study population and comparison}

The base-case analysis is based on a comparison of the use of ONS versus "no use" of ONS in patients undergoing abdominal surgery.

\subsection{Cost assessment}

An incremental costing approach was used, and therefore all drug utilization (and other health care utilization) being similar between the two treatment arms was not included in the model. The incremental cost difference was based on the costs associated with the cost of ONS and hospitalisation. The model is based on the assumption that the use of ONS only has an impact on the LOS. The potential favourable impact on adverse events by ONS and therefore the lower costs caused by adverse events were not included in this analysis, because of lack of appropriate data to feed the model. Thus the costing methodology is based on a conservative approach towards the use of ONS. The real economic benefits will therefore be higher than could be calculated with the current data set (see Discussion). The perspective of the study was a limited societal perspective, because indirect costs due to productivity loss were not included. This is a 
conservative assumption towards the use of ONS, because the lower LOS would lead to lower productivity loss and therefore lower indirect costs. On the other hand, a substantial proportion of patients undergoing abdominal surgery may be retired, as the average age is 63.2 according to a Dutch study ${ }^{12}$. Discounting of costs and effectiveness measures was not performed, because time horizon of the model did not exceed one year.

\section{Data Sources}

\subsection{The number of abdominal surgery procedures}

A CBO publication reports the annual number of surgery procedures ( 1.3 million) in The Netherlands ${ }^{13}$. This is an overall number without defining the type of surgical procedure. The annual number of abdominal surgery procedures is $160,283^{14}$.

\subsection{Prevalence of Disease Related Malnutrition (DRM)}

Several data on prevalence of DRM in the Netherlands have been published: from an overall prevalence of DRM of $25 \%{ }^{12}$ to a more group specific amount of $30 \%$ in surgical patients and $40 \%$ in non-surgical patients ${ }^{1}$. A recent Dutch study reports a range on prevalence of DRM varying from $25 \%$ to $40 \%$ in hospitalised patients, including surgical and non-surgical patients ${ }^{8}$. This report also states that only $50 \%$ of malnutrition is being diagnosed and treated. The most recent Dutch documentation is based on an annual returning independent measurement of the prevalence of DRM within the Dutch Health Care ${ }^{15,16}$.

The base-case analysis is based on data from this Dutch documentation; the range for the sensitivity analysis also includes data for non-surgical patients. Therefore the base case analysis is based on a prevalence of DRM of $30 \%$ with a range varying from $25 \%$ to $40 \%$.

Furthermore, the base-case analysis is based on the assumption that all malnourished patients are treated (eligible patients); a sensitivity analysis is based on the data from "Sneller Beter", which reports that a proportion of $50 \%$ of malnourished patients is not treated with an ONS.

This input data for the Dutch model corresponds with the British Association of Parenteral \& Enteral Nutrition (BAPEN) study from the UK, although the prevalence of DRM is somewhat lower: $29.3 \%$ for patients older than 65 and $20.4 \%$ younger than $65^{5,6}$. The UK data show that the difference in proportion of DRM is higher in the older patients (29.3\% versus $20.4 \%$ ). This difference is however less than $10 \%$, which is much smaller than the range we use for the sensitivity analysis. 


\subsection{Length of Stay (LOS)}

An international observational study, including Dutch centers, evaluated the implementation of an enhanced recovery program in five European centres and examined the determinants affecting recovery and $\operatorname{LOS}^{17}$. This study showed that the median length of stay was 8 days for standard treatment. A multivariate analysis revealed no country specific effect on length of stay. Prismant data from 2003 reports an average length of stay of 12.9 days in abdominal surgery in The Netherlands ${ }^{14}$. For clinical outcomes, the general rule may be to assume that data are not countryspecific $^{18}$. LOS in a hospital was considered a clinical outcome, which is not countryspecific, which was also an essential assumption in the BAPEN report ${ }^{5,6}$. Therefore, international data on LOS were used in this analysis for a Dutch health economic evaluation of ONS. Table 3.1 shows the data on LOS which were reported in the BAPEN report ${ }^{5,6}$, which is based on a $30 \%$ increase of LOS resulting from malnutrition.

The base-case analysis was based on a LOS of 8 days, based on the above mentioned international study, which included Dutch patients, whereas the $30 \%$ increase of LOS resulting from malnutrition was derived from the BAPEN report.

Table 3.1 Data on LOS which were reported in the BAPEN report ${ }^{5,6}$.

\begin{tabular}{|c|c|c|}
\hline Age of population (years) & LOS (days) when risk for DRM & LOS (days) when no risk for DRM \\
\hline$>65$ & 13.981 & 10.755 \\
\hline$<65$ & 5.390 & 4.146 \\
\hline
\end{tabular}

DRM - disease related malnutrition; LOS - length of stay

\subsection{Recommended amount of intake of ONS}

Typical prescription for ONS is 2 bottles $(2 \times 200 \mathrm{ml})$ per day per patient. The literature describes that 7-10 days before surgery the intake of ONS ought to be started, which may be continued until 7-10 days after surgery ${ }^{19-21}$. Therefore, the base-case analysis is based on a mean value of 8.5 days before and after surgery.

\subsection{Costs of treatment}

\section{Costs of ONS}

The price of a standard bottle is $€ 2.19$, which corresponds with the list price as registered in the Dutch market. The costs for a hospital are lower due to discounts. The costs for a patient at the pharmacy are higher due to VAT. Therefore the most realistic price for a bottle would be $€ 2.19$. 


\section{Costs of hospitalisation}

The costs of hospitalisation were derived from the Dutch Costing Manual ${ }^{22}$.

- Per diem academic hospital: $€ 476$

- Per diem general hospital: € 337

- Distribution: academic hospital $16 \%$ and general hospital $84 \%$

The costs were inflated from 2003 to $2008^{23}$.

- Per diem academic hospital: $€ 504$

- Per diem general hospital: € 357

\section{Results}

\subsection{Base-case analysis}

The results of the base-case analysis are shown in Table 3.2. This analysis shows that the use of ONS does not lead to additional costs. In fact, the use of ONS reduces the costs from $€ 3318$ to $€ 3066$, which corresponds with a $€ 252$ (7.6\%) cost saving per patient. The additional costs of ONS are more than balanced by a reduction on hospitalisation costs. The hospitalisation costs reduce from $€ 3,318$ to $€ 3,044$ per patient, which is an $8.3 \%$ cost saving and corresponds with 0.72 days reduction in LOS. The use of ONS would lead to an annual cost saving of $€ 40.4$ million based on 160,283 abdominal procedures per year.

A scenario analysis was based on LOS of 12.9 days according to Prismant data ${ }^{14}$. In this analysis, the use of ONS reduces the costs from $€ 5350$ to $€ 4931$, which corresponds with a $€ 419$ (7.8\%) cost saving per patient.

Table 3.2 Results: base case results and sensitivity analyses.

\begin{tabular}{|c|c|c|c|c|c|}
\hline \multirow{2}{*}{\multicolumn{2}{|c|}{ Base case }} & range & ONS & no ONS & savings \\
\hline & & & $€ 3066$ & $€ 3318$ & $€ 252$ \\
\hline \multirow{2}{*}{\multicolumn{2}{|c|}{ Proportion malnutrition }} & $25 \%$ & $€ 3063$ & $€ 3318$ & $€ 255$ \\
\hline & & $40 \%$ & $€ 3074$ & $€ 3318$ & $€ 244$ \\
\hline Eligible & & $50 \%$ & $€ 3192$ & $€ 3318$ & $€ 126$ \\
\hline \multirow{2}{*}{\multicolumn{2}{|c|}{ Price ONS }} & 1.97 & $€ 3064$ & $€ 3318$ & $€ 254$ \\
\hline & & 2.37 & $€ 3068$ & $€ 3318$ & $€ 250$ \\
\hline \multirow{2}{*}{\multicolumn{2}{|c|}{ Cost hospitalisation }} & 357 & $€ 2878$ & $€ 3113$ & $€ 235$ \\
\hline & & 504 & $€ 4054$ & $€ 4395$ & $€ 341$ \\
\hline \multirow[t]{2}{*}{ Use of ONS } & before and & 7 & $€ 3063$ & $€ 3318$ & $€ 255$ \\
\hline & after operation & 10 & $€ 3070$ & $€ 3318$ & $€ 248$ \\
\hline & $-25 \%$ & $€ 2305$ & $€ 2489$ & $€ 184$ \\
\hline \multicolumn{2}{|c|}{ all patients } & $25 \%$ & $€ 3828$ & $€ 4148$ & $€ 320$ \\
\hline \multicolumn{2}{|c|}{ Length of stay } & $-25 \%$ & $€ 2838$ & $€ 3021$ & $€ 183$ \\
\hline \multicolumn{2}{|c|}{ only risk patients } & $25 \%$ & $€ 3295$ & $€ 3615$ & $€ 320$ \\
\hline
\end{tabular}

ONS - oral nutritional supplement 


\subsection{Sensitivity analysis}

The results of the sensitivity analyses are presented in Table 3.3. These results show that the use of ONS in all sensitivity analyses remains cost saving compared with "no use" of ONS.

Table 3.3 Results of two-way sensitivity analyses.

\begin{tabular}{|c|c|c|c|c|c|c|}
\hline Sens $=>$ & 0,7500 & 0,8750 & 10,000 & 11,250 & 12,500 & \\
\hline \multicolumn{7}{|c|}{ Risk_LOS_no supply_larger } \\
\hline \multirow[t]{3}{*}{15,000} & $€ 2305$ & $€ 2610$ & $€ 1914$ & $€ 3218$ & $€ 3523$ & FSMP \\
\hline & $€ 2626$ & $€ 2976$ & $€ 3326$ & $€ 3676$ & $€ 4026$ & No FSMP \\
\hline & $€ 321$ & $€ 366$ & $€ 1412$ & $€ 458$ & $€ 503$ & Savings \\
\hline \multirow[t]{3}{*}{13,875} & $€ 2305$ & $€ 2610$ & $€ 2914$ & $€ 3219$ & $€ 3523$ & FSMP \\
\hline & $€ 2549$ & $€ 2888$ & $€ 3228$ & $€ 3568$ & $€ 3908$ & No FSMP \\
\hline & $€ 243$ & $€ 278$ & $€ 314$ & $€ 349$ & $€ 385$ & Savings \\
\hline \multirow[t]{3}{*}{12,750} & $€ 2305$ & $€ 2610$ & $€ 2914$ & $€ 3219$ & $€ 3523$ & FSMP \\
\hline & $€ 2471$ & $€ 2801$ & $€ 3131$ & $€ 3460$ & $€ 3790$ & No FSMP \\
\hline & $€ 166$ & $€ 191$ & $€ 217$ & $€ 241$ & $€ 266$ & Savings \\
\hline \multirow[t]{3}{*}{11,625} & $€ 2305$ & $€ 2610$ & $€ 2914$ & $€ 3219$ & $€ 3523$ & FSMP \\
\hline & $€ 2394$ & $€ 2714$ & $€ 3033$ & $€ 3352$ & $€ 3671$ & No FSMP \\
\hline & $€ 89$ & $€ 104$ & $€ 119$ & $€ 133$ & $€ 148$ & Savings \\
\hline \multirow[t]{3}{*}{10,500} & $€ 2305$ & $€ 2610$ & $€ 2914$ & $€ 3219$ & $€ 3523$ & FSMP \\
\hline & $€ 2317$ & $€ 2626$ & $€ 2935$ & $€ 3244$ & $€ 3553$ & No FSMP \\
\hline & $€ 12$ & $€ 16$ & $€ 21$ & $€ 26$ & $€ 30$ & Savings \\
\hline
\end{tabular}

FSMP - food for special medical purposes; LOS - length of stay; Sens - sensitivity

\subsection{Threshold analysis}

Threshold analyses were performed in order to calculate the break-even point for LOS and risk reduction at which the total costs for both treatment strategies are equal.

The first threshold analysis was performed on LOS. This analysis shows that the threshold for LOS is only 0.64 days. This value can be considered an unrealistic value compared with the actual LOS in the UK. This would mean that even at a LOS of 1 day, the use of ONS is still cost-effective. As abdominal surgery requires at least two days of hospitalisation, this threshold analysis shows that the cost-effectiveness of ONS does not depend on local Dutch data on LOS. The second threshold analysis was performed on the increase of LOS for patients with malnutrition. This analysis shows that the threshold for the increase of LOS in risk patients is only $2.7 \%$. This value can also be considered unrealistically low compared with the increase of $30 \%$ LOS in the UK. Therefore this threshold analysis shows that the cost-effectiveness of ONS does not depend on local Dutch data on reduction of LOS. 


\section{Discussion}

An analysis was performed for the use of ONS, being a medical nutrition product, in abdominal surgery in order to assess the health economic impact in The Netherlands. The rational for performing this health economic analysis in abdominal surgery is that this is the most studied indication. The assumption of this study was that there were no clinical differences between the treatment arms, except for LOS.

We have shown that the use of ONS is cost-effective, because of the following:

1) Total costs for treatment with ONS are not higher than a treatment strategy without ONS: the additional costs for ONS are more than balanced by a reduction in hospitalisation costs due to a reduction in LOS.

2) The analysis is based on similar clinical properties for both treatment strategies. However, the use of ONS is associated with a higher effectiveness, as this treatment leads to a reduction of the LOS.

Consequently, the use of ONS yields at least a similar effectiveness without extra costs and therefore can be considered cost-effective (position 1 in Figure 3.2). Even if we assume that there is no gain in effectiveness, the use of ONS remains cost-effective, as similar effectiveness is provided at lower costs. The results of this health economic analysis show that the use of ONS leads to lower treatment costs per patient and therefore can be considered cost-effective. The assumption for this health economic analysis is that there is no difference in mortality, complications and quality of life between the use of ONS versus "no use" of ONS in patients undergoing abdominal surgery. This is a conservative assumption towards the use of ONS, because metaanalyses show a reduction in mortality, complications and an improvement in quality of life ${ }^{5-8}$. The real economic benefits for the use of ONS are therefore in fact higher than could be calculated with the current data set. A reduction of complications contributes considerably to a reduction in LOS and therefore would lower the costs. However, we could not use these data in our model due to the fact that these outcomes for the studied patient group were not the primary ones. Indirect costs due to productivity loss were not included in this analysis. This is a conservative assumption towards the use of ONS, because the lower LOS would lead to lower indirect costs. On the other hand, a substantial proportion of patients undergoing abdominal surgery may be retired. We may also expect that the use of ONS in fact leads to cost savings in other health care budgets: fewer complications during hospitalisations will also lead to fewer follow-up costs (re-admissions, consultations, medication) ${ }^{24}$. Therefore we may conclude that this health economic analysis is based on conservative assumptions for the use of ONS.

Sensitivity analyses were performed on all parameters, including LOS and per diem costs. The results showed that the use of ONS in all sensitivity analyses remains cost saving compared with "no use" of ONS. 


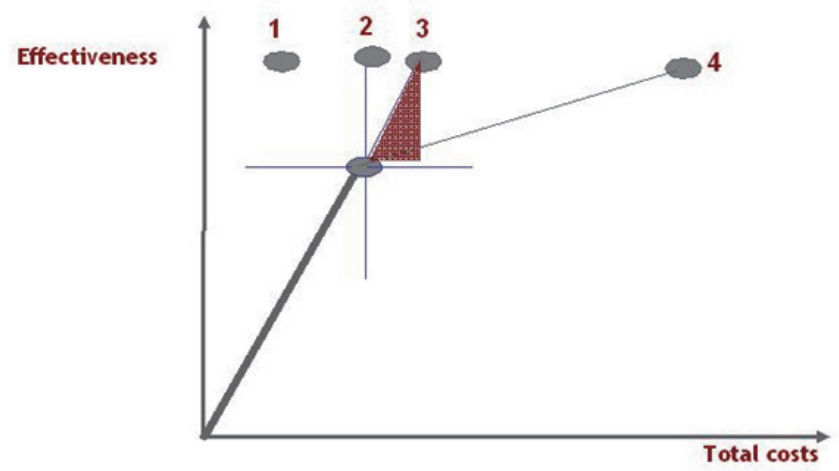

Figure 3.2 Cost-effectiveness diagram.

\section{Conclusion}

We performed a health economic analysis in order to assess the health economic impact of ONS in The Netherlands. This analysis was performed for the use of ONS, being a medical nutrition product, in abdominal surgery and showed that the use of ONS is cost-effective in the Dutch health care setting. 


\section{References}

1. Naber TH, Schermer T, de Bree A, et al. Prevalence of malnutrition in nonsurgical hospitalized patients and its association with disease complications. Am J Clin Nutr 1997; 66: 1232-1239.

2. Stratton RJ, Elia M. Who benefits from nutritional support: what is the evidence? Eur J Gastroenterol Hepatol 2007; 19: 353-358.

3. Martyn CN, Winter PD, Coles SJ, et al. Effect of nutritional status on use of health care resources by patients with chronic disease living in the community. Clin Nutr 1998; 17: 119-123.

4. Tan SS, KoopmanschapMA. The cost of disease related malnutrition and the cost-effectiveness of nutrition interventions: a feasibility study for the Netherlands. Data on file; 2007.

5. Elia M, Stratton RJ, Russell C, et al. The cost of disease-related malnutrition in the UK and economic considerations for the use of oral nutritional supplements (ONS) in adults. A report by the Health Economic Group of the British Association for Parenteral and Enteral Nutrition (BAPEN). Redditch, BAPEN; 2005.

6. Elia M, Zellipour L, Stratton RJ. To screen or not to screen for adult malnutrition? Clin Nutr 2005; 24: 867-884.

7. Stratton RJ, Ek AC, Engfer M, et al. Enteral nutritional support in prevention and treatment of pressure ulcers: a systematic review and meta-analysis. Ageing Res Rev 2005; 4: 422-450.

8. Sneller Beter. Implementatie van vroege herkenning \& behandeling van ondervoeding in de kliniek en op de polikliniek in Nederlandse ziekenhuizen. Available at http//www.snellerbeter.nl/fileadmin/ snellerbeter/documenten/Ondervoeding/19projectplan_maasziekenhuispantein.doc. Accessed on May 12, 2008. [Dutch].

9. Potter JM. Oral supplements in the elderly. Curr Opin Clin Nutr Metab Care 2001; 4: 21-28.

10. Stratton RJ, Green CJ, Elia M. Disease-related Malnutrition: An Evidence based Approach to Treatment, 1st Ed., Oxford: UK CABI Publishing; 2003.

11. Weinstein MC, Fineberg HV. Clinical decision Analysis. Philadelphia, Pa: WB Saunders Co; 1980: 228-265.

12. Kruizenga HM, Wierdsma NJ, van Bokhorst - de van der Schueren MAE, et al. Screening of nutritional status in The Netherlands. Clin Nutr 2003; 22: 147-152.

13. Kwaliteitsinstituut voor de Gezondheidszorg (CBO). Richtlijn Perioperatief voedingsbeleid; 2007. Available at http//www.cbo.nl. Accessed on May 20, 2008. [Dutch].

14. Prismant. Data on number of hospitalisations and length of stay; 2003. [Dutch].

15. Halfens RJG, Janssen MAP, Meijers JMM. Ondervoeding. In: Rapportage resultaten. Landelijke prevalentiemeting zorgproblemen 2006. Maastricht, The Netherlands: Universiteit Maastricht Zorgwetenschappen sectie Verplegingswetenschap; 2006: 79-101. [Dutch].

16. Halfens RJG, Meijers JMM, Neyens JCL, et al. Ondervoeding. In: Rapportage resultaten. Landelijke prevalentiemeting zorgproblemen 2007. Maastricht, The Netherlands: Universiteit Maastricht, Onderzoeksinstituut CAPHRI, Department of Health Care and Nursing Sciences; 2007: 81-108. [Dutch].

17. Maessen J, Dejong CHD, Hausel J, et al. A protocol is not enough to implement an enhanced recovery programme for colorectal resection. Br J Surg 2007; 94: 224-231.

18. Nuijten MJ. The selection of data sources for use in modelling studies. Pharmacoeconomics 1998; 13: 305-316.

19. French Speaking Society for Parenteral and Enteral Nutrition (F.S.S.P.E.N.). Perioperative artificial nutrition in elective adult surgery. Clin Nutr 1996; 15: 223-229.

20. McClave SA, Snider HL, Spain DA. Preoperative Issues in Clinical Nutrition. Chest 1999; 115: 64S-70S.

21. American Society for Parenteral and Enteral Nutrition (A.S.P.E.N.). Guidelines for the Use of Parenteral and Enteral Nutrition in Adult and Pediatric Patients. JPEN Suppl 2002; 26: 1SA-138 SA

22. Oostenbrink JB, Bouwmans CAM, Koopmanschap MA, et al. Handleiding voor kostenonderzoek. Geactualiseerde versie, Diemen: CVZ; 2004. [Dutch].

23. Centraal Bureau voor de Statistiek (CBS); Statline cijfers. Available at http// www.cbs.nl; nl$\mathrm{NL} / \mathrm{menu} / \mathrm{cijfers}$. Accessed on May 20, 2008. [Dutch].

24. Gariballa S, Forster S, Walters S, et al. A randomized double-blind placebo-controlled trial of nutritional supplementation during acute illness. Am J Med 2006; 119: 693-699. 


\section{4}

The budget impact of oral nutritional supplements for disease related malnutrition in elderly in the community setting 


\section{Abstract}

A health economic analysis was performed to assess the economic impact on the national health care budget of using oral nutritional supplements (ONS), being a food for special medical purposes (FSMP) also known as medical nutrition, for the treatment of disease related malnutrition (DRM) in the community in the Netherlands. An economic model was developed to calculate the budget impact of using ONS in community dwelling elderly ( $\geq 65$ years) with DRM in the Netherlands. The model reflects the costs of DRM and the cost reductions resulting from improvement in DRM due to treatment with ONS. Using ONS for the treatment of DRM in community dwelling elderly, leads to a total annual cost savings of $€ 13$ million (4.7\% savings), when all eligible patients are treated. The additional costs of ONS ( $€ 57$ million) are more than balanced by a reduction of other health care costs, e.g. re-/hospitalization ( $€ 70$ million). Sensitivity analyses were performed on all parameters, including duration of treatment with ONS and the prevalence of DRM. This budget impact analysis shows that the use of ONS in the management of DRM in elderly patients in the community may lead to cost savings in the Netherlands. 


\section{Introduction}

Malnutrition is a prevalent problem, which is known for many years and is defined as a state of nutrition in which a deficiency, excess (or imbalance) of energy, protein, and other nutrients causes measurable adverse effects on tissue/body form (body shape, size and composition) and function, and clinical outcome ${ }^{1}$. Malnutrition thus includes both over-nutrition (overweight and obesity) and under-nutrition (insufficient nutrition). For the purposes of this article the term malnutrition is used only for undernutrition in health care, which is caused by changes of the body metabolism due to acute or chronic diseases and/or treatment interventions, which increases the daily nutritional needs, also known as disease related malnutrition (DRM). Due to lack of adequate nutrition because of this increased nutritional need, an individual may move from a good nutritional status to frank disease related malnutrition in a matter of weeks, months or years. The key factor in the development of DRM is a nutritional intake that is insufficient to meet the increased nutritional requirements. DRM adversely impacts on every organ system in the body with potentially serious consequences on a physical and psycho-social level that in turn contribute to increased morbidity and mortality ${ }^{2}$.

As a consequence, treatment should be focused not only on the underlying disease but also on the nutritional status.

DRM is highly prevalent in Europe, as about 20 million patients are affected by disease related malnutrition, costing EU governments up to $€ 120$ billion annually ${ }^{3,4}$. DRM affects many people across all healthcare settings, from older people living in the community to patients in the hospital with specific conditions. A comparison of the results of the measurement of DRM in the Netherlands, Austria, Switzerland, New Zealand and Germany show that about $25 \%$ of hospitalized patients and patients in care homes are malnourished ${ }^{5}$. European studies regarding the community dwelling elderly, report a prevalence of DRM ranging from $19 \%$ in Russia up to $84 \%$ in Ireland ${ }^{1,6}$. In the Netherlands about $50 \%$ of the patients in all healthcare settings are at risk of DRM and $25 \%$ are actually malnourished ${ }^{7}$. Comparing prevalence rates in different countries and settings thus reveals that DRM in general is common, but that there is considerable fluctuation due to no universally accepted definition of malnutrition and screening tools for DRM.

As mentioned, DRM is common across a variety of patient and age groups, but older people are particularly at risk; a large-scale survey showed that the risk is $40 \%$ greater in people aged over 65 years, than in people under 65 years ${ }^{8}$. With an ageing population disease related malnutrition continues to be a major public health concern.

The consequences of DRM, if left untreated, are serious: an increase of complication rates, morbidity, mortality, hospital readmissions and length of hospital stay ${ }^{9,10}$. These consequences result in an increased use of healthcare resources (extra physicians' visits, extended length of stay in hospitals, extra costs in care homes etc.). ${ }^{11}$ In 2007 
a cost of illness study was performed in the Netherlands by the Institute for Medical Technology Assessment B.V. (iMTA) of the Erasmus University Rotterdam. This study reports that the additional costs of DRM in the Netherlands are $€ 1.7$ billion in 2006, which equals $2.8 \%$ of the total Dutch national health expenditures at that time (see section 2.4.5).

Patients with DRM are often not able to meet the increased nutritional requirements with their daily food due to a number of different reasons related to disease and disability, impacting on food intake, losses of nutrients and/or increased requirements. Although in some cases improvement of the quality or quantity of food supplied can ameliorate the problem, in many cases the person concerned is simply unable or unwilling to consume sufficient normal food to meet their requirements to manage the DRM. In this case, it is vital to consider other options to improve nutritional intake, such as enteral nutritional support. The term enteral nutrition, also known as medical nutrition, comprises all forms of nutritional support that imply the use 'dietary foods for special medical purposes' as defined by the European Commission Directive 1999/21/EC independent of the route of application. It includes oral nutritional supplements (ONS) as well as tube feeding via nasogastric, naso-enteral or percutaneous tubes ${ }^{12}$. Meta-analyses on treatment of DRM with medical nutrition show a reduction in mortality and complications (e.g. sepsis, wound care and pneumonia), improvement of wound healing, and an increase of quality of life $\mathrm{e}^{10,13,14}$. Stratton and Elia concluded that enteral nutritional support can be an important part of the management of any patient ${ }^{15}$.

The published literature (meta-analyses and systematic reviews) provides evidence that oral nutritional supplements (ONS), being food for special medical purposes (FSMP), are an effective treatment for patients with DRM:

- Mortality rates are significantly lower (odds ratio of $0.61 ; 95 \% \mathrm{Cl} 0.48-0.78$ ) $^{1}$. Metaanalyses consistently show a reduction in mortality, e.g. a $24 \%$ reduction ${ }^{1}$, particularly in undernourished older people ${ }^{16-18}$.

- Complication rates, including infections, are significantly reduced (odds ratio of $0.31 ; 95 \% \mathrm{Cl} 0.17-0.56)^{1,15}$. Another systematic review showed that medical nutrition can significantly reduce the risk (25\% risk reduction) of developing pressure ulcers ${ }^{14}$.

- ONS have been demonstrated to be more effective than dietary advice and snacks $^{15,19}$.

- Potential cost savings as a result of reduced healthcare use can be realized in both the hospital and the community setting ${ }^{20}$. A previous Dutch health economic analysis by our group showed that the use of ONS for treating patients in the hospital setting would lead to an annual cost saving of $€ 40.4$ million per year in the Netherlands ${ }^{21}$. 
In summary, DRM is common and may be costly, if left untreated. Therefore the objective of this study is to assess the economic benefit for the society in the Netherlands when community dwelling elderly ( $\geq 65$ years) patients with DRM are treated with ONS.

\section{Methods}

\subsection{Health economic modelling - model design}

A health economic model was constructed using decision analytical techniques ${ }^{22}$. The model calculates the budget impact of using ONS in patients who are eligible (section 2.2, 2.4.1 and 2.4.2) for ONS due to DRM. The model allows the assessment of the cost savings resulting from improvement in DRM due to treatment with ONS. Clinical probabilities and resource utilization were based on clinical trials and published literature (section 2.4.3); cost data were derived from official price tariffs.

Figure 4.1 shows the structure of the model for treatment with ONS. The first branch point in a tree is called a decision node because it corresponds to a choice of treatment - ONS or "no ONS" - in patients eligible for ONS due to DRM. A decision node is represented as a small square ( $\square$ ). Subsequent to the decision node, the structure of the decision tree is shown, which is identical for both treatment options. The other branch points indicate probabilities. DRM status may improve (reduction of malnutrition), or may deteriorate or remain similar (no reduction of malnutrition).

Data sources used included published literature, clinical trials, official Dutch price/tariff lists and national population statistics. To be able to test the robustness of the outcomes of the model to the variance in the input values, a sensitivity analysis was performed. A sensitivity analysis is a technique for systematically changing variables in a model to determine the effects of such changes ${ }^{23}$. Our univariate sensitivity analyses (a single variable and its attributes of the applicable major entity that is being analysed in the study) were based on the modification of the basic clinical and economic assumptions in the model. This procedure entails changing one of the model parameters through a range of plausible values and assessing the effect on the overall outcome of the analysis.

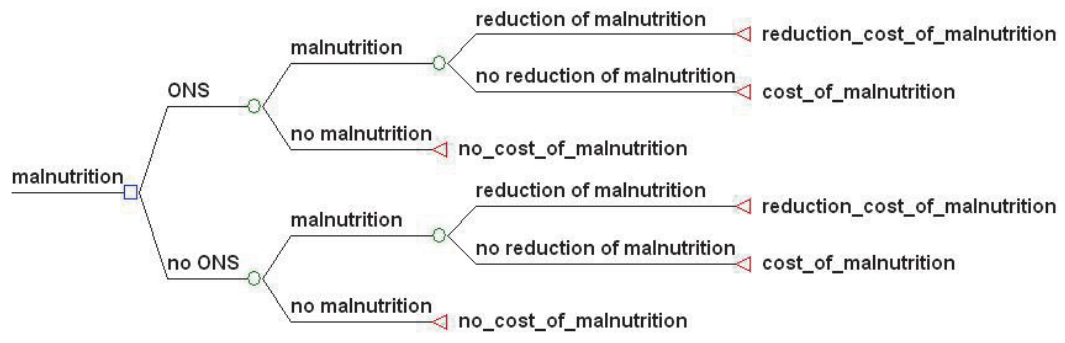

Figure 4.1 Model to calculate the budget impact of the use of ONS; a linear decision Tree. 


\subsection{Study Population: type of patients, type of intervention and comparator}

The study population is based on a comparison of the use of ONS versus "no use" of ONS due to DRM in elderly patients of 65 years and over ( $\geq 65$ years) in the community setting. ONS is the intervention and "no use" of ONS is the comparator, meaning that this group of patients with DRM is getting the standard care (e.g. their normal daily food as usual without any special nutritional intervention like ONS). This study population is the most studied and common in clinical trials regarding ONS. To be able to calculate the budget impact of the use of ONS, an incremental costing approach was used (section 2.3). The incremental cost difference was based on the costs associated with the cost of ONS and the cost of illness of DRM. All health care costs other than use of ONS and costs of DRM are not included in the model.

The rational for selecting elderly patients is that ageing will have an increasing impact on the Dutch healthcare budget. Maintaining an adequate functional status in older people is considered a high priority by the World Health Organization to help prevent disability and institutionalization ${ }^{24}$. Institutionalization generally means high health care costs, especially in hospitals, which was also shown by the cost of illness analysis for DRM in the Netherlands (2.4.5). Preventing hospitalization or decreasing the duration of hospitalization will therefore most probably lead to cost savings. The cost savings due to a reduction of hospital length of stay by treating patients with ONS in the Netherlands has recently been published ${ }^{21}$.

The focus of this analysis is on the use of ONS in the community setting. Within the national health care system in the Netherlands, the costs of treatments in the community considerably affect the total health care budget. In 2005 , about $6 \%$ of the population older than 30 years received publicly financed nursing and care, two thirds received some form of home care and one third lived in a home. The sector nursing and residential care spent nearly $€ 10$ billion of the total public spending in that year, which is approximately $2 \%$ of gross domestic product in the Netherlands. Spending on public nursing care between 2005 and 2030 is expected to increase by $3.4 \%$ per annum. This is faster than the growth in the number of users (1.2\%) and a result of rising health care costs and increasing health care needs ${ }^{25}$. Therefore interventions used to manage DRM in the community setting in the Netherlands, may have a major impact on the national health care budget. Patients living at home, who may or may not be assisted by home care and patients living in residential homes, are considered community dwelling patients ${ }^{26}$. Dutch home care services deliver care and nursing to patients living at home. This involves general and special nursing, household care and personal care. Residential homes offers assisted living (a save living environment) to older people who are still able to do a considerable part of their daily activities themselves. The perspective of this study is that of the compartment of patients living at home with assistance of home care ("thuiszorg" in Dutch) and patients living in residential homes ("verzorgingshuis" in Dutch) being the community setting. 


\subsection{Cost Assessment}

An incremental costing approach was used: all drug utilisation (and other health care utilisation), being similar between the two treatment arms, is not included in the model. The incremental cost difference was based on the costs associated with the cost of ONS and the cost of illness of DRM. The model is based on the assumption that the use of ONS only has an impact on re-/hospitalization due to DRM.

The perspective of the study was a limited societal perspective, because indirect costs due to productivity loss were not included, as the study population concerns elderly people, most likely to be retired. Discounting of costs and effectiveness measures was not performed, because the time horizon of the model did not exceed one year.

\subsection{Data}

\subsubsection{The Total Number of Patients}

The Dutch Central Buro for Statistics (CBS) reports that the total number of elderly patients ( $\geq 65$ years) in home care in the Netherlands was 499,700 in $2004^{27}$. As no data were available for 2009, the increase from 119,000 in five previous years was extrapolated to the subsequent five years giving a figure of 620,000 in 2009 using CBS 2006 data $^{27}$. There are 100,223 persons living in residential homes in the Netherlands ${ }^{28}$. As these data do not indicate the proportion of patients older than 65 years, we made the assumption that $100 \%$ is 65 years or older. The analysis is therefore based on a total number of 720,223 patients in 2009.

\subsubsection{Prevalence of Disease Related Malnutrition (DRM)}

In the Netherlands the department of Health Care and Nursing Science of the University of Maastricht is performing an annual national independent measurement of health care problems. Since 2004 this annual Dutch National Prevalence Measurement of Care Problems (LPZ) includes also an audit on DRM. The report of 2009 shows that one out of two patients in the Dutch health care system is at risk of DRM and $25 \%$ is malnourished. In home care and care homes the prevalence of DRM is somewhat lower but the prevalence of DRM is still $20 \%$ with a mean age of the population of 77 years ${ }^{7}$. The base case analysis is based on data from this Dutch report, which provides a prevalence of $20 \%$ of DRM in elderly ( $\geq 65$ years) living in the community setting.

\subsubsection{Re-/hospitalization}

A number of studies have been done in the community setting, but only a few have incorporated end-points which are amenable to economic modelling. Nevertheless, three studies in the community have shown that ONS result in a reduction in re/hospitalization ${ }^{29-31}$. Re-/hospitalization is a key driver of costs and is one of the consequences of $\mathrm{DRM}^{9-11}$ when left untreated. To be able to calculate the budget 
impact of ONS for malnutrition in the community setting, we used the re/hospitalization data as indication for the impact of ONS on DRM due to lack of other amenable data. For each study we calculated the probability of re/hospitalization (Table 4.1) which was then used as a measure for the reduction of DRM; for our economic analysis, a probability of 0.72 means that DRM is reduced by $27 \%$.

The study by Gariballa tested whether ONS for older patients (>65 years) during acute illness leads to a clinical benefit. This study provided a reduction of re-/hospitalization from $40 \%$ to $29 \%$ over a period of 6 months ${ }^{29}$. In another study by Chapman, ONS was tested in community-dwelling undernourished elderly alone or in combination with a hormonal supplement. Fewer patients needed hospitalization in the group, which received only the ONS (38.5\%) versus the group which received the no (=standard) treatment $(69 \%)^{30}$. Norman studied the effect of ONS (intervention group) versus no ONS (control group) in malnourished patients after hospital discharge for three months. Non elective readmissions were higher in the control group than in the intervention group ( $48 \%$ and $26 \%$ resp.) $)^{31}$.

For clinical outcomes, the general rule may be to assume that data are not countryspecific $^{32}$. Re-/hospitalization is considered a clinical outcome. Therefore the international data on re-/hospitalization were used in this analysis for a Dutch health economic evaluation of ONS in elderly patients ( $\geq 65$ years) in the community setting.

The base case analysis was based on a rather conservative reduction of DRM of $25 \%$ based on the most conservative probability of reduction in re-/hospitalization shown in the described international studies (Table 4.1).

Table 4.1 Results of international studies and meta-analysis on probability of re-/hospitalization of ONS.

\begin{tabular}{lcccc}
\hline Re- hospitalization & With ONS & Without ONS & Difference & Probability \\
\hline Gariballa $2006^{27}$ & $29 \%$ & $40 \%$ & $11 \%$ & 0.72 \\
Chapman $2009^{28}$ & $38 \%$ & $69 \%$ & $31 \%$ & 0.55 \\
Norman $2008^{29}$ & $26 \%$ & $48 \%$ & $22 \%$ & 0.54 \\
\hline
\end{tabular}

ONS - oral nutritional supplement

\subsubsection{Recommended amount of intake, duration and type of ONS}

The typical prescription for ONS is two bottles $(2 \times 200 \mathrm{ml})$ per day per patient. The studied duration of time using ONS varies from six weeks ${ }^{29}$ to one year ${ }^{30}$. In the study by Norman the duration of ONS was three months ${ }^{31}$. International recommendations for patients who are identified as malnourished on screening, state that monitoring should be in place monthly to every two to three months with a maximum of monitoring for three to six months by healthcare professionals with the relevant skills and training (www.bapen.org.uk; www.NICE.org.uk). The base case analysis was based on the most realistic and conservative period of three months.

The Dutch Guidelines for the treatment of DRM describe the nutritional need for patients with DRM, including the use of ONS ${ }^{33}$. The type of this nutrition intervention 
depends on several facts, like the nutritional intake with the daily food, which differs per patient. For our analysis we used the price of the most used ONS product (a "standard" ONS), containing energy $(1.5 \mathrm{kcal} / \mathrm{ml})$ and all the basic nutrients like protein carbohydrates, fat, fibres and vitamins and minerals.

\subsubsection{Costs of DRM}

In 2007 a rough estimate was made for the disease related costs of malnutrition in the Netherlands by a university-based scientific institute that is distinguished by independent research in medical technology assessment, including health economics and health outcomes research and dedicated to support the use of cost-effectiveness information in healthcare decision making. (Institute for Medical Technology Assessment B.V. (iMTA), Erasmus University, Rotterdam, The Netherlands). The total additional costs of DRM in the total care sector were estimated at $€ 1.7$ billion for 2006 which equals $2.8 \%$ of the total Dutch national health expenditure and $5.8 \%$ of the total costs of the healthcare sectors analysed in the report (hospital-, nursing home-, residential home- and home care setting) at that time ${ }^{34}$. The total costs of DRM were analysed separately according to gender (men and women), age ('18< age < 60' and 'age $>60^{\prime}$ ), healthcare sector (hospital-, nursing home-, care home- and home care setting), and disease. To be able to take into account the effects of aging, because especially old people use a lot of care, analyses were made for an age group of patients older than 18 and younger than 60 years of age and for the group of 60 years and older. About $50 \%$ of the total expenditure on disease related malnutrition was attributable to the hospital setting ( $€ 830$ million). The proportions for the nursing home- ( $€ 352$ million), residential home- (€ 305 million) and home care setting (€ 196 million) accounted for $21 \%, 18 \%$ and $12 \%$ respectively. The calculations were based on the total costs per illness category, national prevalence data on DRM and a weighting factor for the extra costs of care for patients with DRM versus patients with no DRM. The total costs of care per illness category were based on the data of the Dutch National Institute for Public Health and the Environment (RIVM) from 2003, which were indexed to $2006^{35}$. The national prevalence data on DRM were taken from the LPZ of that year ${ }^{36}$ and the weighting factor was based on a Dutch study which showed that the length of stay for patients with DRM was longer $(30 \%)$ than for patients without $\mathrm{DRM}^{37}$. For home care, residential- and nursing home care, international studies have shown a significantly increased use of healthcare resources and costs by patients identified as malnourished or at risk of malnutrition compared with non-malnourished patients ${ }^{1,38-41}$. As concrete figures of the increase use of healthcare resources in these settings in the Netherlands are lacking, the same weight factor of 1.3 for these non-hospital sectors was used.

Moreover, this weighting factor of 1.3 was comparable with those used for the estimations of the costs of DRM in the United Kingdom and in Germany (1.3 and 1.4 respectively) ${ }^{10,42}$. For our current analysis, we used this iMTA report and indexed the 
costs of DRM per illness category to 2009, using the inflation index rate from CBS, Statistics Netherlands. We only did this indexing for the group of patients aged 60 years of age and older (elderly) in the settings residential- and home care, as these settings are community settings in the Netherlands (Table 4.2).

Table 4.2 Costs of DRM in elderly (> 60 years) per illness category in community in The Netherlands in 2009 (million Euros)* $^{*}$.

\begin{tabular}{lccc}
\hline Illness category & Residential home & Home care & Total \\
\hline infectious diseases & 720.000 & 1.160 .000 & 1.880 .000 \\
cancer & 1.816 .765 & 16.083 .713 & 17.900 .478 \\
endocrinology & 971.757 & 3.215 .000 & 4.186 .757 \\
diabetes & 1.228 .387 & 3.215 .000 & 4.443 .387 \\
haematology & 230.000 & 1.520 .000 & 1.750 .000 \\
psychiatry & 83.775 .896 & 11.047 .385 & 94.823 .280 \\
neurology & 997.523 & 4.782 .222 & 5.779 .745 \\
dementia & 1.394 .273 & 10.294 .199 & 11.688 .472 \\
spinal cord injury & 1.193 .333 & 7.173 .333 & 8.366 .667 \\
eye/ear & 0 & 0 & 0 \\
cardiovascular & 10.206 .524 & 15.590 .556 & 25.797 .080 \\
CVA, hemiparesis & 13.288 .667 & 16.026 .517 & 29.315 .184 \\
respiratory & 3.709 .924 & 8.221 .544 & 11.931 .468 \\
gastro-intestinal & 913.889 & 7.731 .331 & 8.645 .220 \\
urogenital & 904.896 & 0 & 904.896 \\
dermatology & 436.739 & 2.446 .434 & 2.883 .173 \\
musculoskeletal & 2.976 .678 & 32.377 .870 & 35.354 .549 \\
congenital & 0 & 0 & 0 \\
traumata - intoxications & 4.849 .538 & 5.143 .498 & 9.993 .036 \\
hip replacement & 0 & 0 & 0 \\
\hline Total & 109.730 .125 & 146.028 .603 & 275.643 .390 \\
\hline
\end{tabular}

*Based on cost of care per illness of the Dutch National Institute for Public Health and the Environment (RIVM) $^{33}$ indexed to 2009

\subsubsection{Costs of Treatment}

The price of a standard bottle ONS is $€ 2.20$, which corresponds with the list price in 2009 as registered in the Dutch market. The costs for a hospital are lower due to discounts. The costs for a patient at the pharmacy are higher due to a mark-up for the pharmacist and VAT. Therefore the most realistic price for a bottle would be $€ 2.37$, including VAT, which is used in the analysis. 


\section{Data sources}

\subsection{Base case analysis}

The base case analysis is based on the following values:

- Total number of patients: A total of 720,223 patients were used for the base case analysis, based on national data (section 2.4 .1$)^{27,28}$. The sensitivity analysis is based on a range varying between plus and minus $10 \%$ of the total number of patients.

- Proportion of DRM: The base case analysis (20\%) is based on Dutch data regarding prevalence of DRM in the community setting in the Netherlands ${ }^{7}$. The sensitivity analysis is based on a range varying the base case value by plus and minus $10 \%$ and plus and minus $20 \%$. We tested two ranges in order to assess the level of sensitivity of the outcomes of the model to this parameter as this parameter is key driver of the model.

- Duration and amount of intake of treatment with ONS: The base case analysis is based on a mean duration of treatment of 12 weeks with $2 \times 200 \mathrm{ml}$ per day (section 2.4.4). A sensitivity analysis is performed varying the duration from 2 months to 4 months.

- Reduction of DRM: The base case analysis was based on a rather conservative reduction of DRM of $25 \%$ based on the most conservative probability of reduction in re-/hospitalization shown in the described international studies (section 2.4.3)

The results of the base case analysis are shown in Table 4.3. This analysis shows that the use of ONS for elderly with DRM in the community setting does not lead to additional costs. In fact, the use of ONS reduces the costs from $€ 275.643$ million to $€ 262.657$ million which corresponds with a total national cost saving of $€ 12.986$ million (4.7\% savings). The additional costs of ONS ( $€ 57.335$ million) are more than balanced by a reduction of the total costs of DRM due to a reduction of re/hospitalization. Therefore, the use of ONS would lead to a positive annual budget impact of nearly $€ 13$ million when all eligible patients are treated, based on the population of 720,223 patients living in the community setting in the Netherlands in 2009.

Table 4.3 Results of the base case analysis: budget impact of ONS (without and with ONS) in elderly with DRM in the community in the Netherlands in 2009 (million Euros).

\begin{tabular}{lclr}
\hline & Without ONS & With ONS & \multicolumn{1}{c}{ Savings } \\
\hline Costs of DRM & $€ 275.643$ & $€ 205.322$ & $€ 70.321$ \\
Costs of ONS & $€ 0$ & $€ 57.335$ & $-€ 57.335$ \\
Budget impact & $€ 275.643$ & $€ 262.657$ & $€ 12.986$ \\
\hline
\end{tabular}

DRM - disease related malnutrition; ONS - oral nutritional supplements 


\subsection{Sensitivity analysis}

The results of the sensitivity analyses are presented in Table 4.4 We tested two ranges in the sensitivity analysis in order to assess the sensitivity of the outcomes of the model to the key parameters in the model. These results show that the use of ONS remains cost saving compared with "no use" of ONS in nearly all sensitivity analyses. The budget impact is most sensitive to the duration of treatment with ONS; the break-even for the duration of treatment is 3.7 months.

Table 4.4 Results of the base-case* and the sensitivity analyses** (million Euros).

\begin{tabular}{|c|c|c|c|c|}
\hline Analysis & Range*** & $\begin{array}{c}\text { Without } \\
\text { ONS }\end{array}$ & $\begin{array}{l}\text { With } \\
\text { ONS }\end{array}$ & Savings \\
\hline Base case & & $€ 276$ & $€ 263$ & $€ 13$ \\
\hline \multirow[t]{4}{*}{ Prevalence malnutrition } & $-10 \%$ & $€ 276$ & $€ 257$ & $€ 18$ \\
\hline & $+10 \%$ & $€ 276$ & $€ 268$ & $€ 7$ \\
\hline & $-20 \%$ & $€ 276$ & $€ 251$ & $€ 24$ \\
\hline & $+20 \%$ & $€ 276$ & $€ 274$ & $€ 1$ \\
\hline \multirow[t]{2}{*}{ Total number of patients } & $-10 \%$ & $€ 276$ & $€ 257$ & $€ 18$ \\
\hline & $+10 \%$ & $€ 276$ & $€ 268$ & $€ 7$ \\
\hline \multirow[t]{2}{*}{ Duration of treatment ONS } & -1 month & $€ 276$ & $€ 244$ & $€ 32$ \\
\hline & +1 month & $€ 276$ & $€ 282$ & $-€ 6$ \\
\hline
\end{tabular}

* the overall outcome of the budget impact analysis following the calculation model for using ONS or not using ONS by elderly patients in the community; ${ }^{* *}$ checking the robustness (sensitivity) of the base case by changing one of the model parameters through a range of plausible values; ${ }^{* * *}$ the values used in the base case are changed by a range of plausible values. ONS - oral nutritional supplement

\section{Discussion and conclusion}

An analysis was performed to assess the economic impact of the use of ONS in community dwelling elderly patients ( $\geq 65$ years) with DRM, on the national health care budget in the Netherlands. The rational for performing this budget impact analysis for the cohort of elderly patients in the community is that the ageing society in the Netherlands in the future will have a high impact on the healthcare budget. Therefore interventions used to manage DRM in the community setting in the Netherlands, may have a major favourable impact on the national health care budget, as the proportion of elderly will increase. Each year the Dutch Ministry of Health has to decide which interventions will be reimbursed and a budget impact calculation can provide valuable information for the decision making process. This budget impact analysis shows that using ONS for the treatment of DRM in community dwelling elderly leads to cost savings: additional costs for ONS are offset by substantial cost savings and therefore support the existing clinical guidelines also from an economic point of view. In the UK, the British Association for Parenteral and Enteral Nutrition (BAPEN) has used a similar approach to inform their National Institute for Health and Clinical Excellence (NICE) to 
support the guideline development and contribute to the evidence base, as economic evaluations are included in their guidance in order to recommend those treatments that represent value for money. Their systematic analysis of the costs of disease-related malnutrition in the UK and use of oral nutritional supplements in hospital and community settings showed also some insights into the economic burden of malnutrition and the value of oral nutritional supplements in one healthcare system ${ }^{43}$.

Recently other economic studies in the field of DRM have been performed for the UK by Guest et al. ${ }^{44}$ and Cawood et al. ${ }^{45}$ and for Germany by Norman et al. ${ }^{46}$. The study of Guest et al. can be considered a cost of illness study as this study gives a good overview of the current way malnourished patients are treated in the community including the economic impact, although the nutritional intervention was often inappropriate (vitamin and mineral supplements). Guest et al. also show that only $23 \%$ of the malnourished patients are actually treated with a nutritional intervention. The study by Cawood et al. has yet only been published as an abstract, but the described methods seem similar to our analysis. A big difference in both budget impact analyses is the inclusion of the cost of patient monitoring, which is one of the limitations of our study. The study by Norman et al. is a cost utility analysis of ONS, in which the costeffectiveness of the improvement of quality of life has been calculated in terms of Quality Adjusted Life Years (QALY). Both studies provide important information on the economics of disease related malnutrition, but the UK study does not include the impact of ONS, and the German study is limited to the patient-based level without extrapolation to the economic impact at a population level. As a consequence the results of these two studies are not comparable with the results of our own economic analysis. In addition, the two studies were performed outside the Netherlands, where different treatment patterns and financing systems may lead to different costs.

One of the limitations of our study is that we did not include all costs due to lack of data, e.g. the cost of patient monitoring (assessment and follow up) for DRM. Also due to lack of data on patients living at home without assistance of home care, the perspective of this study is that of the compartment of patients living at home with assistance of home care. This may also be a limitation of this study.

The used duration of treatment with ONS may be another limitation. Patients of 65 years and older with a range of chronic diseases could be in need of ONS for a longer period of time than three months to recover from DRM. The treatment with ONS could then lead to a cost-increase. The sensitivity analysis on the duration of treatment though, showed that the outcome of the model is rather robust to changes in treatment duration. Finally we had to use indirect clinical data for calculating the direct effect of ONS on DRM. As only data of the effect of ONS in the community exist on re/hospitalization, which is one of the consequences of $\mathrm{DRM}^{9-11}$, we used re/hospitalization as the efficacy measure of ONS on DRM. The probability value on re/hospitalization we used in this analysis $(0.75)$ has been confirmed by a recent metaanalysis on hospital re-/admission. This systematic review and meta-analysis by 
Stratton et al. examined the effect of ONS versus routine care (no ONS) on admissions/readmissions in the community setting. The three studies we used as basis for our analysis were part of the total amount of six studies used in this meta-analysis. ONS significantly reduced the proportion of patients admitted or readmitted to hospital from $33 \%$ to $24 \%$ with a probability of 0.73 . When including only trials in the elderly (mean age $\geq 65$ years), the result remained significant (OR 0.63 (95\% Cl 0.45 to 0.88 ), $\mathrm{p}=0.007)^{47}$. Implicitly we also assumed that there is no difference in mortality, complications and Quality of Life between the use of ONS versus "no use" of ONS in malnourished elderly patients living in the community. This is a conservative assumption towards the use of ONS, because studies in elderly have shown a reduction in mortality, complications and an improvement in quality of life ${ }^{14,17,18,30}$ which are also consequences of DRM. But because of the fact that these outcomes were not specific enough, we did not use these data in our model. So the real economic benefits for the use of ONS may be in fact higher than was calculated with the current data set.

Despite the limitations, we have shown that the use of ONS has a positive impact on the national budget, because:

1) Total costs for treatment with ONS are not higher than a treatment strategy without ONS: the additional costs for ONS are more than balanced by a reduction of the health care costs due to a reduction of the costs of DRM.

2) The analysis is based on similar clinical properties for both treatment strategies with regards to mortality and complications. However, the use of ONS is associated with a higher effectiveness, as this treatment leads to a reduction of DRM only.

Sensitivity analyses were performed and resulted in the fact that the use of ONS in nearly all parameters remains cost saving compared to "no use" of ONS. The budget impact is most sensitive to the duration of treatment with ONS. Treating patients for 4 months with $2 \times 200 \mathrm{ml}$ per day, the costs savings are lost. The break even for using the ONS is 3.7 months, meaning that at that point the costs and the savings are equal. In conclusion, this budget impact analysis for the use of ONS in elderly patients ( $\geq 65$ years) with DRM living in the community setting in the Netherlands showed that the use of ONS in this group of patients may lead to a positive impact on the national health care budget in the Netherlands. 


\section{References}

1. Stratton RJ, Green CJ, Elia M. Disease-related malnutrition: an evidence based approach to treatment. Wallingford: CABI Publishing; 2003

2. Elia M, Russell C. Combating Malnutrition: Recommendations for action. Report from the Group on Malnutrition, Led by BAPEN. Redditch, BAPEN; 2009.

3. Ljungqvist O, de Man F. Under nutrition - a major health problem in Europe. Nutr Hosp 2009; 24: 368-370.

4. Ljungqvist O, van Gossum A, Sanz M, et al. The European fight against malnutrition. Clin Nutr 2010; 29: 149-150.

5. Halfens RJG, Schols JMGA, Bartholomeyczik S, et al. International Prevalence Measurement of Care Problems (LPZ): 2009-2010 at a glance. Maastricht, The Netherlands: Datawyse; 2011.

6. Gurina NA, Frolova EV, Degryse JM. A roadmap of aging in Russia: the prevalence of frailty in community-dwelling older adults in the St. Petersburg district--the "Crystal" study. J Am Geriatr Soc 2011; 59: 980-988.

7. Halfens RJG, Meijers JMM, Neyens JCL, et al. Rapportage Landelijke Prevalentiemeting Zorgproblemen 2009. Maastricht, The Netherlands: Universiteit Maastricht, CAPHRI School for Public Health and Primary Care, Department of Health Care and Nursing Science; 2009. p. 71-89. [Dutch].

8. Russell CA, Elia M, on behalf of BAPEN and collaborators. Nutrition Screening Survey in the UK in 2008: Hospitals, Care Homes and Mental Health Units. A report by the British Association for Parenteral and Enteral Nutrition (BAPEN). Redditch, BAPEN; 2009.

9. Sorensen J, Kondrup J, Prokopowicz J, et al. EuroOOPS: an international, multicentre study to implement nutritional risk screening and evaluate clinical outcome. Clin Nutr 2008; 27: 340-349.

10. Elia M, Stratton RJ, Russell C, et al. The cost of disease-related malnutrition in the UK and economic considerations for the use of oral nutritional supplements (ONS) in adults. A report by the Health Economic Group of the British Association for Parenteral and Enteral Nutrition (BAPEN). Redditch, BAPEN; 2005.

11. Martyn CN, Winter PD, Coles SJ, et al. Effect of nutritional status on use of health care resources by patients with chronic disease living in the community. Clin Nutr 1998; 17: 119-123.

12. Lochs $\mathrm{H}$, Allison SP, Meier $\mathrm{R}$, et al. Introductory to the ESPEN guidelines on enteral nutrition: terminology, definitions and general topics. Clin Nutr 2006; 25: 180-186.

13. Sneller beter. Implementatie van vroege herkenning \& behandeling van ondervoeding in de kliniek en op de polikliniek in Nederlandse ziekenhuizen; 2008. Available at http//www.snellerbeter.nl/ fileadmin/snellerbeter/documenten/Ondervoeding/19projectplan_maasziekenhuispantein.doc. Accessed on May 12, 2008. [Dutch].

14. Stratton RJ, Ek AC, Engfer M. et al. Enteral nutritional support in prevention and treatment of pressure ulcers: a systematic review and meta-analysis. Ageing Res Rev 2005; 4: 422-450.

15. Stratton RJ, Elia M. Who benefits from nutritional support: what is the evidence? Eur J Gastroenterol Hepatol 2007; 19: 353-358.

16. Milne AC, Potter J, Vivanti A. et al. Protein and energy supplementation in elderly people at risk from malnutrition. Cochrane Database: Syst Rev 2, CD003288; 2009.

17. Milne AC, Potter J, Avenell A. Protein and energy supplementation in elderly people at risk from malnutrition. Cochrane Database: Syst Rev 2, CD003288; 2005.

18. Milne AC, Avenell A, Potter J. Meta-analysis: protein and energy supplementation in older people. Ann Intern Med 2006; 144: 37-48.

19. Stratton RJ, Bowyer G. Elia M. Food snacks or liquid oral nutritional supplements as a first-line treatment for malnutrition in post-operative patients? Proc Nutr Soc 2006; 65: 4A.

20. NICE Clinical guideline (CG) 32. Nutrition Support in adults: oral nutrition support, enteral tube feeding and parenteral nutrition; 2006. London: National Collaborating Centre for Acute Care, Commissioned by the National Institute for Clinical Excellence. Available at http://www.nice.org.uk/CG32. Accessed on February 26, 2011.

21. Freijer K, Nuijten MJC. Analysis of the health economic impact of medical nutrition in the Netherlands. EJCN 2010; 64: 1229-1234. 
22. Weinstein MC, Fineberg HV. Clinical decision Analysis. Philadelphia, Pa: WB Saunders Co; 1980: 228-265.

23. Saltelli A, Ratto M, Andres T, et al. Global Sensitivity Analysis. The Primer; Chichester: JohnWiley \& Sons; 2008.

24. WHO. Active Ageing: A Policy Framework. Geneva: WHO; 2002.

25. Woittiez I, Eggink E, Jonker J-J, et al. Vergrijzing, verpleging en verzorging. Ramingen, profielen en scenario's 2005-2030. Den Haag, The Netherlands: Sociaal en Cultureel Planbureau (SCP-publicatie 2009/17); 2009. [Dutch].

26. Schols JMGA, Crebolder HFJM, van Weel C. Nursing Home and Nursing Home Physician: The Dutch Experience. J Am Med Dir Assoc 2004; 5: 207-212.

27. Centraal Bureau voor de Statistiek (CBS). Gezondheid en zorg in cijfers 2006. Available at http://www.cbs.nl. [Dutch].

28. Actiz. Cijfers 2009. Available at: http://www.actiz.nl.

29. Gariballa S, Forster S. Walters S, et al. A randomized double-blind placebo-controlled trial of nutritional supplementation during acute illness. Am J Med 2006; 119: 693-699.

30. Chapman M, Visvanathan R, Hammond AJ, et al. Effect of testosterone and a nutritional supplement, alone and in combination, on hospital admissions in undernourished older men and women. Am J Clin Nutr 2009; 89: 880-889.

31. Norman K, Kirchner H, Freudenreich $\mathrm{M}$, et al. Three month intervention with protein and energy rich supplements improves muscle function and quality of life in malnourished patients with non-neoplastic gastrointestinal disease--a randomized controlled trial. Clin Nutr 2008; 27: 48-56.

32. Nuijten MJ. The selection of data sources for use in modelling studies. Pharmacoeconomics 1998; 13: 305-316.

33. Stuurgroep Ondervoeding. Richtlijn Screening en behandeling van ondervoeding. Available at: http://www.stuurgroepondervoeding.nl. Accessed 2011, at fileadmin/dbc/Stuurgroep. [Dutch].

34. Van der Heijden E, Schols JMGA, van Binsbergen JJ, et al. Behandeling van ondervoeding noodzakelijk en (kosten)effectief onderdeel van het medisch handelen. TSG 2009; 8: 341-345. [Dutch].

35. Slobbe LCJ, Kommer GJ, Smit JM, et al. Kosten van Ziekten in Nederland 2003; Zorg voor Euro's-1. Rijksinstituut voor Volksgezondheid en Milieu (RIVM): Rapport 270751023/2011. Bilthoven, The Netherlands: RIVM; 2006 [Dutch].

36. Meijers JMM, Janssen MAP, Schols JMGA, et al. Ondervoeding. In: Rapportage resultaten. Landelijke prevalentiemeting zorgproblemen 2006. Maastricht, The Netherlands: Universiteit Maastricht, Zorgwetenschappen, sectie Verplegingswetenschap; 2006:79-102. [Dutch].

37. Kruizenga HM, van Tulder MW, Seidell JC, et al. Effectiveness and cost-effectiveness of early screening and treatment of malnourished patients. Am J Clin Nutr 2005; 82: 1082-1089.

38. Müller MC, Uedelhofen KW, Wiedemann UCH. Mangelernährungkostet 9 Milliarden Euro jährlich. CEPTON; 2007. Available online at http://cepton.eu/ publications/ download/ Pressemitteilung-Studie070621.pdf. [German].

39. Banks MD, Graves N, Bauer JD, et al. The costs arising from pressure ulcers attributable to malnutrition. Clin Nutr 2010; 29: 180-186.

40. Cawood AL, Rust S, Walters E, et al. The impact of malnutrition on health care use in hospital outpatients. Proc Nutr Soc 2010; 69: E149.

41. Norman K, Pichard C, Lochs H, et al. Prognostic impact of disease-related malnutrition. Clin Nutr 2008; 27: 5-15.

42. Pirlich M, Schütz T, Norman K, et al. The German hospital malnutrition study. Clin Nutr 2006; 25: 563-572.

43. Russell CA. The impact of malnutrition on health care costs and economic considerations for the use of oral nutritional supplements. Clin Nutr Suppl 2007; 2: 25-32.

44. Guest JF, Panca M, Baeyens JP, et al. Health economic impact of managing patients following a community-based diagnosis of malnutrition in het UK. Clin Nutr 2011; 30: 422-429.

45. Cawood AL, Green C, Stratton RJ. The budget impact of using oral nutritional supplements in older community patients at high risk of malnutrition in England. Proc Nutr Soc 2010; 69: E544. 
46. Norman K, Pirlich M, Smoliner C, et al. Cost-effectiveness of a 3-month intervention with oral nutritional supplements in disease-related malnutrition: a randomised controlled pilot study. EJCN 2011; 65: 735-742.

47. Stratton R, van Binsbergen J, Volkert D, et al. Systematic review and meta-analysis of the effects of oral nutritional supplements on hospital admissions. ESPEN 2011 (abstract OPO38). Available online at https://b-com.mci-roup.com/AbstractList/ESPEN2011.aspx. 


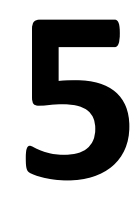

The economic value of enteral medical nutrition in the management of disease related malnutrition: a systematic review

Karen Freijer Martijn JL Bours Mark JC Nuijten Marten J Poley Judith MM Meijers Ruud JG Halfens Jos MGA Schols 


\section{Abstract}

Economic evaluations for medical nutrition, such as oral nutritional supplements (ONS), are relatively uncommon compared with other health technologies, and represent an area that has not been reviewed so far. In this systematic review, economic evaluations of enteral medical nutrition in the management of disease related malnutrition (DRM) were reviewed and qualified to estimate the economic value. Initially 481 studies were found of which 37 full text articles were assessed for eligibility and were rated on their quality using the Quality of Health Economic Studies (QHES) instrument. The final review focused on the high QHES quality economic evaluation studies. As both the studied medical nutrition intervention as well as the form of the economic evaluation varied, a quantitative synthesis (meta-analysis) was not attempted but a critical analysis and comparison of the individual study results were performed. ONS was the most studied intervention, covering several patient populations and different health care settings. Outcomes included cost savings $(n=3)$, no significant extra costs per unit of clinical and/or functional improvement $(n=1)$ or significantly higher costs per unit of clinical and/or functional improvement but still cost-effective for the used threshold $(n=4)$. This review shows that the use of enteral medical nutrition in the management of DRM can be efficient from a health economic perspective. 


\section{Introduction}

The situation in developed countries regarding health care is changing. An economic crisis is demanding budget constraints, while at the same time healthcare costs are likely to continue rising as populations get older, technology improves and public expectations grow ${ }^{1}$. Therefore, there is growing pressure on decision makers and health care providers to obtain the maximum possible benefit, given the resources available $^{2}$. This is where health economic evaluations can play an important role. In essence, these are comparative analyses of both the costs and consequences (or outcomes) of two or more possible treatments ${ }^{3}$. Depending on whether the consequences are expressed as monetary measures, natural units or preference-based measures, the analysis may be a cost-benefit (CBA), cost-effectiveness (CEA) or costutility analysis (CUA) ${ }^{4,5,6}$. The main outcome of such analyses is expressed as the difference in costs divided by the difference in effects, the so-called incremental costeffectiveness ratio (ICER), for example costs per life-year gained. Comparing the costeffectiveness ratio of a studied treatment with the ratios of other programs will tell whether or not the studied treatment is indeed efficient (cost-effective).

Economic evaluations for pharmaceuticals and other health technologies, including devices, have been common practice since the 1990s. Since that time, reimbursement agencies in different countries have developed evaluation guidelines, resulting in a large body of published literature on economic evaluations of health technologies ${ }^{7}$. Health economic evaluations for medical nutrition though are not common yet. Medical nutrition comprises parenteral nutrition, regulated in pharmaceutical legislation, as well as all forms of nutritional support that are regulated as "foods for special medical purposes"(FSMP), defined by the European Commission Directive $1999 / 21 /$ EC independent of the route of application ${ }^{8}$. For the purposes of this systematic review, the term medical nutrition is used only for FSMP, which is a category of dietary foods for particular nutritional uses, specially processed or formulated and intended for the dietary management of patients and to be used under medical supervision. One of the indications for the use of medical nutrition is malnutrition ${ }^{9-11}$. There is convincing clinical evidence for the benefits of medical nutrition, including weight gain, improvement of muscle function, reduction in mortality, complications and (re-)admission, improvement of wound healing and an increase of quality of life ${ }^{12-16}$. For the purposes of this systematic review, the term malnutrition is used only for undernutrition in health care, caused by changes of the body metabolism due to acute or chronic diseases and/or treatment interventions, which increases the daily nutritional needs, also known as disease related malnutrition (DRM). Although in some cases improvement of the quality or quantity of food supplied can ameliorate the problem, in many cases the person concerned is simply unable or unwilling to consume sufficient normal food to meet their requirements to manage the DRM. In this case, it is vital to consider other options to improve nutritional intake, such as FSMP products, which 
includes oral nutritional supplements (ONS) as well as enteral tube feeding (ETF) via nasogastric, naso-enteral, or percutaneous tubes.

In the European Union countries, about 20 million patients are affected by DRM (33 million in Europe), costing EU governments up to $€ 120$ billion annually ( $€ 170$ billion in Europe $)^{17-19}$. In the USA about 33\% - 54\% of the hospitalized patients are suffering from DRM depending on the screening method used. The prevalence of protein energy under-nutrition for residents of long-term care facilities is between $23 \%$ and $85 \%$ and up to $65 \%$ of residents has unintended weight loss and under-nutrition ${ }^{10}$. Total costs associated with DRM in the USA have not been calculated as such, but several studies show increased costs reaching from a mean daily expense of $\$ 228$ per patient for malnourished patients compared with a mean daily expense of $\$ 138$ per patient for well-nourished patients ${ }^{20}$. Also patients who experienced declines in their nutrition status during their hospital stays had higher mean hospital charges $(\$ 45,762)$ compared to patients who remained nourished during their hospitalizations $(\$ 28,631)^{21}$.

To estimate the efficiency (costs in relation to effects) in high-quality economic evaluations of enteral medical nutrition for DRM in adults in developed countries, we conducted a systematic review of published studies on this topic.

\section{Methods}

This systematic review was conducted according to the UK National Health Service Centre for Reviews and Dissemination (CRD) guidelines ${ }^{22}$ and the PRISMA guidelines ${ }^{23}$. The principle stages and steps undertaken in the reviewing process are shown in Figure 5.1 .

\subsection{Eligibility criteria, search strategy and study selection}

Full published studies that met the inclusion and exclusion criteria were eligible for reviewing. The commonly used standard elements of the review question, being patients, intervention(s), comparator(s), outcome(s), study design (PICOS) ${ }^{22}$ formed the basis for defining the eligibility criteria:

\section{Patients}

Adult patients suffering from or at risk of DRM, independent of the used screening tool to assess (risk of) DRM, in any setting, were included. Children (patients younger than 18 years of age) and pregnant patients were not included in this review because health care management of children and pregnant patients is not comparable to that of (nonpregnant) adults, including the method of measurement and management of DRM. As DRM is mainly prevalent in developed countries and malnutrition in developing countries is a different problem, studies done in developing countries were excluded from this systematic review. No restrictions were placed on sample size. 


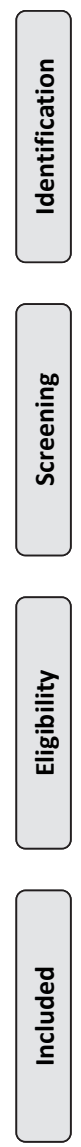

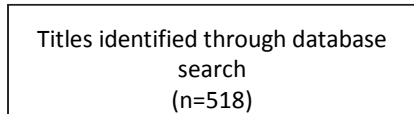

$(n=518)$
Additional titles identified from other reviews and from consulting experts $(n=4)$

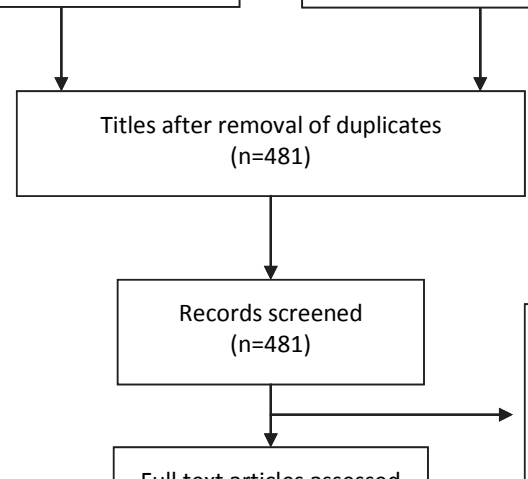

Records excluded based on titles and abstracts which didn't meet inclusion criteria $(n=444)$

Full text articles excluded, with following reasons: book (1), not available (1), no economic evaluation study (20), no medical

Studies included in qualitative synthesis $(n=14)$ nutrition as intervention (1)

Figure 5.1 Flow Diagram of the systematic review process.

\section{Intervention}

Eligible were economic evaluations, defined as studies in which both costs (inputs) and consequences (outputs) were investigated for both the intervention and the comparator, that focused on any form of enteral medical nutrition (sole or as part of a total intervention program). Enteral medical nutrition was defined as the enteral nutritional support that is regulated as "foods for special medical purposes (FSMP)", as defined by the European Commission Directive 1999/21/EC independent of the route of application ${ }^{8}$. There was no limitation regarding the duration of intervention. Economic evaluations of parenteral nutrition (intravenous medical nutrition) were out of the scope of this systematic review, as this form of medical nutrition is only indicated whenever enteral nutrition is not an (sufficient) option. 


\section{Comparator}

No restrictions were set for the comparator, also indicated as control group, in the economic evaluations. Usual or standard care, meaning any or no form of nutritional care without using enteral medical nutrition, could therefore also be the comparator.

\section{Outcome and study design}

Only studies in which both costs (inputs) and consequences (outputs) were investigated for the intervention and the comparator were eligible for inclusion, using the technique of either cost-effectiveness analysis, cost-utility analysis, or cost-benefit analysis. All other studies were excluded, except for budget impact analyses as these are considered a relatively recent method for economic evaluation in the field of health $\operatorname{care}^{24}$. No restrictions were placed on studies with regard to year of publication.

\section{Other}

Studies in languages other than English, incomplete articles, reviews, abstracts, books or conference proceedings were excluded.

The literature search was performed in November 2012 using the sources routinely used for effectiveness reviews, including Medline, EMBASE, CAB Abstracts as well as resources that focus on economic studies, i.e. HEED ${ }^{25}$. Experts in the field of the economic aspects of medical nutrition were consulted for additional studies. The terms used for the database search included single words and combinations of these words regarding economic evaluation, medical nutrition and DRM: cost, economic, financial, budget, effectiveness, Quality Adjusted Life Years (QALY), benefit, health economics, savings, cost-effective, analysis, oral, nutrition, supplement, support, sip, feed, food for special medical purposes (FSMP), medical, enteral, status, risk, malnutrition, under nutrition, sarcopenic(-ia), underweight, cachexic(-ia), deplete, deprivation. The exact search strategy, using MeSH terms, is outlined in Table 5.1.

The first step to identify potentially relevant articles consisted of screening all titles and abstracts according to the inclusion and exclusion criteria, which was done by one researcher (KF). Next, screening of full articles identified as possibly relevant in the initial screening took place independently by two assessors (KF and MB) or by another assessor (MP) if the article was authored by one of these two assessors. Final inclusion of the studies was determined after a consensus meeting about study eligibility between the assessors. 
Table 5.1 MesH terms used in search strategy.

((Cost)()effective?) OR (cost()utility) OR ((budget or economic or financial)()(implication? Or impact)) OR (economic()(evaluation or study)) OR (economic()considerations) OR (economic()results) OR costs OR QALY OR (economic()model) OR (calculation()model) OR (cost()benefit) OR (healthcare(2w)(use or utilization or utilisation or expenditure)) or (health(w)economic?) or (cost(w)(analysis or savings or implication?)) or $(\operatorname{cost}(w)$ (minimisation or minimization)) or reimbursement) AND ((Oral()nutrition?()supplement?)OR (nutrition?()(intervention or support or therapy)) OR (oral()(nutrition or feed? Or supplement?)) OR (sip(w)(feeds or feeding)) OR (food(2w)special()medical()purposes) or FSMP OR (medical()nutrition) OR (medical()food) OR ((enteral or tube)()(feed? or nutrition))) AND ((nutritional()(status or risk)) or malnutrition OR undernutrition or (under()nutrition) OR malnourished or undernourished or underweight OR frail OR frailty OR sarcopenia or sarcopenic OR cachexia or cachectic OR (nutrition?()(deplet? Or depriv?))) OR (cost or costs or economic? Or finance? Or budget or qaly or calculation or healthcare or reimburse?)/title only NOT (animal or Animals OR rat or rats or mice or mouse or rodent or dogs or ((mineral or vitamin)()supplement?) OR (fortified()food) OR child or children OR infant or infants or newborn or neonat? Or pregnant or pregnancy or pediatric or paediatric)/title only.

\subsection{Data extraction, quality assessment and outcome measures}

A pre-established extraction template was made to outline study characteristics and outcome data of all studies that met the inclusion criteria. To avoid discrepancies, the two assessors started outlining data of only three articles using this template independent from each other, after which they compared and discussed the extracted data. This resulted in clear instructions about coding and extracting the data. The quality of the included studies was assessed by the two independent assessors (KF and $\mathrm{MB}$ ) using the 16-item validated Quality of Health Economic Studies (QHES) instrument, which emphasizes appropriate methods, valid and transparent results, and comprehensive reporting of results in each health economic evaluation by using a standardized scoring system (Table 5.2). The QHES scoring system can be used to quickly and accurately stratify studies by quality level based on a cut-off score, e.g. scores $<75$ (low quality) versus $\geq 75$ (high-quality), enabling simple comparison among rated studies. To promote the inter-rater reliability among the assessors, two articles were independently scored by the three assessors before all the included studies were rated using the QHES. This resulted in clear instructions and decision rules to reach consistency among the three assessors in the QHES rating. The most important rules were to only award the indicated item points when the related question could be undoubtedly answered with a full 'yes' to all question components. When a certain question was not at all applicable for the specific study, a 'yes' was scored. Cohen's Kappa was calculated as a measure of inter-observer agreement between the quality ratings of the two assessors. The QHES is scored on 16 criteria, selected by a panel of health economic experts, each having a weighted point value adding up to a total score of 0 (lowest quality) to 100 (highest quality) points ${ }^{26,27}$ (Table 5.2). This continuous scale can also be dichotomized to differentiate between high-quality studies (75-100 points) and studies of lower quality ( $<75$ points) ${ }^{27}$. Alternatively, studies may be divided into 4 groups: (1) extremely poor quality (0-24); (2) poor quality (25-49); (3) fair quality (50-74); and (4) high-quality $(75-100)^{27,28}$. 
Table 5.2 The Quality of Health Economic Studies (QHES) Instrument ${ }^{26,27 .}$

\begin{tabular}{|c|c|c|c|c|}
\hline & Question & points & yes & no \\
\hline 1 & Was the study objective presented in a clear, specific, and measurable manner? & 7 & & \\
\hline 2 & $\begin{array}{l}\text { Were the perspective of the analysis (societal, third-party payer, etc.) and reasons } \\
\text { for its selection stated? }\end{array}$ & 4 & & \\
\hline 3 & $\begin{array}{l}\text { Were variable estimates used in the analysis from the best available source (i.e. } \\
\text { randomized control trial - best, expert opinion - worst)? }\end{array}$ & 8 & & \\
\hline 4 & $\begin{array}{l}\text { If estimates came from a subgroup analysis, were the groups prespecified at the } \\
\text { beginning of the study? }\end{array}$ & 1 & & \\
\hline 5 & $\begin{array}{l}\text { Was uncertainty handled by: (1) statistical analysis to address random events; (2) } \\
\text { sensitivity analysis to cover a range of assumptions }\end{array}$ & 9 & & \\
\hline 6 & Was incremental analysis performed between alternatives for resources and costs? & 6 & & \\
\hline 7 & $\begin{array}{l}\text { Was the methodology for data abstraction (including the value of health states and } \\
\text { other benefits) stated? }\end{array}$ & 5 & & \\
\hline 8 & $\begin{array}{l}\text { Did the analytic horizon allow time for all relevant and important outcomes? Were } \\
\text { benefits and costs that went beyond } 1 \text { year discounted (3-5\%) and justification } \\
\text { given for the discount rate? }\end{array}$ & 7 & & \\
\hline 9 & $\begin{array}{l}\text { Was the measurement of costs appropriate and the methodology for the } \\
\text { estimation of quantities and unit costs clearly described? }\end{array}$ & 8 & & \\
\hline 10 & $\begin{array}{l}\text { Were the primary outcome measure(s) for the economic evaluation clearly stated } \\
\text { and were the major short term, long term and negative outcomes included? }\end{array}$ & 6 & & \\
\hline 11 & $\begin{array}{l}\text { Were the health outcomes measures/scales valid and reliable? If previously tested } \\
\text { valid and reliable measures were not available, was justification given for the } \\
\text { measures/scales used? }\end{array}$ & 7 & & \\
\hline 12 & $\begin{array}{l}\text { Were the economic model (including structure), study methods and analysis, and } \\
\text { the components of the numerator and denominator displayed in a clear, } \\
\text { transparent manner? }\end{array}$ & 8 & & \\
\hline 13 & $\begin{array}{l}\text { Were the choice of economic model, main assumptions, and limitations of the } \\
\text { study stated and justified? }\end{array}$ & 7 & & \\
\hline 14 & Did the author(s) explicitly discuss direction and magnitude of potential biases? & 6 & & \\
\hline 15 & $\begin{array}{l}\text { Were the conclusions/recommendations of the study justified and based on the } \\
\text { study results? }\end{array}$ & 8 & & \\
\hline 16 & Was there a statement disclosing the source of funding for the study? & 3 & & \\
\hline
\end{tabular}

There are 16 dichotomous (yes/no) items in this questionnaire, each weighted by importance as determined by an expert panel of health economists. The quality score is calculated by subtracting points from 100 for questions answered with no. Therefore, the highest possible score is 100 , and the lowest is 0 . Studies with a score exceeding 75 points are considered of high quality.

Adequate sensitivity analysis includes 2-way analysis and beyond (e.g., Monte Carlo analysis). Therefore, sensitivity analyses limited to 1-way results are not adequate to receive points for item 5 .

At a minimum, studies should describe clearly the databases searched, key words used, dates queried, or prioritization scheme for study types.

Reprinted with permission from Spiegel BMR, Targownik LE, Kanwal F, et al. The quality of published health economic analyses in digestive diseases: A systematic review and quantitative appraisal. Gastroenterology 2004; 127: 403-411, with permission from Elsevier. 


\section{Results}

\subsection{Overall literature search findings ( $n=37$ economic evaluation studies)}

The search strategy resulted in 522 studies eligible for inclusion, of which 481 records remained after removing duplicates (Figure 5.1). After having evaluated the titles and the abstracts (when available) according to the in- and exclusion criteria, a total of 37 full text articles were assessed for eligibility ${ }^{10,29-64}$. Studies of which the abstract was not available and eligibility was not clear from the title alone were also included for total text reading.

After reading these full articles, 20 studies turned out to not meet the inclusion criteria because of not being an economic evaluation according to the definition used for our review (see Methods), one study appeared to be a book, one study could not be obtained as a full article and in one study the intervention was fortified nutrition instead of medical nutrition, resulting in a total of 14 studies included for the qualitative synthesis using the QHES instrument ${ }^{30,36-39,44,45,47,48,54,56,58,63,64}$.

\subsection{Qualitative synthesis by the QHES instrument ( $n=14$ economic evaluation studies)}

In most of these 14 studies, ONS was used as enteral medical nutrition ( $\mathrm{n}=10$ studies) versus usual or standard care, including no use of ONS, in different health care settings: two studies in the hospital setting ${ }^{54,64}$, five in the community setting, being home, care home or nursing home setting ${ }^{30,38,47,48,58}$ and four studies in both hospital and community setting ${ }^{37,45,56,63}$. Only four studies evaluated the economic value of using ETF. In some but not all of the studies the perspective was mentioned, being the specific viewpoint of the study and the economic model used, which impacts the quality of the study according to the QHES. Studies were not in all cases specifically designed for the purpose of an economic evaluation, which also is a factor of influence on the quality of the study rated by the QHES. The assessors rated eight of the 14 economic evaluations as a high-quality study ( $\geq 75$ points) (Table 5.3 ). The other six studies were all but one of fair quality (50-74 points) (Table 5.4). Cohen's Kappa was 0.60 , indicating fair to good agreement ${ }^{65}$. This suggests that the identification of high versus low quality studies by means of the QHES checklist, using a cut-off value of 75 points, was fairly consistent between assessors ${ }^{65}$. Three studies ${ }^{44,54,58}$ rated as a high-quality evaluation by one assessor and rated as a fair quality study by the other, with a difference of just a few points, before the final inclusion based on consensus, strongly influenced the Kappa score. The QHES questions addressing the health economic aspects of the study (Table 5.2, questions 5-13) were scored higher by the assessor with knowledge of health economics than the other assessor who is an epidemiologist with little knowledge of health economics. 


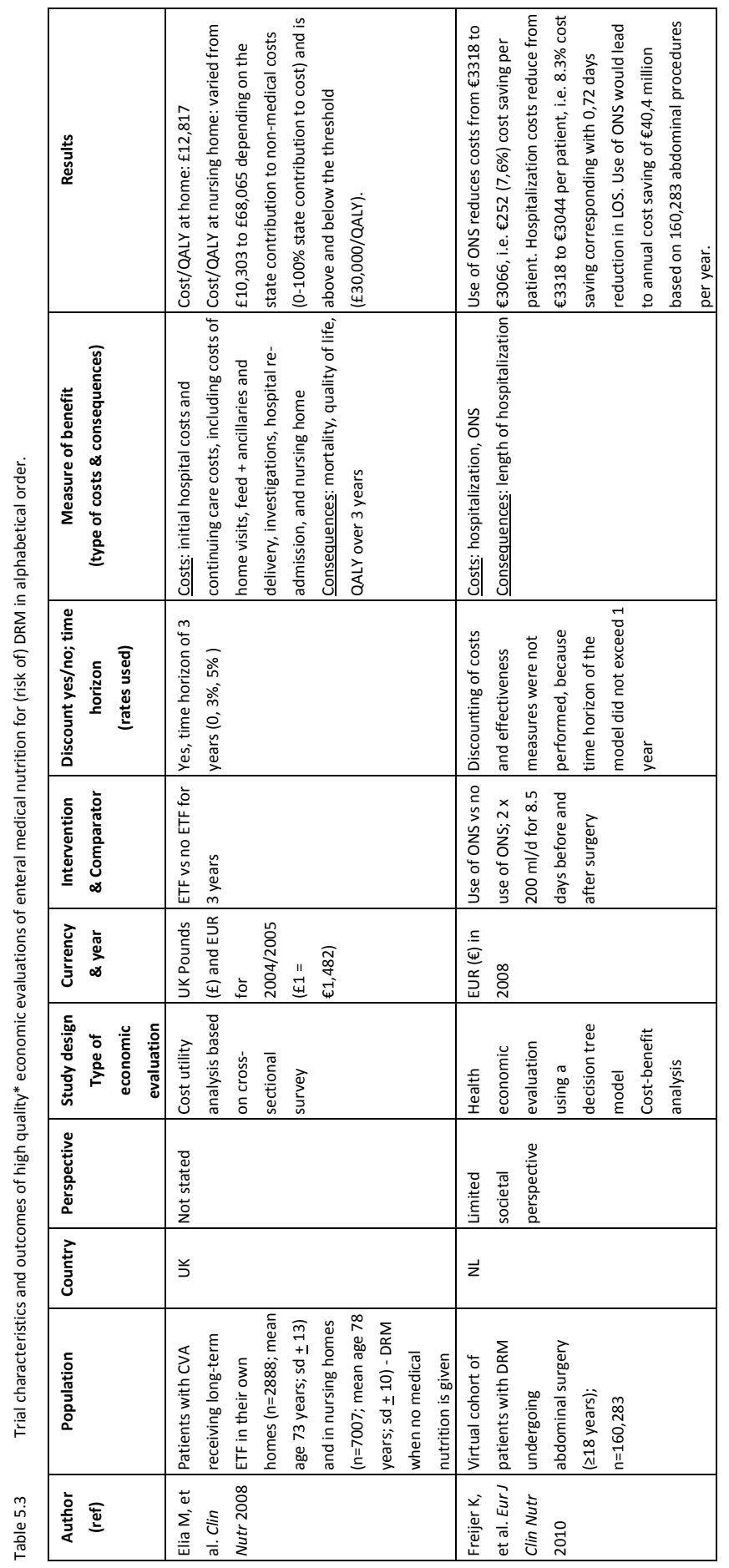




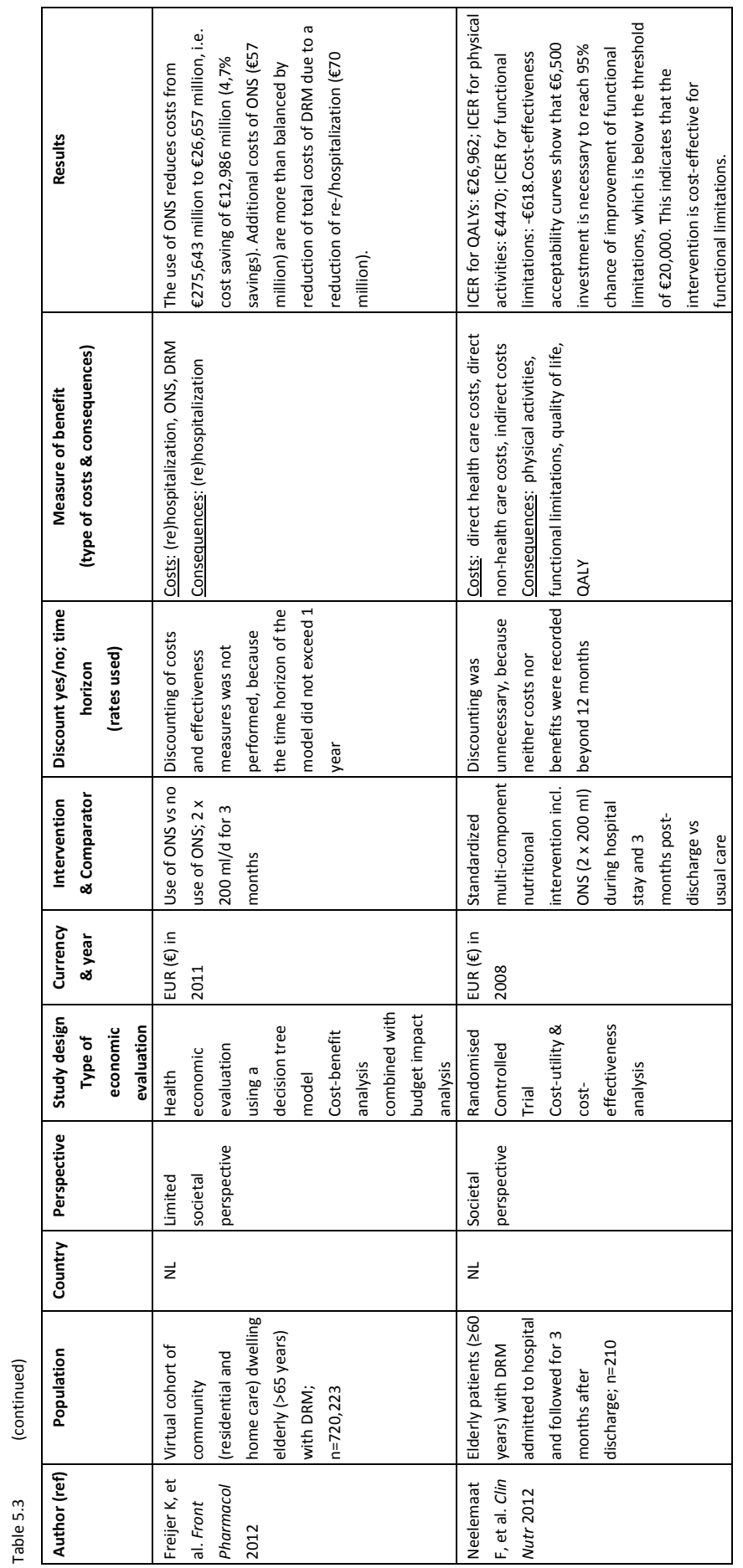




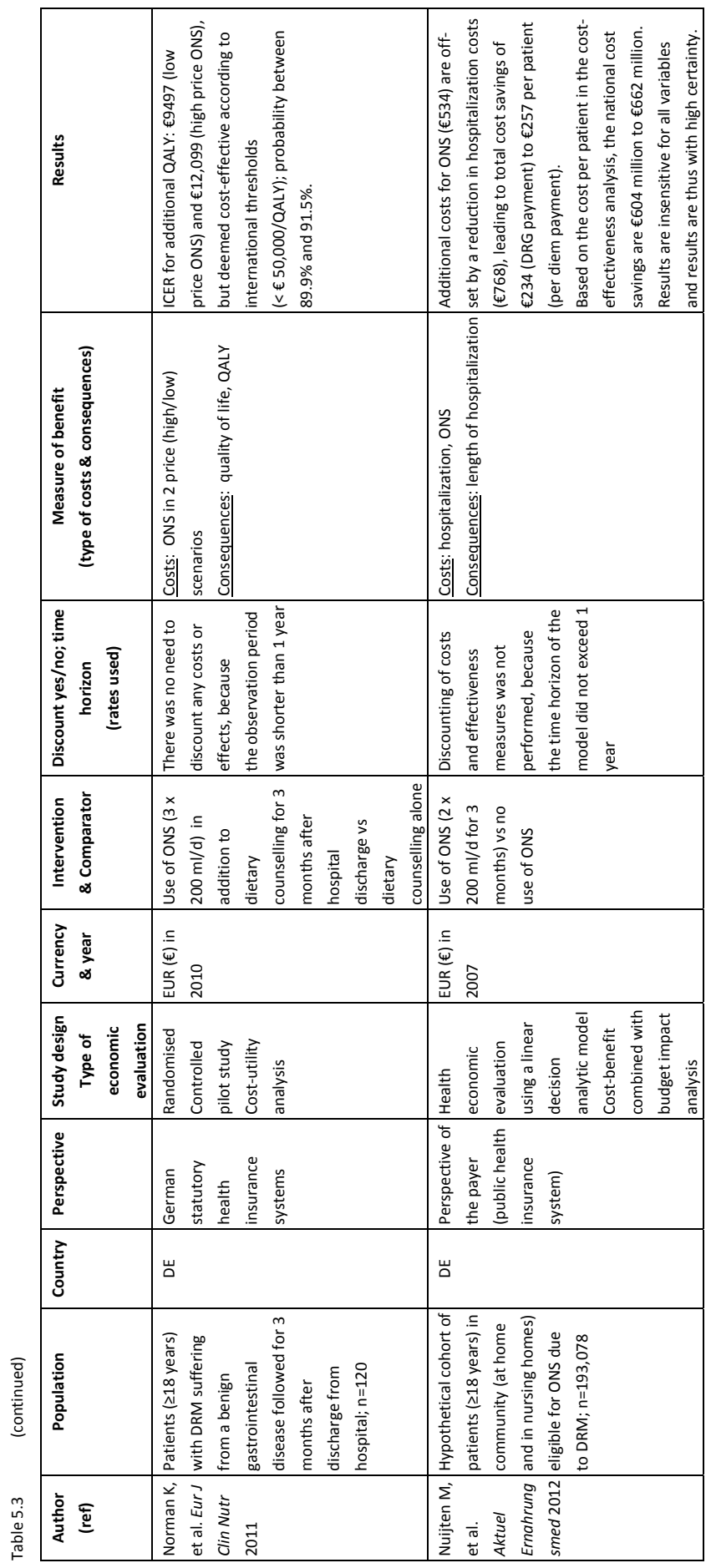




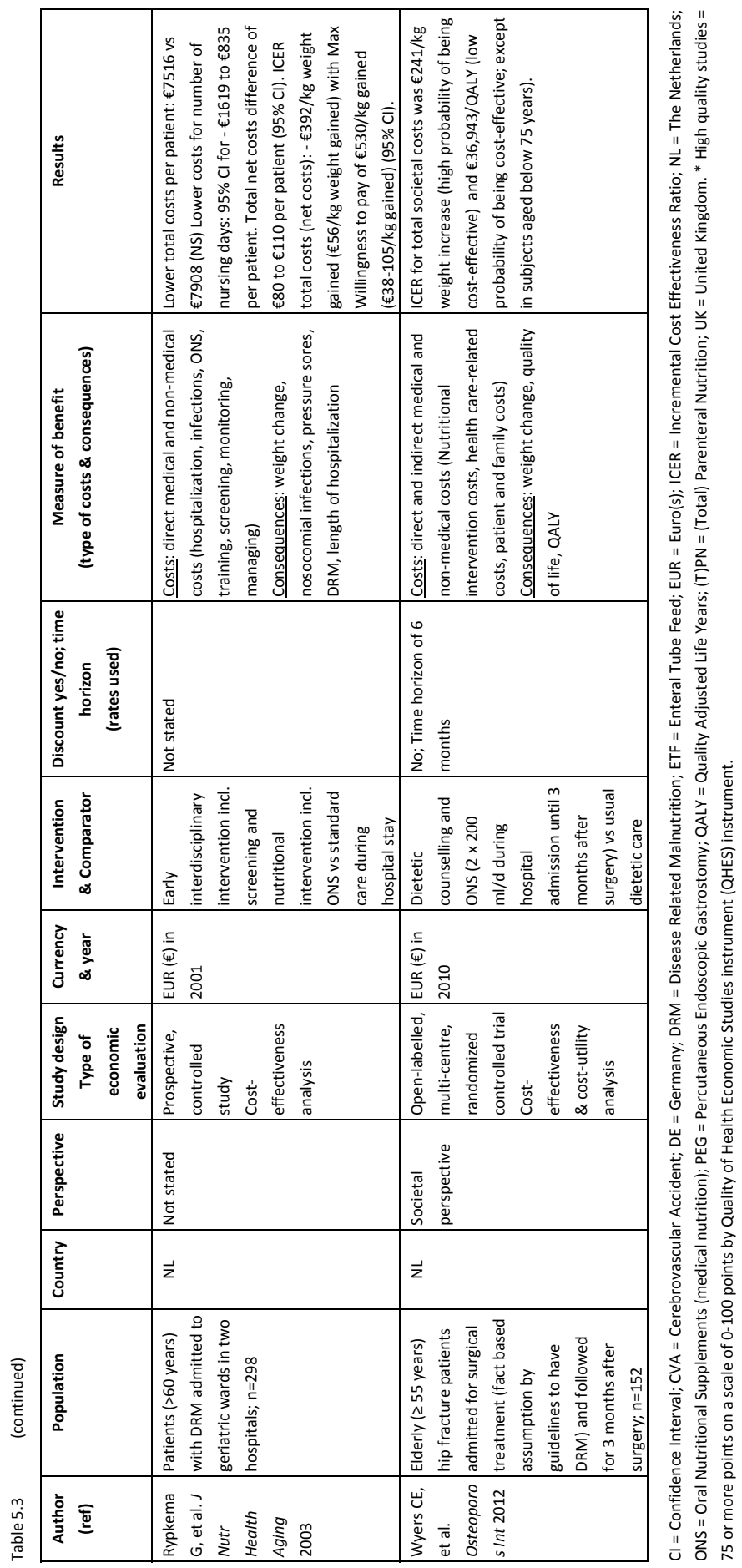




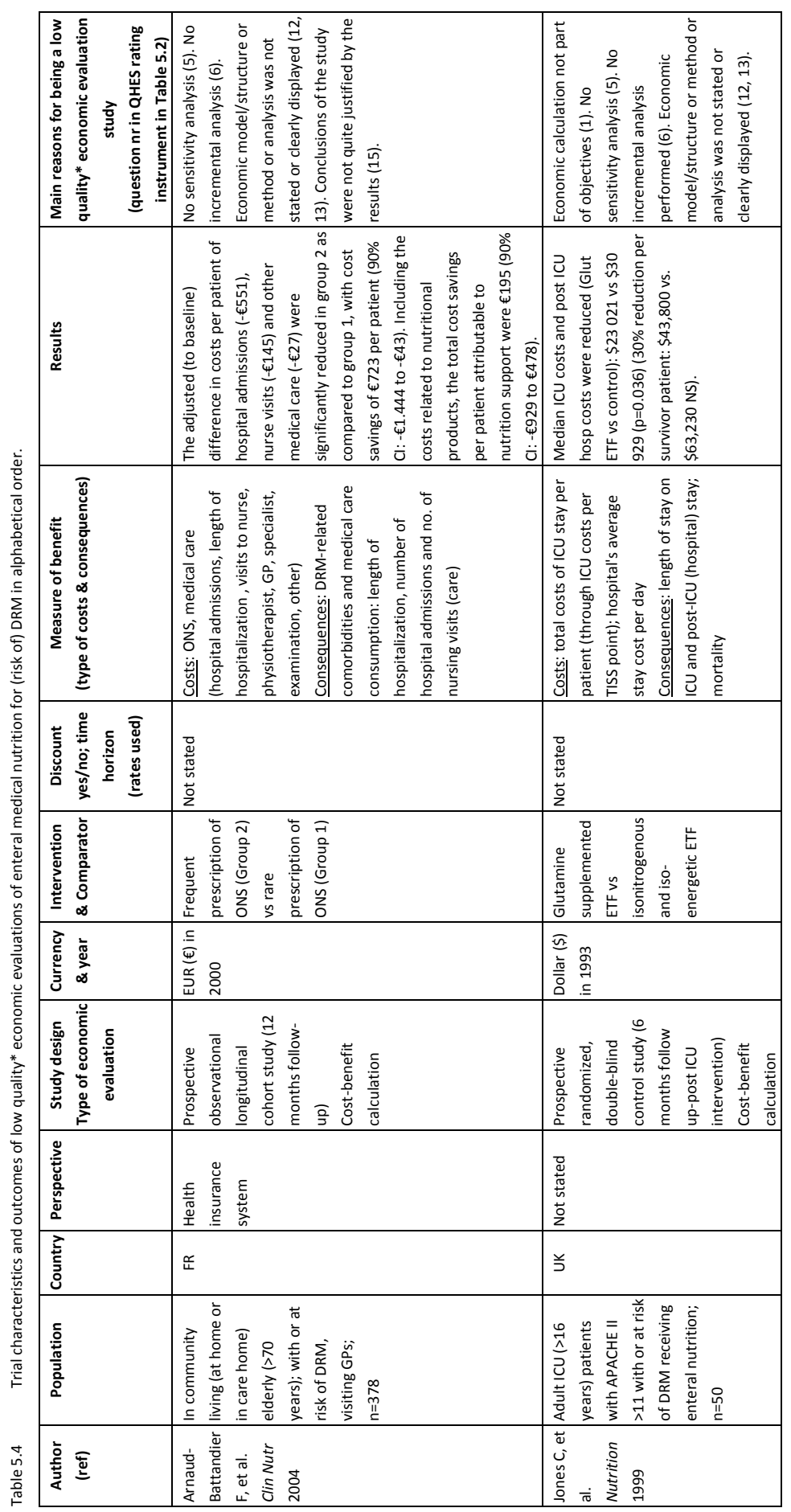




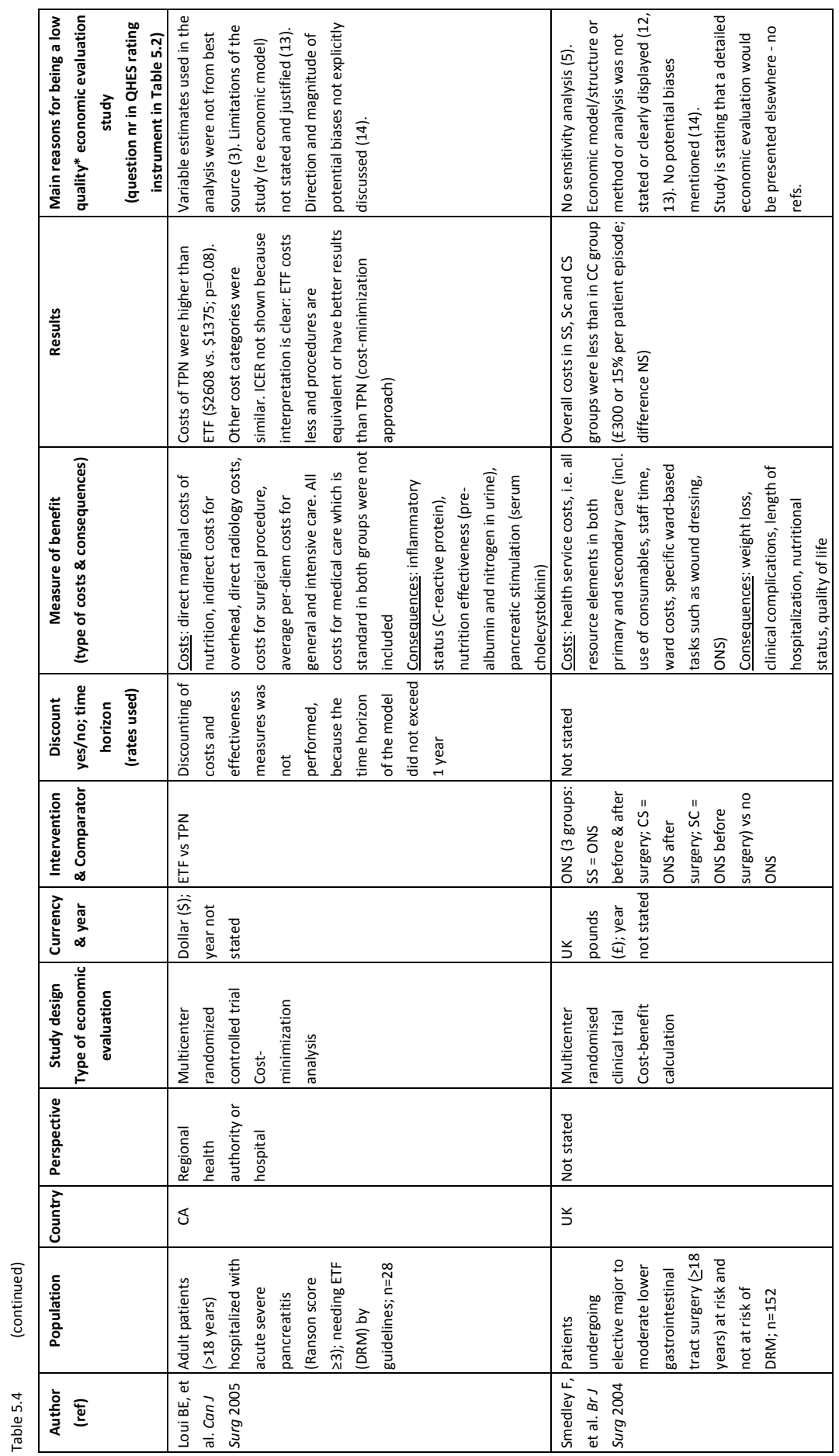




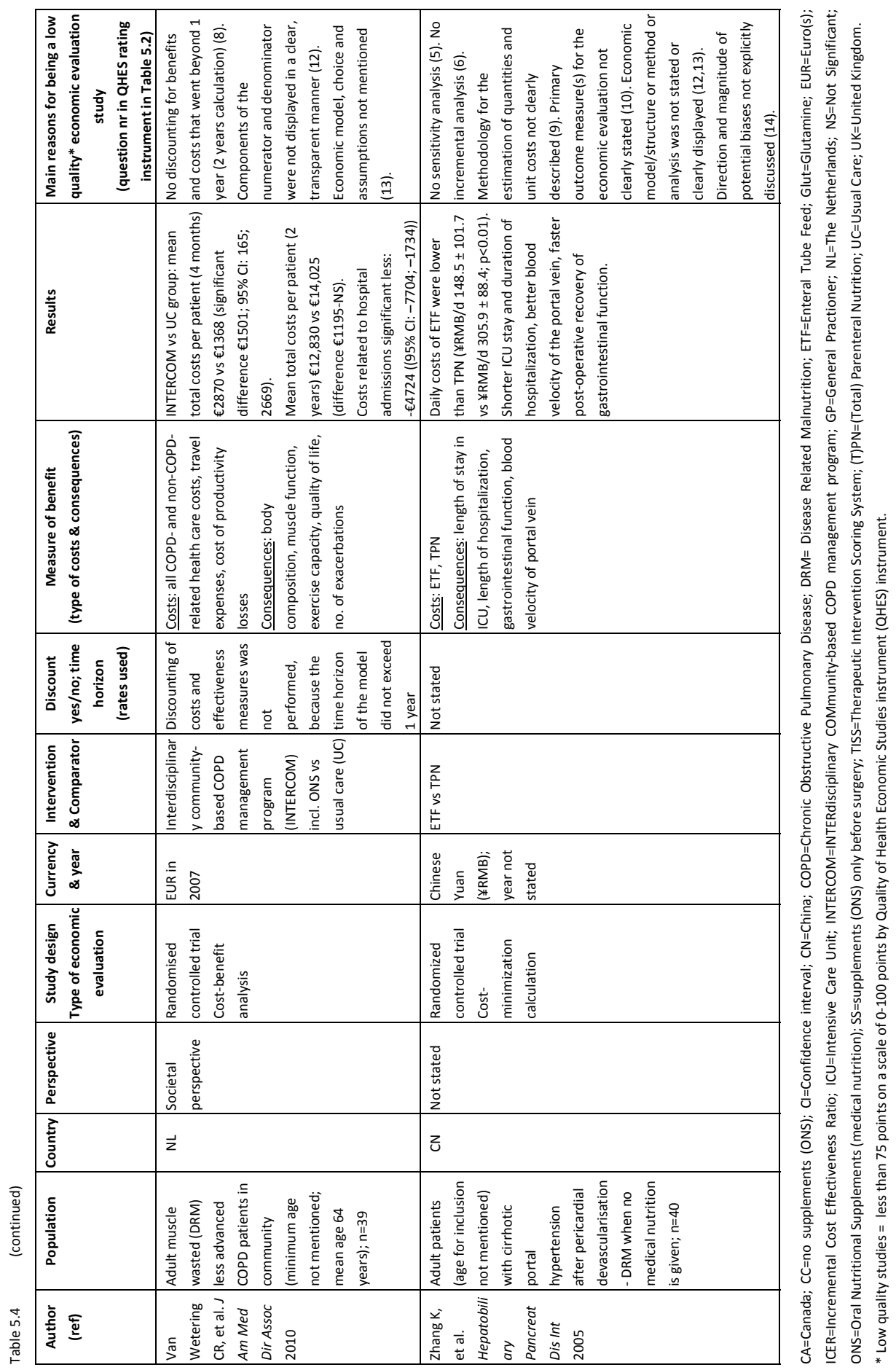


Especially these questions have a high scoring value and are thus of big influence on the total QHES score of a study. Finally one of these three studies was included as a highquality study according to the quality assessment method.

The remainder of the Results section will focus on the high-quality studies.

\subsection{Characteristics and outcomes of high quality studies}

\subsubsection{Patient population}

Two evaluations were done for adult hospital patients 37,54 , two studies analyzed the economic value of the intervention for adult patients admitted to the hospital and subsequently followed after discharge ${ }^{47,63}$ and in the other four evaluations adult community patients (at home, in nursing home and/or in residential home) were studied. In five of the eight high-quality studies, it concerned an elderly population which was defined as 55 years of age and older ${ }^{63}$, older than 60 years of age ${ }^{54}, 60$ years of age and over ${ }^{45}$ and 65 years of age and older ${ }^{38}$. In the study of Elia et al. ${ }^{36}$ results showed that the mean age of the studied CVA patients was older than 70 years of age. The other evaluations studied a population of 18 years of age and older. DRM was defined as having a Body Mass Index (BMI in $\mathrm{kg} / \mathrm{m}^{2}$ ) $\leq 20$ and/or $\geq 5 \%$ unintentional weight loss in the previous month and/or $\geq 10 \%$ unintentional weight loss in the previous six months ${ }^{45}$, or DRM was defined using the Subjective Global Assessment $(\mathrm{SGA})^{47}$ or the Mini Nutritional Assessment $(\mathrm{MNA})^{54}$. In the modeling evaluations, national data of DRM were used from official reports in which DRM was defined using the SGA or the Malnutrition Universal Screening Tool (MUST) ${ }^{48}$, or when one of the following three criteria was met: 1 ) BMI $<18.5$ or $\leq 20$ in patients of $\geq 65$ years of age; 2 ) BMI between 18.5 and 20 (BMI between 20 and 23 in patients of $\geq 65$ years of age) combined with three days no or little food intake or more than a week less food intake than usual; 3) More than three kg unintentional weight loss in the previous months or more than six $\mathrm{kg}$ unintentional weight loss in the previous six months $\mathrm{s}^{37,38}$. In the study of Wyers et al. ${ }^{63}$ in which the population consisted of hip fracture patients, DRM was not specifically defined as an inclusion criterion since they used the evidence-based fact that at the time of hospital admission for surgical treatment of their hip fracture, hip fracture patients are reported to be malnourished. The same was done in the study of Elia et al. in which the evidence- based fact was used that CVA patients die from DRM when they are not treated with $\mathrm{ETF}^{36}$.

\subsubsection{Enteral medical nutrition and duration of intervention}

The most frequently studied interventions were ONS (in seven studies) and one highquality economic evaluation studied ETF. The duration of the intervention with enteral medical nutrition varied from days to months and even some years, depending on the study design. The duration of the ONS intervention in the analysis of Freijer et al. ${ }^{37}$ was 
17 days, following the guideline for the specific population. In the other evaluations the duration of nutritional intervention including ONS varied from one month ${ }^{54}$ to three months ${ }^{38,45,48,63}$ and even three years ${ }^{36}$, as the latter concerned the chronic use of ETF by patients with CVA. In all of the economic evaluations done alongside a clinical trial or survey, the use of ONS or ETF for the malnourished patients was part of a protocolled multi component nutritional intervention that consisted of continuous use of ETF together with continuing care of health care professionals (e.g. general practitioner, dietician etc. $)^{36}$; an energy and protein enriched diet, two ONS per day, calcium-vitamin D supplement and telephone counseling by a dietician ${ }^{45}$; dietary counseling at discharge to improve the protein and energy intake with normal food and three ONS per day ${ }^{47}$; an interdisciplinary intervention existing of early screening for DRM, dysphagia and dehydration at admission, treatment by a dietician (high energy diet or ONS), speech/language therapist (swallowing therapy) and a geriatrician (rehydration and medical interventions) ${ }^{54}$; frequent dietetic counseling and two ONS per day ${ }^{63}$. In the modeling studies ${ }^{37,38,48}$ the nutritional intervention consisted of the enteral medical nutrition used.

\subsubsection{Control group}

In nearly all the ONS studies the control group received usual or standard care that consisted of no (protocolled) nutritional support including no (standard) use of ONS. In the evaluations using the modeling technique ${ }^{37,38,48}$, the control group received no ONS. Patients allocated to the control group in the study of Neelemaat et al. ${ }^{45}$ received usual care, i.e., they were given nutritional support only on prescription by their treating physician. In general, they did not receive post-discharge nutritional support. In the study of Norman et al. ${ }^{47}$, the control group received dietary counseling at discharge to improve their protein and energy intake with normal food and in the study of Wyers et al. $^{63}$, they received dietetic care or nutritional supplements only on demand of the medical doctor in charge: ten patients (13\%) received ONS and 18 patients $(23 \%)$ received dietetic counseling. The control group in the study of Rypkema et al. ${ }^{54}$ received standard care, meaning not protocolled care. The economic evaluation for $\mathrm{ETF}^{36}$ used a virtual control group that used no ETF assuming that these patients would die immediately without cost to the state (base case). In the sensitivity analysis, the outcome was calculated assuming that these patients survived for a mean period of 0.125 years (in a separate analysis for 0.25 years) with a quality of life half of those continuing ETF. The analysis was repeated assuming that the quality of life was the same as those continuing on ETF.

\subsubsection{Outcomes}

\subsubsection{ETF in community setting}

The only evaluation that studied ETF was a cost-utility analysis ${ }^{36}$ showing long term intervention (median length of feeding of 2.08 years (range 1.28-4.15 years)) with ETF 
in patients with CVA at home in the UK seemed to be cost-effective using the cost threshold of $f 30,000 / Q A L Y$ set by the National Health Service in England (NICE). The incremental cost-utility ratio (extra costs/extra QALY) of $£ 12,817 / Q A L Y$ ( $£ 10,351$ $£ 16,826$ using $95 \% \mathrm{Cl}$ for quality of life; $£ 1=€ 1,482 ; 30 / 06 / 2005)$ was far below the used cost threshold. The same intervention given to CVA patients in nursing homes was only cost-effective in terms of cost/QALY when the non-medical costs were paid privately, being $£ 10,304$ (below the cost threshold) and not by the state, being $£ 68,064$ (above the cost threshold). The sensitivity analysis showed that the outcome was insensitive to variations in the frequency of home visits by health care workers, the outcome of the patients who reverted to full oral feeding, discounting of costs, to the computed survival time of stroke patients without ETF and to the quality of life.

\subsubsection{ONS in hospitalized patients}

One study reported the savings per patient and on a yearly basis (cost-benefit) when abdominal surgical patients with DRM were managed with ONS as part of the total treatment versus no $\mathrm{ONS}^{37}$. Costs savings were achieved because the total additional costs of ONS were more than balanced by a $30 \%$ reduction in hospitalization costs ( $€$ 3318 to $€ 3044$ per patient). Sensitivity analysis showed that the use of ONS remained cost saving compared with 'no use' of ONS. Calculation of the breakeven point (threshold) for length of stay (LOS) in hospital and risk reduction, at which the total costs for both treatment strategies are equal, showed that the threshold for LOS was 0.64 days and that the threshold for the increase of LOS in risk patients was $2.7 \%$. Rypkema et al. ${ }^{54}$ showed that the early interdisciplinary intervention was neutral in total costs per patient but with better clinical outcomes: significant $(p<0.001)$ improvement in average weight in intervention group ( $0.9 \mathrm{~kg}$ gain; $\mathrm{sd} \pm 0.2 \mathrm{~kg}$ ) versus control group ( $0.8 \mathrm{~kg}$ loss; $\mathrm{sd}+0.3 \mathrm{~kg}$ ), significant improvement of DRM (defined as number of patients with $>3 \%$ weight loss) in the intervention group (11/105 versus 42/140; $p<0.001$ ) and a significantly lower number of hospital acquired infections in the intervention group (33/140 versus 58/158; $\mathrm{p}=0.01$ ). Incremental Cost Effectiveness Ratios (ICERs) showed that the intervention was efficient: $€ 56 / \mathrm{kg}$ weight gain with a willingness to pay of $€ 98-€ 105(95 \% \mathrm{Cl})$ using the net costs (nursing day costs excluded as no difference in hospital stay was found) and a saving of $€ 392 / \mathrm{kg}$ weight gain with a maximum willingness to pay $€ 530 / \mathrm{kg}$ weight gain using the total costs.

\subsubsection{ONS started in hospital, continued in community setting}

A multi-component nutritional intervention during three months in elderly patients suffering from DRM versus usual care, resulted in no significant extra costs (mean difference of $€ 445$ (95\% Cl: $-2779 ; 3938)$ ) and a significant improvement in functional limitations measured using a validated questionnaire (mean difference of - 0.72 (95\% $\mathrm{Cl}:-1.15 ;-0.28))^{45}$. Three months after the given intervention patients could, for example, dress themselves and climb up a stairs themselves, while patients in the 
control group were less able. No significant difference was shown regarding mean number of QALYs measured using the EuroQol-5Dimensions instrument (EQ-5D) (mean difference of $0.02(95 \% \mathrm{Cl}:-0.01 ; 0.02))$ and regarding physical activities measured using a validated questionnaire (mean difference of 0.10 (95\% Cl:-0.53; 0.73). The ICER of $€ 618 /$ point improvement of functional limitations showed that the intervention was cost effective with a probability of $40 \%$. When a threshold of $€ 6,500$ was used, meaning that in this study society would be willing to pay this amount of money for one point improvement in functional limitations, the intervention was efficient with a probability of $95 \%$ in comparison with usual care regarding functional limitations. Wyers et al. ${ }^{63}$ showed that the intensive nutritional intervention during three months in elderly hip fracture patients resulted in no significant extra total costs (mean difference of €457; $\mathrm{p}=0.0665)$ and a significant effect on weight of $1.91 \mathrm{~kg}(95 \% \mathrm{Cl}: 0.60-3.22 ; \mathrm{p}=0.005)$, but no significant effect for change in QALY $(95 \% \mathrm{Cl}:-0.12 ; 0.08 ; p>0.05)$. The intervention was cost-effective regarding weight with a probability of $\sim 70 \%$ when a threshold of $€ 2,500$ was used and with a probability of $98 \%$ when society would be willing to pay $€ 5000$, as the ICER for total societal costs was $€ 241 / \mathrm{kg}$ weight gain. It was likely not efficient from a societal perspective to use this intervention for change in QALY (ICER of $€ 36,943 / Q A L Y ; 45 \%$ probability to be cost-effective at a threshold of $€ 20,000 / Q A L Y$ and $60 \%$ probability at a threshold of $€ 80,000 / Q A L Y)$. Sensitivity analysis showed that the intervention was cost-effective for weight change regardless of whether the patient was suffering from DRM or not. With respect to QALYs, it was shown that the patient age was of influence whether the intervention was likely to be efficient from a societal perspective (in patients aged between 55 and 74 years, a 85\% probability at a threshold of $€ 20,000 / Q A L Y$ and a $98 \%$ probability at a threshold of $€ 80,000 / Q A L Y)$.

\subsubsection{ONS in community dwelling patients}

Managing all eligible community dwelling elderly patients in The Netherlands suffering from DRM (based on a population of 720,223 patients living in residential homes and home care) with ONS during three months, seemed to be costs saving as the total costs of DRM in this patient population was diminishing from $€ 275,643$ to $€ 262,657$ million due to a reduction in (re)hospitalization ${ }^{38}$. In this budget impact analysis based on costbenefit outcomes, the additional costs of ONS ( $€ 57$ million) were more than balanced by this reduction in (re)hospitalization costs ( $€ 70$ million). Sensitivity analysis showed that the outcome was most sensitive to the duration of treatment with ONS; the breakeven for the duration of treatment was 3.7 months. In all the other ranges of the key parameters used in the model, the outcome remained positive, meaning that the use of ONS remained cost saving compared with "no use" of ONS. Patients suffering from a benign gastrointestinal disease with DRM in Germany, who were managed with ONS in addition to dietary counseling for 3 months after hospital discharge, had a significantly $(p=0.003)$ higher mean quality of life and less acute readmissions (17 versus 24; 
$\mathrm{p}=0.029$ ), compared to dietary counseling alone in the same patient population, which resulted in 0.045 extra QALY's (or: an additional 16 days of full quality of life per year) gained $^{47}$. The additional total costs (based on the ONS costs only as readmissions collected from hospital system and patients themselves) were between $€ 540.16$ ( $p \leq 0.001)$ and $€ 424.02$ ( $p \leq 0.001$ ), which resulted in an ICER of $€ 12099$ and $€ 9497$ per additional QALY, using high and low prices for ONS respectively. When society would be willing to pay $€ 50.000 /$ QLY, the intervention would be cost-effective with an $89.9 \%$ (high-price scenario) and a $91.5 \%$ probability. The modeling study of Nuijten et al. ${ }^{48}$ showed that patients in the German community suffering from (risk of) DRM who were treated with ONS for three months versus no ONS, would lead to a total cost saving of $€ 234$ per patient due to reduction in hospitalization costs (€949 versus €1717), in which the additional costs for ONS (€534) were completely offset. Budget impact analysis showed an annual cost saving of $€ 604$ million. The calculations of the cost savings remained stable both in a scenario analysis and in all sensitivity analyses.

\section{Discussion}

To our knowledge, this is the first systematic review of research on the efficiency of enteral medical nutrition for DRM in adults in developed countries. The results show that managing several patient populations suffering from or at risk of DRM in different health care settings with enteral medical nutrition is an efficient intervention. ONS was the most frequently studied form. The duration of using enteral medical nutrition varied from three years in CVA patients with ETF to 17 days ONS in abdominal surgery patients. The mean duration of using ONS was three months. The economic value of enteral medical nutrition was calculated for the Netherlands (63\%), Germany (25\%) and the United Kingdom (12\%). In all of the economic evaluations done alongside a clinical trial or survey $(62 \%)$, the use of ONS or ETF was part of a protocolled multi component nutritional intervention and the control group received usual or standard care that consisted of no (protocolled) nutritional support including no (standard) use of ONS. In the evaluations using modeling techniques, the intervention consisted of ONS only versus no use of ONS in the control group ${ }^{37,38,48}$. In all but one study ${ }^{38}$, the calculation was done using the cost-effectiveness, cost-benefit or the cost-utility analysis method. The study of Freijer et al. ${ }^{38}$ was a Budget Impact Analysis (BIA) and in another study a BIA was used next to a cost-effectiveness calculation ${ }^{48}$. In this review, we regarded these BIAs as economic evaluations, because they included a measure of the effectiveness of the new technology, not only a measure of its costs (which actually is in accordance with a recent definition of a $\mathrm{BIA}^{24}$ ).

After the review was completed, a large USA study was published confirming our results ${ }^{66}$. This eleven-year (2000-2010) retrospective study containing information on 44 million adult inpatient episodes (20\% of all US inpatient episodes) on the impact of ONS on hospital outcomes, showed that ONS patients had a shorter length of stay by 
2.3 days (95\% confidence interval $[\mathrm{Cl}]-2.42$ to -2.16 ), from 10.9 to 8.6 days, and decreased episode cost of $\$ 4734(95 \% \mathrm{Cl}-\$ 4754$ to $-\$ 4714)$, from $\$ 21,950$ to $\$ 17,216$. Restricting the matched sample to the 862,960 episodes where patients were readmitted at some point, ONS patients had a reduced probability of early readmission (within 30 days) of 2.3 percentage points $(95 \% \mathrm{Cl}-0.027$ to -0.019$)$, from $34.3 \%$ to $32.0 \%{ }^{66}$.

This systematic review has some limitations. First, as economic evaluations are only performed when the consequence(s) of the investigated technology are positive, trials showing no clinical benefit of FSMP are typically not part of health economic analyses and, therefore, may be underrepresented in the current review. However, it may be remembered here that our review aimed to examine the cost-effectiveness of FSMP, based on the evidence-based assumption that FSMP has clinical advantages. Its aim was not to provide a review of the clinical outcomes of FSMP. Another limitation is that the review can be biased because only published articles in the English language were included. Whenever feasible, all relevant studies should be included in a systematic review, regardless of publication in peer reviewed journals and language. Realistically, this is not always possible due to lack of time, resources and facilities for translation ${ }^{22}$. Therefore it might be that some unpublished data or data published in other than the English language have been missed in this review. On the other hand, we used search resources that specifically focus on economic studies, i.e. HEED ${ }^{25}$, consulted experts in the field of the economic aspects of medical nutrition for additional studies and extensively investigated all references in the full text articles. A third limitation that could have biased our review, is that the conclusions are based only on high-quality economic evaluations (i.e., a score of 75 and above by the QHES instrument). The choice to use this cut-off point was based on two studies in which the QHES was examined and valuated ${ }^{27}$ and in which the QHES was used as the rating instrument for systematically reviewing health economic analyses ${ }^{28}$. As rating scores below 75 points meant that economic evaluations were fair (50-74 points) to extremely poor (0-24 points), we only focused on the results of the high-quality ones, possibly effecting the final outcome of this systematic review. However, by basing our conclusions only on high-quality studies with generally higher (internal) validity, our results are less prone to bias.

One of the reasons the QHES instrument was chosen as the rating instrument, was the believe that the quantitative score that can be calculated with the QHES, may enable a variety of users, not only HE experts, to better judge the relative quality of different studies and to facilitate the decision-making process. This believe was based on the positive results of a survey among users who are not generally expert in evaluating health economic analyses and of whom 76\% indicated they would use this QHES ${ }^{27}$. Other reasons for choosing the QHES were: a) this rating instrument has been validated in a survey including 60 experts (30 clinicians and 30 health economists) in 6 disease categories; b) QHES is generating quantitative scores and not open ended items in 
which each criterion is of equal weight and needs specific expertise to identify highquality health economic evaluations e.g. the British Medical Journal checklist ${ }^{67}$ and the Journal of the American Medical Association user's guide ${ }^{67,68}$ are most commonly used; c) reliability and validity of the QHES has been shown to be high with an intraclass correlation coefficient (ICC) of $0.81^{69}$, a good overall construct validity based on high correlation between subjective assessment and QHES $(r=0.78)^{26,27}$ and a Cohen's Kappa score of 0.8 in another quality review of economic evaluations ${ }^{28}$. In our study, Cohen's Kappa was 0.6 , meaning that assessors were fairly consistent in their identification of high-quality evaluations using the QHES instrument ${ }^{65}$. Although the Kappa score is acceptable, it can be discussed whether the QHES is a good and appropriate rating instrument when not all assessors have (similar) experience in evaluating health economic studies. The mean total QHES rating score of the 14 included studies was just below the cut-off score of 75 for the epidemiologist with no health economic knowledge $(72$;sd \pm 21$)$, whereas it was just above the cut-off for the assessor with some health economics experience $(79 ; s d \pm 21)$ (Table 5.5). The main differences in rating scores between both assessors in this review concerned the health economic questions in the QHES (questions 5-13 in Table 2), which are of big influence on the total rating score.

Table 5.5 QHES Scores of the Included Studies in Alphabetical Order.

\begin{tabular}{|c|c|c|c|c|c|}
\hline No. & Article & $\begin{array}{l}\text { QHES score } \\
\text { assessor } 1\end{array}$ & $\begin{array}{l}\text { QHES score } \\
\text { assessor } 2\end{array}$ & $\begin{array}{l}\text { QHES score } \\
\text { assessor } 3\end{array}$ & $\begin{array}{c}\text { Conclusion } \\
\text { quality* }\end{array}$ \\
\hline 1 & $\begin{array}{l}\text { Arnaud-Battandier } \\
\text { (2004) }\end{array}$ & 52 & 55 & & fair \\
\hline 2 & Elia (2008) & 87 & 76 & & high \\
\hline 3 & Freijer (2012) & & 89 & 89 & high \\
\hline 4 & Freijer (2010) & & 86 & 84 & high \\
\hline 5 & Jones (1999) & 52 & 52 & & fair \\
\hline 6 & Louie (2005) & 70 & 69 & & fair \\
\hline 7 & Neelemaat (2012) & 100 & 86 & & high \\
\hline 8 & Norman (2011) & 100 & 100 & & high \\
\hline 9 & Nuijten (2012) & 95 & 92 & 76 & high \\
\hline 10 & Rypkema (2003) & 81 & 80 & & high \\
\hline 11 & Smedley (2004) & 52 & 66 & & fair \\
\hline 12 & van Wetering (2010) & 72 & 55 & & fair \\
\hline 13 & Wyers (2012) & 100 & 93 & & high \\
\hline \multirow[t]{3}{*}{14} & Zhang (2005) & 40 & 23 & & poor \\
\hline & mean & 75,1 & 73,0 & & \\
\hline & sd & 22,0 & 21,1 & & \\
\hline
\end{tabular}

*Studies may be divided into 4 groups: (1) extremely poor quality (0-24); (2) poor quality (25-49); (3) fair quality (50-74); and (4) high-quality (75-100) ${ }^{28,29}$

Another potential limitation of the QHES instrument is that several items can be multi interpretable because more than one issue is often addressed per item without any standardized rules for when to score a 'yes' or a 'no' for that particular item. Therefore, 
before we started reviewing the included studies, we reached consensus on our own rules when to score a 'yes' or a 'no', which might have influenced the total scoring and, thereby, the quality ratings. Extensive training of all the assessors by the developers of the instrument in how to interpret the QHES items might help elevating the Cohen's Kappa score, as was done in another systematic review of economic evaluations using the $\mathrm{QHES}^{28}$. Another solution might be that the developers of the QHES instrument will create a standard set of rules on how to use and interpret each of the 16 items in this rating instrument.

The general picture that emerged from the studies included in this review - irrespective of whether they used modeling techniques or were performed alongside a clinical trial - is that using enteral medical nutrition in the management of DRM is an efficient intervention. However, there were some differences between the studies, of which the main one was the inclusion of different costs. For example, some studies, especially those using modeling techniques, only looked at the costs of the enteral medical nutrition, due to lack of data on other costs like those of patient monitoring (assessment and follow up) for DRM. It can be debated though whether these costs of patient monitoring should be incorporated. When the invested time in monitoring patients will lead to an increase of hospital capacity, the additional costs of time spent on the patient should be incorporated into the total costs within the economic evaluation; it reflects full opportunity costs in a situation where there is more full capacity, expressed by the need to recruit extra nurses. Yet, when the invested time is part of the relevant jobs, then these costs will be the same in both the control and the intervention group, and should be excluded from the total costs in the calculation. Screening and management for DRM can be seen as part of the standard management of all patients, as DRM is not a disease on its own, but always caused by an existing disease for which the patient is treated. Management for DRM should thus be an integrated part of the total management of the patient.

Another difference between the studies included in the review was that the outcome measure varied widely. In our opinion, a measure for clinical outcome, e.g. complications, (re)hospitalization, or quality of life, should be the preferred one, as the added value is not clear of some functional and nutritional outcomes like weight gain or improvement of nutrients intake. From a methodological point of view though, there are a lot of challenges for enteral medical nutrition compared to pharmaceutical products. These issues could be addressed and taken into account in outcome research to be able to perform economic evaluations for enteral medical nutrition that show a clear economic added value. Furthermore, the discussion (and in fact the relevance of the cost-effectiveness argument) is not so much about whether a technology (FSMP in this case) is cost saving or not. Rather, economic evaluations aim to reveal whether a technology is cost-effective, that is, whether the effects are large enough to justify its costs. 


\section{Conclusions}

This systematic review was the first to estimate the costs in relation to the outcomes (efficiency) of enteral medical nutrition for DRM in adults in developed countries. Full economic evaluations that met the inclusion criteria were rated on their quality first, before judging the results, as high-quality studies have generally higher validity. Managing several patient populations suffering from or at risk of DRM in different health care settings with enteral medical nutrition, seem to be an efficient intervention from a health economic perspective, in most cases even leading to costs savings. 


\section{References}

1. Organisation for Economic Co-operation and Development (OECD). Health at a Glance: Europe 2010, OECD Publishing. http://dx.doi.org/10.1787/health_glance-2010-en. Accessed on November 30, 2012.

2. Organisation for Economic Co-operation and Development (OECD). Health at a Glance 2011: OECD Indicators, OECD Publishing. http://dx.doi.org/10.1787/health_glance-2011-en. Accessed on November 30, 2012.

3. Collaboration between International Network of Agencies for Health Technology Assessment (INAHTA), Health Technology Assessment international (HTAi) and other partner organizations. Available at http://htaglossery.net. Accessed on January 31, 2013

4. Robinson R. Economic evaluation and health care. What does it mean? B Med J 1993; 307: 670-673.

5. Drummond MF, Sculpher MJ, Torrance GW, et al. Basic types of economic evaluation. In: Methods for the economic evaluation of health care programmes, 3rd Ed., New York: Oxford University Press; 2005 : 7-26.

6. Detsky AS, Naglie IG. A Clinician's Guide to Cost-Effectiveness Analysis. Ann Intern Med 1990; 113: 147-154.

7. Hutton J. 'Health economics' and the evolution of economic evaluation of health technologies. Health Econ 2012; 21: 13-18.

8. Lochs $\mathrm{H}$, Allison SP, Meier $\mathrm{R}$, et al. Introductory to the ESPEN guidelines on enteral nutrition: terminology, definitions and general topics. Clin Nutr 2006; 25: 180-186.

9. ESPEN Guidelines on adult enteral nutrition. Clin Nutr 2006; 25: 177-360.

10. NAIT (National Alliance for Infusion Therapy) and A.S.P.E.N. (the American Society for Parenteral and Enteral Nutrition) Public Policy Committee and Board of Directors. Disease-related malnutrition and enteral nutrition therapy: a significant problem with a cost-effective solution. Nutr Clin Pract 2010; 25: 548-54.

11. Fight malnutrition. Malnutrition guidelines: Guideline screening and treatment of malnutrition 2012. Available at: http://www.fightmalnutrition.eu. Accessed on January 30, 2013.

12. Stratton RJ, Green CJ, Elia M. Disease-related Malnutrition: An Evidence based Approach to Treatment, $1^{\text {st }}$ Ed., Oxford: UK CABI Publishing, 2003.

13. Elia M, Stratton RJ, Russell C, et al. The Cost of Disease-Related Malnutrition in the UK and Economic Considerations for the use of Oral Nutritional Supplements (ONS) in Adults. Redditch: BAPEN, 2005.

14. Stratton RJ, Ek AC, Engfer M, et al. Enteral nutritional support in prevention and treatment of pressure ulcers: a systematic review and meta-analysis. Ageing Res Rev 2005; 4: 422-450.

15. Stratton RJ, Elia M. Who benefits from nutritional support: what is the evidence? Eur J Gastroenterol Hepatol 2007; 19: 353-358.

16. Cawood AL, Elia M, Stratton RJ. Systematic review and meta-analysis of the effects of high protein oral nutritional supplements. Ageing Res Rev 2012; 11: 278-296.

17. Ljungqvist O, de Man F. Under nutrition - a major health problem in Europe. Nutr Hosp 2009; 24: 368-370.

18. Ljungqvist O, van Gossum A, Sanz M, et al. The European fight against malnutrition. Clin Nutr 2010; 29 : 149-150.

19. Freijer K, Tan SS, Koopmanschap MA, et al. The economic costs of disease related malnutrition. Clin Nutr 2013; 32: 136-141.

20. Correia MI, Waitzberg DL. The impact of malnutrition on morbidity, mortality, length of hospital stay and costs evaluated through a multivariate model analysis. Clin Nutr 2003; 22: 235-239.

21. Braunschweig C, Gomez S, Sheean PM. Impact of declines in nutritional status on outcomes in adult patients hospitalized for more than 7 days. J Am Med Assoc 2000; 100: 1316-1322.

22. Centre for Reviews and Dissemination. Systematic Reviews: CRD's Guidelines for Undertaking Reviews in Health Care. UK: University of York; 2009.

23. Moher D, Liberati A, Tetzlaff J, et al. for the PRISMA Group, 2009. Preferred reporting items for systematic reviews and meta-analyses: the PRISMA statement. Br Med J 2009;339:332-339.

24. Garattini L, van de Vooren K. Budget impact analysis in economic evaluation: a proposal for a clearer definition. Eur J Health Econ 2011; 12: 499-502. 
25. HEED: Health Economic Evaluations Database. Available at: http://www.onlinelibrary.wiley.com/heed. Accessed November 13, 2012.

26. Chiou CF, Hey JW, Wallace JF, et al. Development and validation of a grading system for the quality of cost-effectiveness studies. Med Care 2003; 41: 32-44.

27. Ofman JJ, Sullivan SD, Neumann PJ, et al. Examining the value and quality of health economic analyses: implications of utilizing the QHES. J Manage Care Pharm 2003; 9: 53-61.

28. Spiegel BMR, Targownik LE, Kanwal F, et al. The Quality of Published Health Economic Analyses in Digestive Diseases: A Systematic Review and Quantitative Appraisal. Gastroenterol 2004; 127: 403-411.

29. Position of The American Dietetic Association. Cost-effectiveness of medical nutrition therapy. J Am Diet Assoc 1995; 95: 88-91.

30. Arnaud-Battandier F, Malvy D, Jeandel C, et al. Use of oral supplements in malnourished elderly patients living in the community: a pharmaco-economic study. Clin Nutr 2004; 23: 1096-1103.

31. Braga M, Gianotti L, Gentilini O, et al. Early postoperative enteral nutrition improves gut oxygenation and reduces costs compared with total parenteral nutrition. Crit Care Med 2001; 29: 242-248.

32. Brantsma A, Kelson K, Malcom J. Percutaneous endoscopic gastrostomy feeding in HIV disease. Aust J Adv Nurs 1991; 8: 36-41.

33. Burger B, Schwenk A, Junger $\mathrm{H}$, et al. Oral supplements in HIV-infected patients with chronic wasting. A prospective trial. Med Klin 1994; 89: 579-581.

34. Cimoch PJ. Nutritional health: prevention and treatment of HIV-associated malnutrition. A case manager's guide. J Int Assoc Physicians AIDS Care 1997; 3: 28-40.

35. Elia M, Bistrian BR. The economic, medical/scientific and regulatory aspects of clinical nutrition practice: What impacts what? Nestle Nutr Inst Workshop Ser: Clinical \& Performance Program, 2009, Vol. 12. Available at: http://www.nestlenutrition-institute.org/Resources/Library/Free/workshop/ BookNNIW12/Pages /BookNNIW12 .aspx. Accessed November 1, 2013.

36. Elia $M$, Stratton R. A cost-utility analysis in patients recieving enteral tube feeding at home and in nursing homes. Clin Nutr 2008; 27: 416-423.

37. Freijer K, Nuijten MJC. Analysis of the health economic impact of medical nutrition in the Netherlands. Eur J Clin Nutr 2010; 64: 1229-1234.

38. Freijer K, Nuijten MJC, Schols JMGA. The budget impact of oral nutritional supplements for disease related malnutrition in elderly in the community setting. Front Pharmacol 2012; 3; 78:1-8.

39. Jones C, Palmer ATE, Griffiths RD. Randomized clinical outcome study of critically ill patients given glutamine-supplemented enteral nutrition. Nutrition 1999; 15: 108-115.

40. Kalfarentzos F, Kehagias J, Mead N, et al. Enteral nutrition is superior to parenteral nutrition in severe acute pancreatitis: Results of a randomized prospective trial. Br J Surg 1997; 84: 1665-1669.

41. Koretz RL. Nutritional support: how much for how much? Gut 1986; 27(Suppl 1): 85-95.

42. Kruizenga HM, van Tulder MW, Seidell JC, et al. Effectiveness and cost-effectiveness of early screening and treatment of malnourished patients. Am J Clin Nutr 2005; 82: 1082-1089.

43. Lacson Jr E, Ikizler TA, Lazarus JM, et al. Potential Impact of Nutritional Intervention on End-Stage Renal Disease Hospitalization, Death, and Treatment Costs. J Ren Nutr 2007; 17: 363-371.

44. Louie BE, Noseworthy $T$, Hailey D, et al. Enteral or parenteral nutrition for severe pancreatitis: A randomized controlled trial and health technology assessment. Can J Surg 2005; 48: 298-306.

45. Neelemaat F, Bosmans JE, Thijs A, et al. Oral nutritional support in malnourished elderly decreases functional limitations with no extra costs. Clin Nutr 2012; 31: 183-190.

46. Nicholas JA, Hall WJ. Screening and Preventive Services for Older Adults. Mt Sinai J Med 2011; 78: 498-508.

47. Norman K, Pirlich M, Smoliner C, et al. Cost-effectiveness of a 3-month intervention with oral nutritional supplements in disease-related malnutrition: a randomised controlled pilot study. Eur J Clin Nutr 2011; 65: 735-742.

48. Nuijten M, Mittendorf T. The health economic impact of oral nutritional supplements (ONS) in Germany. Aktuel Ernahrungsmed 2012: 37: 126-133.

49. Ockenga, J. Importance of Nutritional Management in Diseases with Exocrine Pancreatic Insufficiency. HPB 2009; 11(Suppl 3): 11-15.

50. Ofman J, Koretz RL. Clinical economics review: nutritional support. Aliment Pharmacol Ther 1997; 11: 453-471. 
51. Olveira G, Tapia M J, Colomo N, et al. Usefulness of the daily defined dose method to estimate trends in the consumption, costs and prevalence of the use of home enteral nutrition. Clin Nutr 2009; 28: 285-290.

52. Reilly Jr JJ, Hull SF, Albert N, et al. Economic impact of malnutrition: a model system for hospitalized patients. J Parent Ent Nutr 1988; 12: 371-376.

53. Russell CA. The impact of malnutrition on healthcare costs and economic considerations for the use of oral nutritional supplements. Clin Nutr 2007; 2(Suppl): 25-32.

54. Rypkema $\mathrm{G}$, Adang $\mathrm{E}$, Dicke $\mathrm{H}$, et al. Cost-effectiveness of an interdisciplinary intervention in geriatric inpatients to prevent malnutrition. J Nutr Health Aging 2003; 8: 22-27.

55. Scott F, Beech R, Smedley F, et al. Prospective, randomized, controlled single-blind trial of the costs and consequences of systematic nutrition team follow-up over 12 mo after percutaneous endoscopic gastrostomy. Nutrition 2005; 21: 1071-1077.

56. Smedley $F$, Bowling $T$, James $M$, et al. Randomized clinical trial of the effects of preoperative and postoperative oral nutritional supplements on clinical course and cost of care. Br J Surg 2004; 91 : 983-990.

57. Tchekmedyian NS. Pharmacoeconomics of nutritional support in cancer. Semin Oncol 1998;25:62-69.

58. Van Wetering CR, Hoogendoorn M, Broekhuizen R, et al. Efficacy and Costs of Nutritional Rehabilitation in Muscle-Wasted Patients with chronic obstructive pulmonary disease in a community-based setting: a prespecified subgroup analysis of the INTERCOM trial. J Am Med Dir Assoc 2010; 11: 179-187.

59. Waitzberg DL, Yara CB. Costs of patients under nutritional therapy: from prescription to discharge. Curr Opin Clin Nutr Metab Care 2004; 7: 189-198.

60. Wicks C, Somasundaram S, Bjarnason I, et al. Comparison of Enteral Feeding and Total Parenteral Nutrition after Liver Transplantation. Lancet 1994; 344: 837-840.

61. Wilson B, Fernandez-Madrid A, Hayes A, et al. Comparison of the effects of two early intervention strategies on the health outcomes of malnourished hemodialysis patients. J Ren Nutr 2001;11:166-171.

62. Windle EM. Nutrition support in major burn injury: case analysis of dietetic activity, resource use and cost implications. J Hum Nutr Diet 2008; 21: 165-173.

63. Wyers CE, Reijven PLM, Evers SMAA, et al. Cost-effectiveness of nutritional intervention in elderly subjects after hip fracture. A randomized controlled trial. Osteoporos Int 2013; 24: 151-162.

64. Zhang K, Sun W B, Wang HF, et al. Early enteral and parenteral nutritional support in patients with cirrhotic portal hypertension after pericardial revascularization. Hepatobiliary Pancreat Dis Int 2005; 4: 55-59.

65. De Vet HC, Terwee CB, Mokkink LB, et al. Reliability. In: Measurement in Medicine. A Practical Guide, $1^{\text {st }}$ Ed., Cambridge: Cambridge University Press; 2011: 120-122.

66. Philipson TJ, Thornton Snider J, Lakdawalla DN, et al. Impact of oral nutritional supplementation on hospital outcomes. Am J Manag Care 2013; 19: 121-128.

67. Drummond MF, Richardson WS, O'Brien BJ, et al. User's guide to the medical literature. XIII. How to use an article on economic analysis of clinical practice. A. Are the results of the study valid? Evidence-Based Medicine Working Group. J Am Med Assoc 1997; 277: 1552-1557.

68. O'Brien B, Heyland D, Richardson WS, et al. User's guide to the medical literature. XIII. How to use an article on economic analysis of clinical practice. B. What are the results and will they help me in caring for my patients? J Am Med Assoc 1997; 277: 1802-1806.

69. Au F, Prahardhi S, Shiell A. Reliability of two instruments for critical assessment of economic evaluations. Value in Health 2008; 11: 435-439. 


\title{
6
}

Nutrition economics - The view of international experts regarding health economics for medical nutrition in disease related malnutrition

\author{
Karen Freijer \\ Irene Lenoir-Wijnkoop \\ Christine A Russell \\ Marc A Koopmanschap \\ Hinke M Kruizenga \\ Stefan K Lhachimi \\ Kristina Norman \\ Mark JC Nuijten \\ Jos MGA Schols
}

Submitted for publication 


\section{Abstract}

Healthcare systems are currently facing tremendous budget constraints resulting in growing pressure on decision makers and healthcare providers to obtain the maximum possible health benefits of the resources available. Choices have to be made and health economics can help in allocating limited healthcare resources among unlimited wants and needs. Attempts to achieve cost reductions often focus on severe pathologies and chronic diseases as they commonly represent high healthcare expenditures. In this context, awareness of the considerable financial burden caused by disease related malnutrition (DRM) is lacking. Possibilities of reducing costs by optimising the management of DRM through medical nutrition will mostly not even be taken into account. Guided by scientific literature, international experts viewed and discussed the issues for medical nutrition health economic assessment. It was concluded that, although the general principles of health economic studies may apply to all forms of life sciences technology, specific characteristics of medical nutrition do have implications for a valid and reliable health economic evaluation. Broader multidisciplinary expertise is required to address these methodological issues and to provide concrete solutions. This will contribute to an improved management of DRM and facilitate informed decision making for the benefit of both the patient and healthcare. 


\section{Introduction}

The current economic climate and an increasing ageing population cause a need to economize within current healthcare systems. Given the scarce healthcare resources available, decision makers and healthcare providers are challenged to obtain the maximum possible benefit. In this era of competitive healthcare funding, costeffectiveness data can help in decision making, giving health economics (HE) a more prominent role than ever in the overall evaluation of a health technology, also known as health technology assessment $(\mathrm{HTA})^{1,2}$. The field of HE can be described as the application of economic theory, models and empirical techniques to the analysis of decision-making by individuals, healthcare providers and governments with respect to health and healthcare ${ }^{3}$. Since the first HE evaluations for reimbursement application were undertaken in the $1990 \mathrm{~s}^{4}$, the basic methods for performing pharmacoeconomic evaluations have been agreed, documented and disseminated in national pharmacoeconomic guidelines around the world ${ }^{5}$. These guidelines were initially developed for pharmaceutical products, but are now increasingly used for other healthcare technologies, such as medical devices and more recently also for food and medical nutrition. In 2009 it was concluded that HTA societies needed to consider whether the current assessment methods take sufficient account of the specific characteristics of medical devices, as the nature of drugs and these devices is different ${ }^{6-8}$. A similar conclusion arose during recent discussions among nutritionists and experts in the field of $\mathrm{HE}$ which resulted in the creation of a new HE discipline nutrition economics, defined as a discipline dedicated to researching and characterising health and economic outcomes in nutrition for the benefit of society ${ }^{9,10}$.

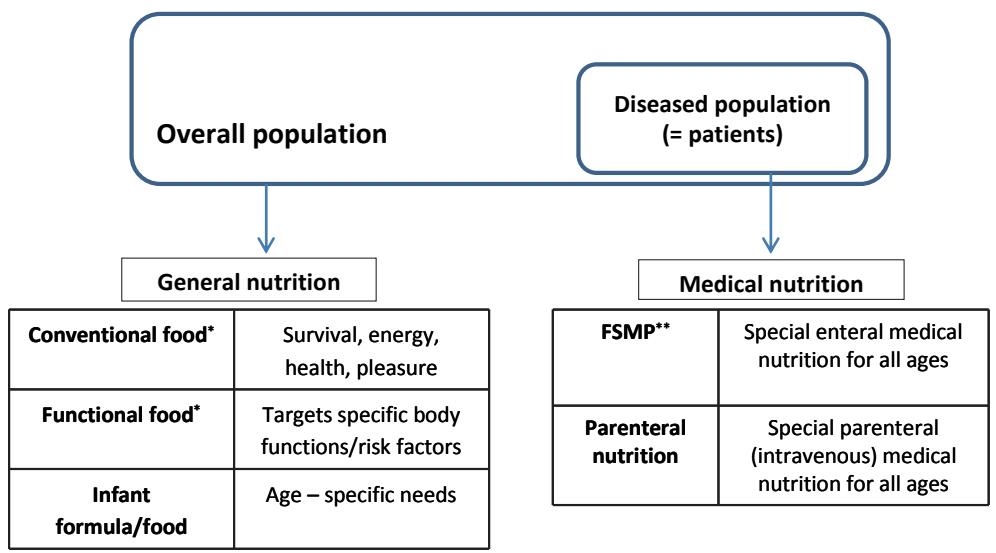

Figure 6.1 Different nutrition categories within nutrition economics.

*focus of expert meetings $1 \& 2^{5,6}$; **focus of expert meeting 3 
Furthermore, it was felt that a policy shift from evidence-based medicine to broader evidence-based decision-making in the field of nutrition is needed due to challenging methodological issues in nutrition research ${ }^{9}$. The same applies to medical nutrition, a distinct nutrition category where the target user group is patients rather than healthy individuals (Fig 6.1). Medical nutrition comprises parenteral (intravenous) nutrition, regulated in pharmaceutical legislation, as well as enteral nutritional support regulated as "foods for special medical purposes"(FSMP), defined by the European Commission Directive 1999/21/EC as "dietary foods intended to meet the particular nutritional requirements of persons affected by or malnourished because of a specific disease, disorder or medical condition; whereas for this reason they must be used under medical supervision which may be applied with the assistance of other competent health professionals"11. FSMP include oral nutritional supplements (ONS) and enteral tube feeds (ETF), administered via nasogastric, naso-enteral, or percutaneous tubes into the gut. They contain macronutrients (carbohydrates, protein, fat) as well as micronutrients (vitamins, minerals, trace-elements) with or without fibre. These products are designed for both inpatients and patients in community settings, either to provide complete daily nutrition or as a supplement to the day-to-day (usual) diet.

Table 6.1 Systemic metabolic stress reactions resulting in catabolism.
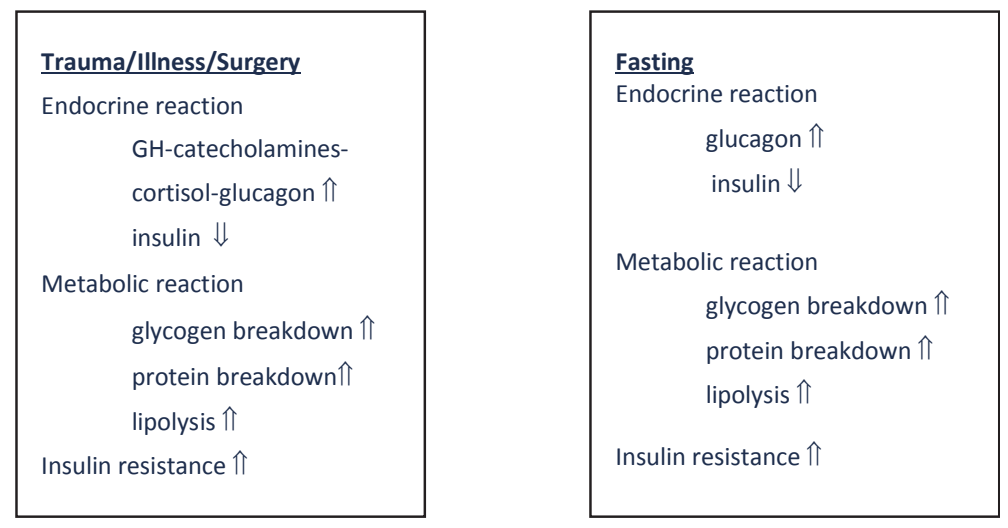

$\Uparrow$, an increase; $\Downarrow$, a decrease

One important indication for the use of medical nutrition is disease related malnutrition $(D R M)^{12-14}$. The causes of DRM are multi-factorial of which metabolic stress of the body due to acute or chronic diseases resulting in catabolism (Table 6.1) is an important one ${ }^{15}$. This breakdown state of the body increases the nutritional needs, in particular for protein. DRM can affect patients of all ages, but becomes a major public health concern with an ageing population, as older people are at increased risk of malnutrition. It has been shown that patients aged 65 years and over on admission to 
hospital have an overall 33\% greater risk of malnutrition than those younger than 65 years $^{16}$. About 33 million patients in Europe are affected by DRM costing governments up to $€ 170$ billion per annum ${ }^{17}$. These expenditures are mainly due to the many adverse consequences associated with DRM, such as higher risk of complications and increased institutionalisations, while in addition the quality of life of these patients is negatively affected $^{15}$ (Fig 6.2). Although in some cases improvement of the quality or quantity of food intake can ameliorate the problem, in many cases individuals simply cannot or are unwilling to consume sufficient normal food to meet their nutritional requirements. As a consequence, FSMP products need to be considered to improve nutritional intake. Extensive clinical evidence has demonstrated that medical nutrition is safe and effective in all healthcare settings in a wide variety of patient groups ${ }^{18,20-23}$. Moreover, studies have shown the economic benefit of using medical nutrition in the management of DRM ${ }^{19,24,25}$. However, recent systematic reviews revealed a substantial variation in the quality of economic evaluations for medical nutrition due to inconsistencies in the health economic assessment methods used ${ }^{26,27}$. Therefore, following two previous meetings on nutrition economics ${ }^{9,10}$, a third international expert meeting was organized to determine the issues for health economic assessment regarding medical nutrition in the management of DRM. For the purpose of the discussion, the term medical nutrition referred to FSMP products and the term malnutrition specifically related to DRM.

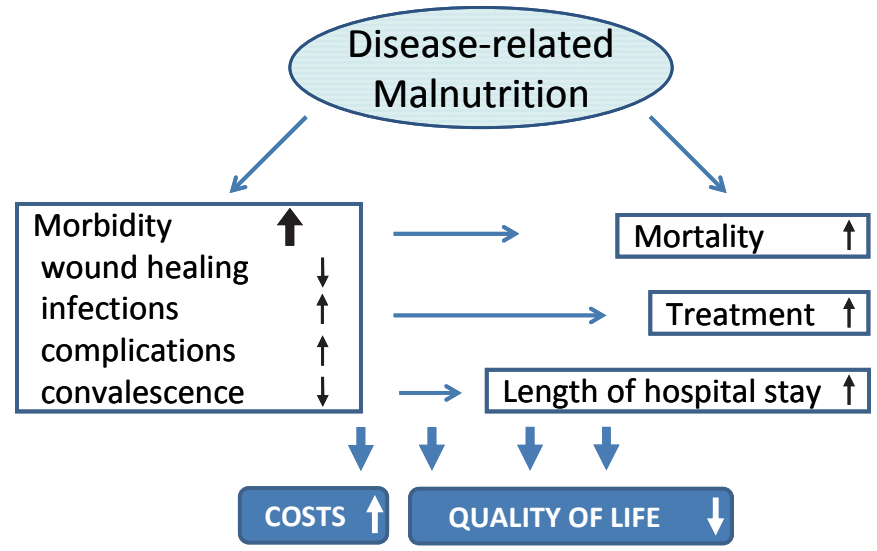

Figure 6.2 Prognostic impact of DRM.

(Adapted from Norman K et al. $2008^{15}$, with permission from Elsevier) 


\section{Methods}

International specialists (the authors of this manuscript) from The Netherlands, France, United Kingdom and Germany with experience in the field of nutrition and medical nutrition, HE and/or HTA gathered for a one day session to clarify the scope and describe the key issues that should be taken into consideration in the total evaluation of medical nutrition. The basic elements of $\mathrm{HE}$, nutrition economics and the use of medical nutrition in the management of DRM were outlined in order to achieve a common understanding by all participants. Each element determining the quality of HE studies was then introduced by short evidence based overview to provide a framework for discussion. Subsequently, each expert was asked to comment on statements regarding the specific item, which was followed by a group debate with the aim of reaching a conclusion.

\subsection{Items for discussion}

The quality of health economic studies is largely determined by the quality of the clinical effectiveness evidence, which in turn, is determined by its validity (accuracy) and reliability (consistency). The validity is affected by both the study setting and design and concerns the likelihood of the observed effect being the result of the specific intervention itself or of other factors, e.g. chance, effect of extra variables (confounding) or errors in translating or collecting the data (bias) ${ }^{28}$. Study population, sample size and comparator are elements that can affect the internal or external validity of the evidence, influencing the extent to which the trial results provide a correct basis for generalisation to different circumstances, such as other patient groups, other settings, modalities of outcomes etc. ${ }^{28}$.

In addition to the items mentioned above, other quality-determining elements of health economic studies were discussed, such as the perspective, relevance of outcomes and discounting.

\section{Report of the discussed items}

\subsection{Study design}

Within healthcare, the principles of evidence-based medicine are commonly used to decide what the best medical care is for individual patients ${ }^{29,30}$. A randomized controlled trial (RCT) with an adequate number of participants is considered to be the gold standard study design with the highest internal validity ${ }^{28}$. During the discussion it was stated that performing RCTs for medical nutrition can present more difficulties than drug intervention RCTs due to the basic differences between nutritional support and drug administration. One major difference is that medical nutrition offers a 
complex mixture of nutrients which are polyvalent, acting fundamentally and interdependently, whereas drugs are chemical entities, mostly one compound, acting symptomatically and focusing on a single effector site, which makes it easier to prove the causality between the drug and a specific health outcome ${ }^{31}$ (Table 6.2). As it is not ethical to withhold food/nutrition from the control group, proving the effect of a nutrition intervention on top of any food and drink consumed can be challenging. Moreover, the experts recognized that medical nutrition usually is an adjuvant to the medical treatment of the disease, as DRM is not a specific clinical condition per se, but mostly occurs as a result of an illness or a combination of illnesses. The medical treatment of the clinical condition can impact on the body's metabolic system, influencing the efficacy of not only nutrients supplied, but also the well-being of the patient. This in itself can result in possible changes of appetite or ability to eat and thereby influence nutritional intake over time, affecting the study results. The reverse can also occur, since an improved nutritional status can affect the efficacy of a drug. These aspects generate many confounding variables in medical nutrition trials. They are less when medical nutrition is used as the sole source of nutrition, but ETF and/or ONS in particular, are mainly used as a supplement to the voluntary daily food intake.

The next issue to consider is heterogeneity within a patient population. Every patient has their own personal nutritional habits, whether or not influenced by treatments for their disease. It is therefore important to accurately record the nutritional intake from the normal diet in each subject in both groups in addition to recording nutritional intake from the trial products. Block randomisation or even use of the minimisation method will help to exclude bias, as it is achieved not only with properly performed randomisation, but also with the advantage that similarity of the two groups is ensured, rather than hoped for $^{32}$.

Another issue to take into account is the duration required to show an effect of the nutrition intervention. It may only be possible to measure intermediate effects, e.g. increase in weight or muscle strength rather than a marked hard clinical outcome such as a decrease in complications, within a reasonable timeframe. Evidence for an indirect link is considered to be less convincing than a direct link, influencing the selection of parameters to measure the effect ${ }^{28}$. Due to these issues, designing and performing a medical nutrition intervention trial remains complex.

Conclusion: Due to distinct characteristics of medical nutrition as compared to a pharmaceutical single target approach, there are several issues concerning the study design that need to be considered when developing or interpreting a medical nutrition trial. These issues might be solved by nutrition specialists in conjunction with epidemiologists and clinicians, working together in order to shape the most appropriate study protocols for optimal assessment of the real impact of medical nutrition interventions. 
Table 6.2 Summary of the differences between general nutrition, medical nutrition and pharmaceutical products.

\begin{tabular}{|c|c|c|c|}
\hline & General nutrition & $\begin{array}{l}\text { Enteral Medical } \\
\text { nutrition (FSMP) }\end{array}$ & Pharmaceutical products \\
\hline Compound & Normal (daily) food & Combination of nutrients & Chemical entities \\
\hline Testing & $\begin{array}{l}\text { Food safety as } \\
\text { prerequisite } \\
\text { Often not tested in } \\
\text { clinical trials } \\
\text { (unless e.g. claim } \\
\text { substantiation) } \\
\text { Real world } \\
\text { interventions are } \\
\text { mainstay for data } \\
\text { collection }\end{array}$ & $\begin{array}{l}\text { In general combination } \\
\text { of nutrients tested in } \\
\text { clinical trials (safety, } \\
\text { tolerance, efficacy) }\end{array}$ & $\begin{array}{l}\text { In general } 1 \text { compound } \\
\text { tested in clinical trials } \\
\text { (phase I-IV: safety, efficacy) }\end{array}$ \\
\hline Registration & No registration & $\begin{array}{l}\text { National registration/ } \\
\text { notification* }\end{array}$ & $\begin{array}{l}\text { European (EMEA), US (FDA) } \\
\text { registration }\end{array}$ \\
\hline Target group & $\begin{array}{l}\text { For (healthy, at } \\
\text { risk) consumer use }\end{array}$ & $\begin{array}{l}\text { For patients use; part of } \\
\text { total medical treatment } \\
\text { (medical supervision) }\end{array}$ & $\begin{array}{l}\text { For patients use; part of } \\
\text { total medical treatment } \\
\text { (medical supervision) }\end{array}$ \\
\hline Reimbursement & Not reimbursed & Frequently reimbursed & Usually reimbursed \\
\hline Trials & & & \\
\hline - Form & \multicolumn{2}{|c|}{$\begin{array}{l}\text { Complex, for FSMP mostly next to daily } \\
\text { nutritional intake }\end{array}$} & Simple - stand-alone \\
\hline - Metabolism & \multicolumn{2}{|c|}{$\begin{array}{l}\text { Complex: combination of nutrients - effect on } \\
\text { multiple physiological systems }\end{array}$} & $\begin{array}{l}\text { Simple: single compound - } \\
\text { effect on single target }\end{array}$ \\
\hline - Effect & \multicolumn{2}{|c|}{$\begin{array}{l}\text { Intermediate - measurable small outcome, } \\
\text { often only on long term }\end{array}$} & $\begin{array}{l}\text { Mediate - measurable large } \\
\text { outcome }\end{array}$ \\
\hline - Compliance & \multicolumn{2}{|c|}{$\begin{array}{l}\text { Versatile for general nutrition; relatively low for } \\
\text { FSMP }\end{array}$} & Relatively high \\
\hline - Interaction & \multicolumn{2}{|c|}{$\begin{array}{l}\text { Multiple, intrinsic as well as with other } \\
\text { components }\end{array}$} & Mostly single \\
\hline - Bioavailability & \multicolumn{2}{|c|}{ Variable } & High \\
\hline - Dose response & \multicolumn{2}{|l|}{ Shallow slope } & Deep slope \\
\hline - Adverse effects & \multicolumn{2}{|l|}{ Low } & High \\
\hline - Sample size & \multicolumn{2}{|l|}{ Usually large } & Relatively small \\
\hline - Comparator & \multicolumn{2}{|l|}{ Complex } & Simple \\
\hline - Study time & \multicolumn{2}{|l|}{ Long } & Short \\
\hline
\end{tabular}

*Legislation or standards on Medical Foods or Foods for Special Medical Purposes (FSMPs) have been established in a number of regions, including the $\mathrm{US}^{(43)}$, Europe ${ }^{(11)}$ and under CODEX ${ }^{(44)}$. The provisions are broadly similar.

\subsection{Study population and sample size}

Critics of medical nutrition trials often state that studies are somewhat "underpowered" ${ }^{33}$ despite statistically significant outcomes in prospective RCT's ${ }^{18-21,23}$. When determining the required sample size of a medical nutrition study population, calculations are influenced by issues addressed above, frequently resulting in the need of a very large study group ${ }^{33}$. However, as in many RCTs, medical nutrition studies are 
generally small due to the constraints in time and resources needed to screen the number of subjects required, further complicated by the fact that nutrition research is rarely getting the priority when allocating the available resources. During the expert meeting, participants agreed that these challenges should be taken into account, in order not to miss out on the added clinical value of nutrition.

Conclusion: Awareness and understanding of the challenges regarding the study population and required sample sizes have to be improved among clinicians and other non-nutrition experts to generate more reliable clinical evidence. If power calculations show that the required sample size is too large to make undertaking a RCT practical an alternative approach such as a well-conducted randomized naturalistic or observational study should be recommended.

\subsection{Choice of comparator}

In this meeting it was emphasized that the choice of a comparator for medical nutrition is complex due to the polyvalence and interaction of nutrients. In a trial investigating the effects of an ONS intervention versus standard care such as dietary counselling or no ONS, the placebo should not contain any nutrients to avoid confounding, whereas when the effect of a disease specific ONS product is studied, the comparator should then be equivalent in all aspects other than the active ingredients in the disease specific ONS.

Conclusion: The choice of an appropriate comparator in medical nutrition interventions is dependent on the definition of standard care, which can be routine clinical care, additional dietary advice and/or standard ONS.

\subsection{Perspective}

The specific viewpoint chosen in a health economic analysis determines the costs and benefits that have to be included. A calculation from a societal perspective is the widest possible perspective and considers the direct medical, direct non-medical and indirect costs. Because of variations in national healthcare structures and environment e.g. differences in financial systems, 33 different pharmacoeconomic guidelines have been published $^{5}$. To be able to collect the right costing data for the perspective chosen, a comprehensive understanding is required regarding the specific national financial structures as well as the use of medical nutrition in all care settings. Furthermore, the informal care burden (e.g. relatives, friends) that often exists could additionally be taken into account.

Conclusion: The perspective recommended in the national health economic guidelines for medical interventions and technologies is also applicable for calculating the health economic value of medical nutrition. However, a comprehensive understanding of the payer framework including all the modalities of providing medical nutrition is required in order to account for all relevant costs. 


\subsection{Data collection - health outcomes}

Outcomes can be divided into clinical and health outcomes, depending on the effect of the investigated intervention. Clinical outcomes demonstrate the effect of a treatment on a disease, whereas health outcomes refer to a broader scope of effects including quality of life and independence. Clinicians mainly look for evidence of the results of treatment, risks and benefits, whereas decision makers focus more on implementing potentially effective strategies to improve the quality and value of care ${ }^{34}$. When identifying measurable outcomes for medical nutrition trials, it is difficult to include a parameter proving a direct effect of the intervention rather than demonstrating an intermediate effect, as stated in the section about the study design. However, evidence for an indirect relationship is considered less convincing than direct relationships and is in many cases not acknowledged, neither with regard to effectiveness nor to the beneficial impact on costs ${ }^{28}$. Data on certain nutritional endpoints, e.g. an increase of body weight or improvement in fat free body mass, are therefore not sufficient and should at least be complemented by data proving a direct link between these nutritional outcomes and a clinical or health benefit, e.g. reduced morbidity or increased quality of life.

Furthermore the experts agreed that as clinical effectiveness studies do not systematically incorporate quality of life measurements, identification of both aspects should ideally be combined during the same trial using validated quality of life instruments, such as the EuroQol-5Dimensions instrument (EQ-5D) ${ }^{35}$. These instruments map the quality of life-related benefits of the intervention as well as the consequences of the adverse effects. Adverse effects represent an important element in drug trials, whereas such concerns are rare in medical nutrition trials. Clinical effectiveness of medical nutrition has to be demonstrated and the evidence acknowledged before an economic evaluation of good quality can be performed.

Conclusion: As for other research methodologies, it is recommended to measure both effectiveness and quality of life or improved functional performance for the health assessment of medical nutrition interventions. The challenge though, is to demonstrate the cause-effect relationship between the medical nutrition and the overall outcomes. Nutritional, clinical, epidemiological and patient-reported outcomes (PRO) specialists should work together to establish the optimal methodological approach and the outcomes to use.

\subsection{Discounting}

Discounting has been defined as "a mathematical process used to bring future costs and benefits to their present value. This implies that future costs and benefits have less value than the same costs and benefits in the present ${ }^{\prime \prime 6}$. In other words, discounting captures the preference of humans to value an immediate benefit higher (or an immediate cost lower) than the same benefit (or cost) realized in the future. Interest 
rates on saving are a prime example of discounting: one forgoes current consumption because future consumption will be higher (the actual amount saved plus the interest rates). In HE evaluations, discounting is intended to make programs comparable when costs and benefits are accrued over time and/or are realized at different time points. For medical nutrition it is just as important as for any other technology to account for future benefits and costs in a consistent manner. The experts therefore agreed that country specific economic evaluation guidelines regarding discounting should be applied in the same way as for other interventions. However, in practice, discounting might not be necessary for medical nutrition interventions in the management of DRM as discounting should only be applied when the time horizon of the studied program exceeds one year.

Conclusion: In the field of nutrition economics for medical nutrition, discount rates should be applied to clinical and economic outcomes in the same way as recommended in the national health economic guidelines.

\section{Discussion and conclusion}

There is convincing clinical evidence of the benefits of enteral medical nutrition, including weight gain, improvement of muscle function, reduction in mortality and complications, reduced length of hospital stay, reduced admissions/re-admissions to hospital, improvement of wound healing and increase in quality of life ${ }^{18,19,21,23,37-39}$. However, critics often judge this evidence as insufficient due to a lack of insight in nutrition-related challenges, particularly in the management of DRM. Healthcare systems are mainly focussed on the existing methodology for data generation in pharmaceutical trials. Adapted economic evaluations for medical nutrition will help to better quantify the added value of this nutrition category. It is therefore essential that the here described methodological challenges for medical nutrition interventions are addressed. After all, the quality of a cost effectiveness study is highly determined by the quality of the effectiveness evidence. The Consolidated Standards of Reporting Trials (CONSORT) Group acknowledged that research of non-pharmacological interventions is different from pharmaceutical research, by developing an extension of the CONSORT Statement for interventions other than pharmaceutical products ${ }^{40}$. In addition, if undertaking a RCT is not feasible because of large sample size required, the STrengthening the Reporting of OBservational studies in Epidemiology. (STROBE) guidelines can be used for reporting outcomes from observational studies ${ }^{41}$. Unfortunately, medical nutrition is not yet included in these initiatives and the related methodological issues remain on the agenda for reaching a scientific consensus, as also confirmed by recent systematic reviews about the economic value of medical nutrition, revealing large differences in the quality of health economic analyses conducted for medical nutrition ${ }^{26,27}$. 
During this international expert meeting, quality-determining elements of health economic studies were extensively discussed to clarify and identify the key issues in assessing the health economic value of medical nutrition for DRM. Although the general methods for performing health economic evaluations can be applied to medical nutrition as to any other technology, it was concluded that specific characteristics of medical nutrition such as study design, study population, sample size, comparator and clinical research outcomes, do need special attention. A limitation of this expert group was that a broader multidisciplinary expertise is required to provide concrete solutions. However, the aim of this report is to first clarify the scope and identify the key issues that should be taken into consideration when evaluating medical nutrition approaches. It is necessary to evolve from assessment on an individual patient level towards a group level both in inpatient and outpatient settings on a national level.

A possible next step in this particular area of nutrition economics might be the establishment of appropriate guidance developed by nutrition specialists, epidemiologists and HTA experts in order to implement good quality methodologies for medical nutrition research.

Researchers and the medical nutrition industry along with policymakers and clinicians will then be able to use a single standard for performing or judging medical nutrition studies to the greater benefit of both patients and healthcare systems ${ }^{33}$. In the current situation, medical nutrition is highly undervalued because of a perceived lack of evidence, resulting in an insufficient prescription by healthcare professionals. This is likely to have an adverse impact on patients suffering from DRM, leading to a higher prevalence of under-nutrition and associated negative clinical and economic consequences. 


\section{References}

1. Organisation for Economic Co-operation and Development (OECD). Health at a Glance 2011: OECD Indicators, OECD Publishing. Available at: http://dx.doi.org/10.1787/health_glance-2011-en. Accessed on November 30, 2013.

2. Ligtenberg G, Staal PC, Goettsch et al. Cost-effectiveness in health care. A report of the Dutch Health Care Insurance Board 2013: 1-41. [Dutch]

3. Arrow KJ. Uncertainty and the welfare economics of medical care. Am Econ Rev 1963; 53: 941-973.

4. Hutton J. 'Health economics' and the evolution of economic evaluation of health technologies. Health Econ 2012; 21: 13-18.

5. International Society for Pharmacoeconomics and Outcomes Research Pharmacoeconomic (ISPOR). Guidelines Around The World. Available at: http://www.ispor.org/peguidelines/index.asp. Last assessed on September 31, 2013.

6. Drummond M, Griffin A, Tarricone R. Economic Evaluation for Devices and Drugs - Same or Different? Value in Health 2009; 12: 402-404.

7. Taylor RS, Iglesias CP. Assessing the Clinical and Cost-Effectiveness of Medical Devices and Drugs: Are They That Different? Value in Health 2009; 12: 404-406.

8. Sorenson $C$, Tarricone $\mathrm{R}$, Siebert $\mathrm{M}$, et al. Applying health economics for policy decision making: do devices differ from drugs? Europace 2011; 13: ii54-ii58.

9. Lenoir-Wijnkoop I, Nuijten MJC, Gutiérrez-Ibarluzea I, et al. Workshop Report: concepts and methods in the economics of nutrition - gateways to better economic evaluation of nutrition interventions. BJN 2012; 108: 1714-1720.

10. Lenoir-Wijnkoop I, Dapoigny $M$, Dubois $D$, et al. Nutrition economics: characterizing the economic and health impact of nutrition. BJN 2011; 105: 157-166.

11. Commission directive 1999/21/EC of 25 March 1999 on dietary foods for special medical purposes. Available at: http://eur-lex.europa.eu/LexUriServ/LexUriServ.do?uri=CELEX:31999L0021:EN:NOT. Assessed on November 25, 2013.

12. ESPEN Guidelines on adult enteral nutrition. Clin Nutr 2006; 25: 177-360. Available at: http// www.espen.org.

13. NAIT (National Alliance for Infusion Therapy) and A.S.P.E.N. (the American Society for Parenteral and Enteral Nutrition) Public Policy Committee and Board of Directors. Disease-related malnutrition and enteral nutrition therapy: a significant problem with a cost-effective solution. Nutr Clin Pract 2010; 25: 548-554.

14. Fight malnutrition. Malnutrition guidelines: Guideline screening and treatment of malnutrition 2012. Available at: http://www.fightmalnutrition.eu. Accessed on November 25, 2013.

15. Norman K, Pichard C, Lochs H, et al. Prognostic impact of disease-related malnutrition. Clin Nutr 2008; 27: 5-15.

16. Russell CA and Elia M. Nutrition screening surveys in UK hospitals 2007-2011. A report based on the amalgamated data from the four Nutrition Screening Week surveys undertaken by BAPEN in 2007, 2008, 2010 and 2011.Redditch: BAPEN; 2014.

17. Ljungqvist O, de Man F. Under nutrition - a major health problem in Europe. Nutr Hosp 2009; 24: 368370 .

18. Stratton RJ, Green CJ, Elia M. Disease-related malnutrition: an evidence based approach to treatment. Wallingford: CABI Publishing; 2003.

19. Elia M, Stratton RJ, Russell C, et al. The Cost of Disease-Related Malnutrition in the UK and Economic Considerations for the use of Oral Nutritional Supplements (ONS) in Adults. Redditch: BAPEN; 2005.

20. Stratton RJ, Elia M. Who benefits from nutritional support: what is the evidence? Eur J Gastroenterol Hepatol 2007; 19: 353-358.

21. Cawood AL, Elia M, Stratton RJ. Systematic review and meta-analysis of the effects of high protein oral nutritional supplements. Ageing Res Rev 2012; 11: 278- 296.

22. $\mathrm{MNI}$ (Medical Nutrition International Industry). Oral nutritional supplements to tackle malnutrition: $a$ summary of the evidence base. 3rd version. Brussels; 2012. p. 1-273. 
23. Stratton RJ, Hébuterne $X$, Elia M. A systematic review and meta-analysis of the impact of oral nutritional supplements on hospital readmissions. Ageing Res Rev 2013; 12: 884- 897.

24. Norman K, Pirlich M, Smoliner C, et al. Cost-effectiveness of a 3-month intervention with oral nutritional supplements in disease-related malnutrition: A randomised controlled pilot study. Eur J Clin Nutr 2011; 65: 735-742.

25. Neelemaat F, Bosmans JE, Thijs A, et al. Oral nutritional support in malnourished elderly decreases functional limitations with no extra costs. Clin Nutr 2012; 31: 183-190.

26. Freijer K, Bours MJ, Nuijten MJC et al. The Economic Value of Enteral Medical Nutrition in the Management of Disease-Related Malnutrition: A Systematic Review. JAMDA 2014; 15: 17-29.

27. Milte RK, Ratcliffe J, Miller MD, et al. Economic evaluation for protein and energy supplementation in adults: opportunities to strengthen the evidence. Eur J Clin Nutr 2013; 67: 1243-1250.

28. Velasco-Garrido M, Busse R. WHO on behalf of the European Observatory on Health Systems and Policies. Policy brief. Health technology assessment. An introduction to objectives, role of evidence, and structure in Europe. This policy brief is one of a series on health care issues by the European Observatory on Health Systems and Policies; 2005. Available at: http://www.euro.who.int/_ data/assets/pdf_file/0018/90432/E87866.pdf

29. Sackett DL, Rosenberg WM, Gray JA, et al. Evidence based medicine: what it is and what it isn't. BMJ 1996; 312: 71-72.

30. Timmermans S, Mauck A. "The promises and pitfalls of evidence-based medicine". Health Aff (Millwood) 2005; 24: 18-28.

31. Heaney RP. Nutrients, Endpoints, and the Problem of Proof. J Nutr 2008; 138: 1591-1595.

32. Treasure T, MacRae KD. Minimisation: the platinum standard for trials? Randomisation doesn't guarantee similarity of groups; minimisation does. BMJ 1998; 317: 362-3.

33. Deutz NEP, Koletzko B, Pichard C. Legal regulations for clinical trials: an opportunity for the future of clinical nutrition research. Clin Nutr 2007; 26, 510-513.

34. Internet Citation: Outcomes Research: Fact Sheet. March 2000. Agency for Healthcare Research and Quality, Rockville, MD. Available at: http://www.ahrq.gov/research/findings/factsheets/ outcomes/outfact/index.html. Assessed on Sept 30, 2013.

35. Hoekstra JC, Goosen JH, de Wolf GS, et al. Effectiveness of multidisciplinary nutritional care on nutritional intake, nutritional status and quality of life in patients with hip fractures: a controlled prospective cohort study. Clin Nutr 2011; 4: 455-461.

36. Collaboration between International Network of Agencies for Health Technology Assessment (INAHTA), Health Technology Assessment international (HTAi) and other partner organizations. Available at http://htaglossery.net. Accessed on November 5, 2013.

37. Stratton RJ, Ek AC, Engfer M, et al. Enteral nutritional support in prevention and treatment of pressure ulcers: a systematic review and meta-analysis. Ageing Res Rev 2005; $4: 422-450$.

38. Gariballa S, Forster $S$, Walters $S$, et al. A randomized double-blind placebo-controlled trial of nutritional supplementation during acute illness. Am J Med 2006; 119: 693-699.

39. Chapman M, Visvanathan R, Hammond AJ, et al. Effect of testosterone and a nutritional supplement, alone and in combination, on hospital admissions in undernourished older men and women. Am J Clin Nutr 2009; 89: 880-889.

40. Boutron I, Moher D, Altman DG, et al. for the CONSORT group. Extending the CONSORT Statement to randomized trials of nonpharmacologic treatment: explanation and elaboration. Ann Intern Med 2008; 148: 295-309.

41. von Elm E, Altman DG, Egger M, et al.; STROBE Initiative. Strengthening the Reporting of Observational Studies in Epidemiology (STROBE) statement: guidelines for reporting observational studies. J Clin Epidemiol 2008; 4: 344-349.

42. Cuthbertson DP. Observations on the disturbance of metabolism produced by injury to the limbs. Quart J Med 1932; 1: 233-246.

43. Medical Foods Guidance Documents \& Regulatory Information. Medical Foods section $5(b)$ of the Orphan Drug Act (21 U.S.C. 360ee (b) (3)). Available at: http://www.fda.gov/Food/GuidanceRegulation/GuidanceDocumentsRegulatoryInformation/MedicalFoo ds/default.htm 
44. Codex Alimentarius Standard 180/1991 Standard for Labelling of and Claims for Foods for Special Medical Purposes. Available at:

http://www.codexalimentarius.org/input/download/standards/294/CXS_180e.pdf 
General discussion 
Chapter 7 


\section{Introduction}

Over the years, evidence of the use of medical nutrition in the management of disease related malnutrition (DRM) has demonstrated functional as well as clinical benefits, but economic benefits are still rarely explored. The aim of this thesis was to explore the health economic value as well as the methodological issues in the cost-effectiveness assessment of medical nutrition in the management of DRM, being under-nutrition in health care. The term medical nutrition in this thesis has been used for Food for Special Medical Purposes (FSMP).

First the costs of DRM in adult patients in The Netherlands were estimated in comparison to other countries to demonstrate the economic burden of this malnutrition. Then two economic evaluations were performed to determine the costeffectiveness of using medical nutrition in the management of DRM in two different adult patient populations in The Netherlands. To have a good overview of the international economic value of medical nutrition in the management of DRM, a systematic review was performed. Finally, during an international expert workshop the appropriate health economic assessment methods for medical nutrition in the management of DRM were explored and discussed.

In this chapter the main findings of our studies are presented. Furthermore, the results will be discussed and methodological challenges and recommendations for practice and future research will be provided.

\section{Main findings of this thesis}

\subsection{DRM in adults - Cost of illness}

Despite or perhaps due to the increased attention for malnutrition over the years on both a national and international level, DRM is still considerably prevalent in various inand outpatient populations. About 33 million patients in Europe are affected by DRM, costing the governments up to $€ 170$ billion annually ${ }^{1}$. With an ageing population DRM continues to become a major public health concern, as increasing age is associated with an increased risk of malnutrition ${ }^{2}$. As DRM impacts every organ system in the body resulting in serious negative health consequences, it can be expected that health care utilization and associated costs to society will increase ${ }^{3-5}$. Unlike other countries, no reliable and accurate estimates of the total additional costs of DRM in all health care settings for The Netherlands have been published. To demonstrate the economic problem of DRM, we performed a cost-of-illness analysis for DRM in The Netherlands (Chapter 2). Results show that the total additional costs of DRM in adult patients in all health care settings were estimated to be $€ 1.9$ billion in 2011 which equals $2.1 \%$ of the total Dutch national health expenditure. The total additional costs for DRM were four 
times higher for the elderly patients (60 years of age and older) than for patients in the age category of $>18$ and $<60$ ( $€ 403$ million) and most costs (66\%) were attributable to the hospital setting ( $€ 1.2$ billion). Furthermore, the calculated costs of DRM per capita in The Netherlands were comparable to most of the estimated costs for other countries.

Yet the estimated costs for DRM in Ireland and the UK seemed even higher. Possible causes for the divergent numbers were found to be differences in the methodology of calculations, different perspectives used and a possible substantial increase of total health care expenditure between the years in which the various assessments were performed. Notwithstanding our conservative calculation, the economic burden of DRM in The Netherlands appeared to be considerable and even higher than the costs of obesity in The Netherlands which were $€ 1.2$ billion at time of publication of our study and $€ 1.6$ billion in a recent update of that report ${ }^{6,7}$.

\subsection{Cost-effectiveness of medical nutrition in the management of DRM in adults}

Money is a scarce commodity, especially in the last years due to an economic crisis. Therefore choices have to be made as a euro can only be spent once. Economic evaluations can help in making these choices by estimating the incremental clinical and economic value of an intervention over one or more other technologies. Valuing the intervention with medical nutrition, being Food for Special Medical Purposes (FSMP) in this thesis, is thus getting of greater importance. Hence we estimated the costeffectiveness of FSMP products in The Netherlands as well as on an international level.

By using the modelling technique we calculated the cost-effectiveness of oral medical nutrition, known as oral nutritional supplements (ONS), in two different adult patient populations in two different settings. The first economic evaluation regarded the value of the use of ONS versus standard care, being no use of ONS, in Dutch abdominal adult surgery patients suffering from DRM. Results demonstrated that this intervention is cost-effective, even when the hospital length of stay would be unrealistic low $(0.64$ days) as shown by the threshold analysis. The use of ONS in this patient group lead to cost-savings and higher effectiveness and is thus a dominant approach over the standard care (Chapter 3)

In our second health economic analysis, the use of ONS versus standard care, being no use of ONS, was valued in the management of DRM in Dutch community dwelling elderly ( $\geq 65$ years). Also this economic evaluation showed that the additional costs of ONS were more than balanced by a reduction in the use of health care resources, decreasing the costs of DRM demonstrating the budget impact of using ONS in this population (Chapter 4).

To answer our third research question, we performed a systematic review in which economic evaluations of enteral medical nutrition in the management of DRM in the 
Western and Eastern world (developed regions), were reviewed and qualified to estimate the economic value. Based on the high quality studies it was concluded that the use of enteral medical nutrition in the management of DRM can be efficient from a health economic perspective, leading in most cases to costs savings (Chapter 5).

\subsection{Issues in assessing the health economic value for medical nutrition}

During our research for this thesis it became evident that consistency in performing economic evaluations for medical nutrition is lacking notwithstanding the existence of cost-effectiveness evaluation guidelines. However these guidelines have initially been developed for pharmaceuticals. As nutrition is not a pharmaceutical product, nutrition economics has been created by experts in the field of both nutrition and health economics $^{8}$. To explore and discuss the appropriate health economic assessment methods for medical nutrition in the management of DRM, we also organized an international expert meeting. Issues in the assessment of both the validity and the reliability of evidence were scrutinized using statements. It was concluded that while the general principles of health economic assessment may apply to all forms of life sciences technology, specific characteristics of medical nutrition do have implications on the quality of the evidence available for a valid health economic evaluation (Chapter 6). Consensus followed by improved publicity about the way to address the methodological issues in the health economic evaluation of medical nutrition are needed to improve the decision making on the management of DRM for the benefit of the patient as well as health care. Subsequently nutrition economic guidelines for medical nutrition may be developed to yield economic data of higher quality which is obtained in a consistent manner.

\section{Methodological challenges and recommendations for the future}

\subsection{Malnutrition-Disease Related Malnutrition (DRM)}

In our research malnutrition has been specified using the widely acknowledged definition, including the members of the European Society for Parenteral and Enteral Nutrition (ESPEN): 'A state of nutrition in which a deficiency, excess or imbalance of energy, protein, and other nutrients causes measurable adverse effects on tissue/body form (body shape, size and composition) function, and clinical outcome ${ }^{\prime 9}$. Malnutrition thus includes both over-nutrition (too many nutrients) and under-nutrition (insufficient nutrition). For the purposes of this thesis the term malnutrition was used only for under-nutrition in health care, also known as DRM. Due to no universally accepted definition there is considerable variance in using this generally common term, including 
screening methods, leading to confusion and research results being difficult to compare. For the future it may be desirable to reach consensus on an international definition for malnutrition including a classification to specify the malnutrition type/syndrome determined by the cause and accompanied by a matching validated screening tool. For example, due to metabolic changes resulting from a metabolic stress situation, e.g. disease, surgery, trauma, the body is moving from an anabolic state to a catabolic state. Under-nutrition may then arise when the increased need for specific nutrients are not met, being DRM. A Delphi study on the elements of the definition and operationalism of this under-nutrition showed that deficiencies of energy or protein and decrease in lean body mass were indeed regarded to be especially important in defining DRM. For operationalism involuntary weight loss, body mass index and no nutritional intake were considered as most important elements ${ }^{10}$.

When under- or over-nutrition is caused by socio-economic aspects, it might be useful to refer to this malnutrition type as socio-economic malnutrition. Furthermore an optimal treatment can only be provided when the cause is known. Next to the aim for reaching consensus on a universal definition for malnutrition it might be helpful to also agree on alignment in the calculation methodology regarding the cost-of-illness for DRM to enable comparison in the magnitude of this health care problem across healthcare settings and countries. In our study it became evident that a possible cause for the divergent DRM costs per capita in several countries was found to be differences in the methodology of calculations among others (Chapter 2). For instance, taking all health care costs into account like total care at home or total GP visits, instead of only the additional health care costs due to DRM as in our cost-of-illness analysis, obviously leads to very high cost estimates of DRM. In order to make a more precise calculation of the Dutch DRM costs, further research is needed regarding concrete figures of the increased use of health care resources in non-hospital health care settings as well as data on the indirect health care costs and of the prevalence rate of DRM in the Dutch outpatient settings. Although our estimate shows considerable additional costs for DRM in Dutch adults, it concerns a conservative calculation from a health care perspective probably demonstrating even higher costs when these lacking data could be included, being then a calculation from the broadest societal perspective. For instance, the existence of increased indirect costs resulting from DRM has been indicated by studies showing impaired physical and psychosocial functions due to DRM. A reduced ability to work, self-neglect and deterioration in social interactions are examples of the effects from these impaired functions ${ }^{4}$. Other data that could help complementing our analysis to demonstrate the actual total costs of DRM in The Netherlands would be the inclusion of the cost of DRM in children. Patients of 18 years of age and younger are not included in our cost-of-illness study because health care management of children is not comparable to that of adults, including the method of measurement of DRM. A recent nationwide study in The Netherlands on DRM in children showed that $19 \%$ of children admitted to Dutch hospitals are malnourished at 
admission and $28 \%$ of children with an underlying disease in hospital are malnourished. Multiple regression analysis demonstrated that children with DRM stayed on average $45 \%$ longer (95\% Cl 7\%-95\%) in the hospital than children without $\mathrm{DRM}^{11}$. This high prevalence of DRM in children and its related clinical consequences, will certainly contribute to the total costs of DRM in The Netherlands.

\subsection{Economic evaluations for medical nutrition}

Both our economic evaluations in this thesis are analyses using the modelling technique (Chapter 3 and 4). Although this technique is a well-recognized method when not all data is available, collecting data on the utilization of health care resources as well as on the quality of life alongside clinical studies is preferred. Also data regarding the direct non-medical costs, e.g. transportation or personnel needed, and the indirect costs, e.g. days missed from work or time lost, can then be collected in detail for estimating the incremental cost-effectiveness ratio (ICER) from the broadest societal perspective. A lack of these data limited both our health economic analyses from a societal perspective to a health care perspective (Chapter 3 and 4). Moreover, the inclusion of different costs appeared to be also the main difference across all health economic evaluations in our systematic review (Chapter 5). Costs like patient monitoring (assessment and follow up) in the management of DRM for example, have been included in some studies but not in others affecting the total incremental costs influencing the final cost-effectiveness result. It can be debated whether these costs should be incorporated. DRM is not a disease on its own but a condition/syndrome resulting from the metabolic stress reaction in the body caused by e.g. an illness for which the patient is treated. Managing DRM should thus probably be an integrated part of the total management of each patient.

To enable better comparison among the results of economic evaluations for interventions in the DRM management, the use of an unequivocal method can help. Our systematic review revealed differences in the methodology of performing health economic evaluations for enteral medical nutrition in the management of DRM affecting the quality of these analyses. This was also confirmed by a recent publication quite similar to our systematic review ${ }^{12}$. The main difference between these two reviews concerns details in the definition of the intervention, comparator and exclusion criteria. However, both studies focussed on the cost-effectiveness of an increased intake of the needed nutrients in adult patients suffering from (risk of) DRM with the same overall conclusion: intervention with nutritional supplements in the management of DRM in adults is cost effective. Although guidelines for assessing economic evaluations exist, they were not fully applied in all the reviewed studies we qualified (Chapter 5) as was also concluded in the systematic review of Milte et al $^{12}$. On the one hand it might be that these guidelines are not known by the researchers, as performing health economic evaluations for medical nutrition is still scarce. Also a lack of knowledge on medical nutrition and DRM can negatively affect the quality of the 
evaluations. On the other hand, these guidelines were initially developed for pharmaceutical products (drugs), of which their detailed application frequently enhances methodological challenges ${ }^{13}$. Our international expert meeting indeed showed that specific characteristics of medical nutrition do require more attention for conducting reliable evaluations. For example the fact that medical nutrition products contain a complex mixture of nutrients which are polyvalent, acting fundamentally and interdependently of each other, making it very challenging to prove the causality between the medical nutrition, mostly given as an additional supplement to the daily (enriched) food too, and a specific health outcome whereas drugs are chemical entities, mostly one compound, acting symptomatically and focusing on a single intervention (Chapter 6). For the further development of health economics for medical nutrition, consensus followed by publicity about the way how to address the methodological issues advisably is the first step. Subsequently more high-quality detailed costeffectiveness studies regarding this nutrition, preferably from a societal perspective, are recommended for demonstrating the economic value.

\subsection{Nutritional intervention - medical nutrition- for DRM}

Our economic evaluations (Chapter 3 and 4) calculated the cost-effectiveness of ONS supplementation in the management of DRM. However some other health economic studies estimated the economic value of a mixture of nutritional interventions existing of e.g. energy and protein enriched diet, a calcium-vitamin $D$ supplement and telephone counselling by a dietician next to the $\mathrm{ONS}^{14}$. Probably both study methodologies bring added value, depending on which questions have to be answered. Regarding reimbursement, cost-effectiveness analyses are needed to proof the economic value of medical nutrition in the management of DRM. When the investigated intervention in an evaluation concerns a mixture, the added value of each individual intervention will not be provided. However, when medical nutrition is provided as a supplement, other nutritional intervention such as enriched nutrition next to the daily basic food products, is also needed to manage DRM in an optimal way as indicated in the guideline 'Screening and Treatment of Malnutrition' ${ }^{15}$. On a decision making level in practice, e.g. budget holders in institutions, it might be useful to show the cost-effectiveness of the recommended total optimal management of DRM following guidelines, existing of a mixture of nutritional interventions instead of only medical nutrition supplementation. An even more extensive health economic analysis can be helpful for health care practitioners, in which also the costs (time) for exercising the muscles of the DRM patient is included. To retain the important lean body mass (Chapter 1 ), this exercise is required in addition to the intake of the extra nutrients needed, to prevent muscle atrophy ${ }^{16}$. Then again it can be debated whether this exercise is part of the nutritional intervention or part of the total medical treatment of the patient which ideally should cover the management of DRM too as DRM is not a disease on its own. By all means, health economic analyses estimating the cost- 
effectiveness of the implementation of the total guideline 'Screening and Treatment of Malnutrition' might be of interest for health care practitioners because of increasing budgets pressure in an era of competitive health care funding.

\subsection{Patients}

Our thesis focussed on adults only because health care management of children is different as stated in the earlier section in this chapter about DRM. As costeffectiveness data is of increasing importance to be applied in health care, assessing the health economic value of medical nutrition in children suffering from DRM is therefore recommended.

\subsection{Nutrition economics}

Calculating the cost-effectiveness of medical nutrition is a new area within health economics and appeared to be challenging as discussed above. Several publications described similar issues for other nutrition interventions as well as for medical devices ${ }^{8,13,17-19}$. Discussions among experts in the field of health economics and nutrition have resulted in the efflorescent discipline of nutrition economics, which has been defined as "a discipline dedicated to researching and characterising health and economic outcomes in nutrition for the benefit of society" ${ }^{8}$. Since the importance of health economics data for all technologies is increasing to be applied in health care, we visualised our idea of how nutrition economics is fitting in within an overall technology evaluation (Figure 7.1).

It is generally known that health economics is crucial in a health technology assessment (HTA) in determining the value of a specific intervention in health care (Chapter 1 ). The stated aim of HTA is to support the decision-making in health care at policy level by providing reliable information. HTA can thus be regarded as a connection between the world of research and the world of decision-making ${ }^{20}$. Next to health economics data, the principles of evidence based medicine (EBM) are commonly used for assessing the internal validity of the clinical evidence (safety, efficacy, effectiveness) and aims to apply the best available evidence gained from the scientific method to clinical decision making on an individual level, as well as on patient group level documented and communicated by clinical practice guidelines ${ }^{21,22}$. As specific methodological issues have emerged regarding nutrition research (Chapter 6), nutrition evidence principles might be summarized and disseminated by the creation of a new field within EBM, such as Evidence Based Nutrition. 


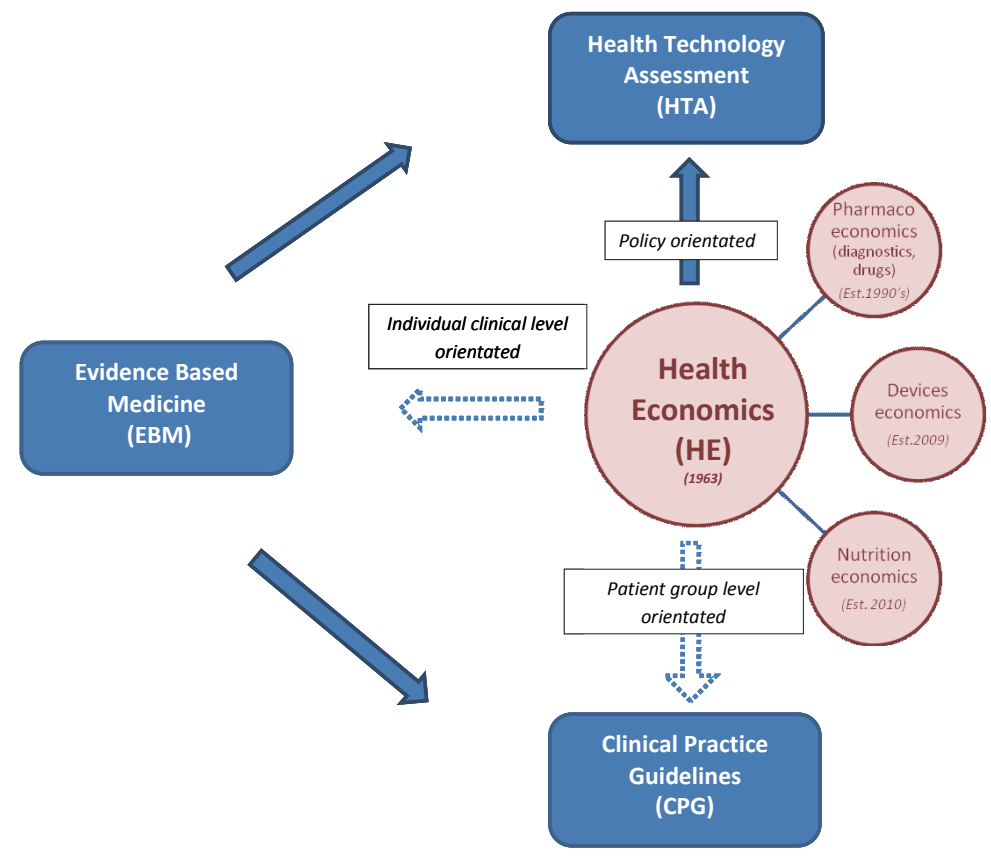

Figure 7.1 Nutrition economics within health economics.

Due to necessary budget constraints within health care, an even more prominent role for cost-effectiveness research is emerging. A recent report of the Dutch Health Care Insurance Board (CVZ) suggests the use of health economics data by health care professionals in the decision making on an individual clinical level as well as for patient groups through guidelines ${ }^{23}$, visualised by the dotted arrows in Figure 7.1. Therefore, we think that our visualised summary of the central role of HE (Figure 7.1) can help in the further development of the new specific HE sections, being Devices economics and Nutrition economics. Published discussions regarding the existing challenges in health economics for devices, medical nutrition and other nutrition interventions can for example be used as the basis for developing more detailed economic guidelines for these specific new HE sections ${ }^{8,13,17-19}$ (Chapter 6).

\section{Relevance for decision making within health care and clinical practice}

DRM is not a new problem and with an ageing population it is of particular concern in older people, as the risk is $40 \%$ higher in people aged over 65 years than in persons 
under this age ${ }^{2,4}$. Although publicity about under-nutrition in health care is increasing, prevalence rates are only slowly diminishing. Maybe more patients are screened for DRM and/or DRM isn't managed in an optimal way due to lack of knowledge. Using the results of our cost-of-illness analysis (Chapter 2) might help DRM in The Netherlands to be regarded just as much of a serious health care problem as obesity that needs to be managed, with a special focus on the elderly patients. Not surprisingly and contrary to obesity, the additional costs of DRM in The Netherlands appeared to be particularly high in patients of 60 years of age and over. Data revealing that costs relating to this malnutrition exceed those associated with obesity also in European countries might be used in a similar way for other countries than The Netherlands ${ }^{24}$.

To be successful in tackling this mostly not visible under-nutrition in contrast to overnutrition, it is essential to translate existing evidence into public health actions in fighting DRM like is done for our increasingly overweight society. This will require public-private partnerships involving governments, academia, health care institutions, civil society and the private sector as these groups have a key role in providing the necessary nutritional solutions. On a government level the acknowledgement of DRM might be achieved by safeguarding reimbursement for cost-effective nutritional interventions and by introducing more mandatory performance indicators on the management of DRM in all health care settings. Guidance on identification and managing patients with (risk of) DRM through education and creating and/or implementing evidence based guidelines, can help health care professionals and practitioners in their acknowledgement of this huge health care problem.

A determining part in health care decision making regards the ever more important cost-effectiveness evidence. As these health economics data is still relatively scarce for medical nutrition, the danger for being excluded in the current competitive health care funding is increasing. Therefore different stakeholders in the Dutch health care may use this thesis as a start in demonstrating the economic value of medical nutrition in the management of the costly DRM, in most cases even leading to cost savings. Particularly in the elderly patients suffering from DRM, the use of medical nutrition has shown to have economic value (Chapter 5). Since the costs of DRM are especially high in this patient group next to an ageing population, the DRM management in these elderly patients might be given priority from a health economic point of view.

Prior to initiating more health economic studies regarding this technology, it is prudent to firstly achieve consensus within a group of experts, followed by publicity, on the way to address specific methodological issues in the total evaluation of medical nutrition (Chapter 6). Unequivocally cost-effectiveness data of high quality will then most probably be realized, increasing the awareness regarding the value of an optimal DRM management, including medical nutrition, for the benefit of the patient as well as for the benefit of the health care. 


\section{References}

1. Ljungqvist O, de Man F. Under nutrition - a major health problem in Europe. Nutr Hosp 2009; 24: 368-370.

2. Russell CA, Elia M, on behalf of BAPEN and collaborators. Nutrition screening survey in the UK in 2008: hospitals, care homes and mental health units. A report by the British Association for Parenteral and Enteral nutrition (BAPEN). Redditch: BAPEN; 2009.

3. Norman K, Pichard C, Lochs H, et al. Prognostic impact of disease-related malnutrition. Clin Nutr 2008; 27: 5-15.

4. Elia M, Russell C. Combating malnutrition: recommendations for action. Report From the Group on Malnutrition, Led by BAPEN. Redditch, BAPEN; 2009.

5. Feldblum I, German L, Bilenko N, et al. Nutritional risk and health care use before and after an acute hospitalization among the elderly. Nutrition 2009; 25: 415-420.

6. Baal van PHM, Heijink R, Hoogenveen RT, et al. Health care costs of unhealthy behavior. Zorg voor euro's -3. National Institute for Public Health and the Environment (Rijksinstituut voor Volksgezondheid en Millieu -RIVM). RIVM rapport 270751015. Bilthoven, The Netherlands: RIVM; 2006:1-62. [Dutch].

7. Panhuis in 't - Plasmans M, Luijben G, Hoogenveen R. Health care costs of unhealthy behavior. Kosten van ziekten notities. National Institute for Public Health and the Environment (Rijksinstituut voor Volksgezondheid en Millieu -RIVM). KVZ 2012-2: 1 -22. [Dutch].

8. Lenoir-Wijnkoop I, Dapoigny $M$, Dubois $D$, et al. Nutrition economics: characterizing the economic and health impact of nutrition. BJN 2011; 105: 157-166.

9. Stratton RJ, Green CJ, Elia M. Disease-related malnutrition: an evidence based approach to treatment. Wallingford: CABI Publishing; 2003.

10. Meijers JMM, van Bokhorst-de van der Schueren MAE, Schols JMG, et al. Defining malnutrition: Mission or mission impossible? Nutrition 2010; 26: 432-440.

11. Joosten KF, Zwart H, Hop WC, et al. National malnutrition screening days in hospitalized children in The Netherlands. Arch Dis Child 2010; 95: 141-145.

12. Milte RK, Ratcliffe J, Miller MD, et al. Economic evaluation for protein and energy supplementation in adults: opportunities to strengthen the evidence. Eur J Clin Nutr 2013; 67: 1243-1250.

13. Drummond M, Griffin A, Tarricone R. Economic Evaluation for Devices and Drugs - Same or Different? Value in Health 2009; 12: 402-404.

14. Neelemaat F, Bosmans JE, Thijs A, et al. Oral nutritional support in malnourished elderly decreases functional limitations with no extra costs. Clin Nutr 2012; 31: 183-190.

15. Fight malnutrition. Malnutrition guidelines: Guideline screening and treatment of malnutrition 2012. Available at: http://www.fightmalnutrition.eu. Accessed November 25, 2013.

16. Gooszen HG, Blankensteijn HD, Borel Rinkes IHM, et al. Voeding. In: Leerboek Chirurgie, 2nd Ed., Houten: Bohn Stafleu van Loghum; 2012. p. 35-45. [Dutch].

17. Lenoir-Wijnkoop I, Nuijten MJC, Gutiérrez-Ibarluzea I, et al. Workshop Report: concepts and methods in the economics of nutrition - gateways to better economic evaluation of nutrition interventions. $B J N$ 2012; 108: 1714-1720.

18. Lenoir-Wijnkoop I, Jones PI, Uauy R, et al. Nutrition economics - food as an ally of public health. BJN 2013; 109: 777-784.

19. Taylor RS, Iglesias CP. Assessing the Clinical and Cost-Effectiveness of Medical Devices and Drugs: Are They That Different? Value in Health 2009; 12: 404-406.

20. Battista RN. Towards a paradigm for technology assessment. In: The scientific basis of health services. London, BMJ Publishing Group; 1996.

21. Timmermans S, Mauck A. "The promises and pitfalls of evidence-based medicine". Health Aff (Millwood) 2005; 24: 18-28. 
22. Velasco-Garrido M, Busse R. WHO on behalf of the European Observatory on Health Systems and Policies. Policy brief. Health technology assessment. An introduction to objectives, role of evidence, and structure in Europe. This policy brief is one of a series on health care issues by the European Observatory on Health Systems and Policies; 2005. Available at: http://www.euro.who.int/ __data/assets/pdf_file/0018/90432/E87866.pdf

23. Ligtenberg G, Staal PC, Goettsch et al. Cost-effectiveness in health care. A report of the Dutch Health Care Insurance Board 2013: 1-41. [Dutch]

24. MNI (Medical Nutrition International Industry). Oral nutritional supplements to tackle malnutrition: $a$ summary of the evidence base. 3rd version. Brussels; 2012: 1-273. 
Summary 


\section{Summary}

Without nutrition life is not possible. Already in the womb sufficient nutrition is needed for the embryo to evolve. From that time we have to eat and drink every day to provide our body with the nutrients needed to meet the requirements to prevent illness as well as to manage metabolic stress situations. Disease, injury, trauma or surgery are examples of such stress situations in which there is an increased need for specific nutrients to strengthen the functioning of our immune system and recovery among others. Malnutrition, meaning under-nutrition (lack of nutrients) in health care also known as disease related malnutrition (DRM) in this thesis, is leading to health impairment associated with high health care costs. DRM is one of the most important indications for the use of medical nutrition, which is a special food indicated to be used in the total treatment of patients. It comprises parenteral (intravenous) as well as enteral (via gastro-intestine) nutrition. The latter was the focus in this thesis and is regulated as "foods for special medical purposes "(FSMP), defined by the European Commission Directive 1999/21/EC independent of the route of application. FSMP products include oral nutritional supplements (ONS) as well as enteral tube feeding (ETF) via nasogastric, naso-enteral, or percutaneous tubes and contain regulated minimum and maximum levels of macro (carbohydrates, protein, fat) and micro (vitamins, minerals, trace-elements) nutrients. These products are not only confined to inpatients, but can also be used by outpatients either as a complete daily nutrition or as a supplement. FSMP has to be used under medical supervision and can be eligible for reimbursement. Over the years, evidence of the use of medical nutrition in the management of DRM has demonstrated functional as well as clinical benefits, but economic benefits are still rarely explored. This thesis therefore explores the health economic value as well as the methodological issues in the cost-effectiveness assessment of medical nutrition.

The introduction section consists of two parts. In the first part relevant background information is given about health economics (HE) including economic evaluations, medical nutrition and about disease related malnutrition as the most prevalent indication of medical nutrition. The second part describes the aims and the outline of this thesis.

To demonstrate the economic problem of DRM, we performed a cost-of-illness analysis for DRM in The Netherlands (Chapter 2). Results show that the total additional costs of DRM in adult patients in all health care settings were estimated to be $€ 1.9$ billion in 2011 which equals $2.1 \%$ of the total Dutch national health expenditure. The total additional costs for DRM were four times higher for the elderly patients (60 years of age and older) than for patients in the age category of $>18$ and $<60$ ( $€ 403$ million) and most costs (66\%) were attributable to the hospital setting ( $€ 1.2$ billion). Furthermore, 
the calculated costs of DRM per capita in The Netherlands were comparable to most of the estimated costs for other countries.

To estimate the health economic value of medical nutrition in the management of DRM, two health economic evaluations and a systematic review were performed. The first economic evaluation regarded the value of the use of ONS versus standard care, being no use of ONS, in Dutch abdominal adult surgery patients suffering from DRM. Results demonstrated that this intervention is cost-effective, even when the hospital length of stay would be unrealistic low ( 0.64 days) as shown by the threshold analysis. The use of ONS in this patient group lead to cost-savings and higher effectiveness and is thus a dominant approach over the standard care (Chapter 3)

In our second health economic analysis, the use of ONS versus standard care, being no use of ONS, was valued in the management of DRM in Dutch community dwelling elderly ( $\geq 65$ years). Also this economic evaluation showed that the additional costs of ONS were more than balanced by a reduction in the use of health care resources, decreasing the costs of DRM demonstrating the budget impact of using ONS in this population (Chapter 4).

To have a good overview of the international economic value of medical nutrition in the management of DRM, a systematic review was performed in which economic evaluations of enteral medical nutrition in the management of DRM in the Western and Eastern world (developed regions), were reviewed and qualified. Based on the high quality studies it was concluded that the use of enteral medical nutrition in the management of DRM can be efficient from a health economic perspective, leading in most cases to costs savings (Chapter 5).

Chapter 6 reports about an international expert workshop that was organized, in which the appropriate health economic assessment methods for medical nutrition in the management of DRM were explored and discussed. Issues in the assessment of both the validity and the reliability of evidence were scrutinized using statements. It was concluded that while the general principles of health economic assessment may apply to all forms of life sciences technology, specific characteristics of medical nutrition do have implications on the quality of the evidence available for a valid health economic evaluation. Consensus followed by improved publicity about the way to address the methodological issues in the health economic evaluation of medical nutrition are needed to improve the decision making on the management of DRM for the benefit of the patient as well as health care. Subsequently nutrition economic guidelines for medical nutrition may be developed to yield economic data of higher quality which is obtained in a consistent manner. 
The general discussion in Chapter 7 provides the main findings, results are discussed and methodological challenges and the following recommendations for practice and future research are given:

- It may be desirable to reach consensus on an international definition for malnutrition including a classification to specify the malnutrition type/syndrome determined by the cause and accompanied by a matching validated screening tool. For example, due to metabolic changes resulting from a metabolic stress situation, e.g. disease, surgery or trauma, the body is moving from an anabolic state to a catabolic state. Under-nutrition may then arise when the increased need for specific nutrients are not met, being DRM. When under- or over-nutrition is caused by socio-economic aspects, it might be useful to refer to this malnutrition type as socio-economic malnutrition.

- It might be helpful to also agree on alignment in the calculation methodology regarding the cost-of-illness for DRM to enable comparison in the magnitude of this health care problem across healthcare settings and countries. In order to make a more precise calculation of the Dutch DRM costs, further research is needed regarding concrete figures of the increased use of health care resources in nonhospital health care settings as well as data on the indirect health care costs and of the prevalence rate of DRM in the Dutch outpatient settings.

- To enable better comparison among the results of economic evaluations for interventions in the DRM management, the use of an unequivocal method can help.

- Health economic analyses estimating the cost-effectiveness of the implementation of the total guideline 'Screening and Treatment of Malnutrition' might be of interest for health care practitioners because of increasing budgets pressure in an era of competitive health care funding.

- Assessing the health economic value of medical nutrition in children suffering from DRM is lacking and therefore recommended.

- Our visualised summary of the central role of HE (Fig 1 in Chapter 6) can help in the further development of the new specific HE sections, being Devices economics and Nutrition economics. Published discussions regarding the existing challenges in health economics for devices, medical nutrition and other nutrition interventions can be used as the basis for developing more detailed economic guidelines for these specific new HE sections.

- To be successful in tackling this mostly not visible under-nutrition in contrast to over-nutrition, it is essential to translate existing evidence into public health actions in fighting DRM like is done for our increasingly overweight society. This will require public-private partnerships involving governments, academia, health care institutions, civil society and the private sector as these groups have a key role in providing the necessary nutritional solutions. On a government level the acknowledgement of DRM might be achieved by safeguarding reimbursement for 
cost-effective nutritional interventions and by introducing more mandatory performance indicators on the management of DRM in all health care settings. Guidance on identification and managing patients with (risk of) DRM through education and creating and/or implementing evidence based guidelines, can help health care professionals and practitioners in their acknowledgement of this huge health care problem.

- Since the costs of DRM are especially high in the elderly patient group next to an ageing population, the DRM management in these elderly patients might be given priority from a health economic point of view.

- Prior to initiating more nutrition economic studies, it is prudent to firstly achieve consensus within a group of experts, followed by publicity, on the way to address specific methodological issues in the total evaluation of medical nutrition (Chapter 6). Unequivocally cost-effectiveness data of high quality will then most probably be realized, increasing the awareness regarding the value of an optimal DRM management, including medical nutrition, for the benefit of the patient as well as for the benefit of the health care. 
Samenvatting 


\section{Samenvatting}

Zonder voeding is leven niet mogelijk. Al in de baarmoeder heeft de embryo voldoende voeding nodig om zich te kunnen ontwikkelen. Vanaf dat moment hebben we dagelijks eten en drinken nodig om ons lichaam van voedingsstoffen te voorzien die nodig zijn om te voorkomen dat we ziek worden en om metabole stress situaties het hoofd te kunnen bieden. Ziekte, verwonding, trauma of een chirurgische ingreep zijn voorbeelden van dergelijke stress situaties waarin er een grotere behoefte bestaat aan specifieke voedingsstoffen om o.a. ons immuunsysteem en herstel te kunnen versterken. Ondervoeding, waarmee in dit proefschrift een tekort aan voedingsstoffen bij patiënten (gezondheidszorg) bedoeld wordt, ook wel bekend als ziektegerelateerde ondervoeding (ZGO), leidt tot een verslechtering van de gezondheid en gaat gepaard met hoge gezondheidszorgkosten. ZGO is een van de belangrijkste indicaties voor het gebruik van medische voeding, hetgeen een speciale voeding is die gebruikt dient te worden als onderdeel van de totale behandeling van een patiënt. Het omvat zowel parenterale (intraveneus) als enterale (via maag-darmkanaal) voeding. Dit proefschrift richt zich op laatstgenoemde en is wettelijk vastgelegd als "dieetvoeding voor medisch gebruik" (DvMG) en moet voldoen aan voorwaarden zoals omschreven in de Richtlijn 1999/21/EG van de Europese Commissie, onafhankelijk van de toedieningsvorm. Zowel orale medische voeding (ONS) als sondevoeding (ETF) via een neus-maag, neus-darm of percutane sondes zijn DvMG producten en bevatten gereguleerde minimum en maximum hoeveelheden van macro- (koolhydraten, eiwit, vet) en microvoedingsstoffen (vitamines, mineralen, spore-elementen). Deze medische voedingen zijn niet alleen bestemd voor klinische patiënten (intramurale setting), maar kunnen ook gebruikt worden door patiënten buiten een gezondheidszorginstelling (extramurale setting), als een complete dagelijkse voeding of als supplement. DvMG dient onder medisch toezicht gebruikt te worden en kan in aanmerking komen voor vergoeding. In de loop der jaren heeft wetenschappelijk bewijs aangetoond dat het gebruik van medische voeding als onderdeel van de totale medische behandeling, zowel functionele als klinische voordelen heeft, echter economische voordelen zijn nog weinig onderzocht. Dit proefschrift onderzoekt daarom wat de gezondheids-economische waarde en de methodologische aspecten zijn in de evaluatie van de kosteneffectiviteit van medische voeding.

De introductie bestaat uit twee delen. In het eerste deel wordt relevante achtergrondinformatie gegeven over gezondheidseconomie inclusief economische evaluaties, over medische voeding en over ziektegerelateerde ondervoeding als de meest voorkomende indicatie voor medische voeding. In deel twee worden de doelstellingen en de opbouw van dit proefschrift beschreven. 
Om het economisch probleem van ZGO aan te tonen, hebben we een kosten-van-ziekte analyse uitgevoerd betreffende ZGO bij volwassenen in Nederland (Hoofdstuk 2). Resultaten laten zien dat de totale additionele kosten van ZGO bij volwassenen in alle gezondheidszorginstellingen werden geraamd op $€ 1,9$ miljard in 2011, hetgeen overeenkomt met $2,1 \%$ van de totale Nederlandse gezondheidszorg-uitgaven. De totale additionele kosten van ZGO waren vier keer hoger voor ouderen (60 jaar en ouder) dan voor patiënten in de leeftijd van $>18$ en $<60$ jaar ( $€ 403$ miljoen) en de meeste kosten (66\%) werden gemaakt in het ziekenhuis (€1,2 miljard). Verder waren de berekende kosten van ZGO per capita in Nederland vergelijkbaar met de meeste geraamde kosten in andere landen.

Om de gezondheidseconomische waarde van medische voeding als onderdeel van de totale behandeling van ZGO in te schatten, zijn twee gezondheidseconomische evaluaties en een systematische review uitgevoerd. De eerste economische evaluatie onderzocht de waarde van het gebruik van orale medische voeding (ONS) ten opzichte van de gebruikelijke zorg, geen ONS, bij volwassen Nederlandse buikchirurgische patiënten met ZGO. Resultaten toonden aan dat deze interventie kosteneffectief is, zelfs wanneer de ziekenhuisverblijfsduur onrealistisch kort (0,64 dagen) zou zijn, zoals de drempel analyse liet zien. Het gebruik van ONS in deze patiënten groep leidt zowel tot kostenbesparingen als ook tot betere effectiviteit en is daarom een dominante aanpak ten opzichte van de gebruikelijke zorg (Hoofdstuk 3).

In onze tweede gezondheidseconomische analyse werd de waarde bepaald van de inzet van ONS ten opzichte van de gebruikelijke zorg (geen ONS), in het totale management van ZGO bij Nederlandse ouderen ( $\geq 65$ jaar) in de extramurale zorg. Ook deze economische evaluatie liet zien dat de additionele kosten van ONS meer dan gecompenseerd werden door een reductie in het gebruik van gezondheidszorgvoorzieningen, leidend tot een verlaging van de ZGO kosten en daarmee de budget impact aantoonde van ONS inzet in deze populatie (Hoofdstuk 4).

Om een goed overzicht te hebben van de economische waarde van medische voeding in het ZGO management op internationaal niveau, werd een systematische review uitgevoerd waarin economische evaluaties van enterale medische voedingen als onderdeel van het ZGO management in de Westerse en Oosterse wereld (ontwikkelde gebieden) beoordeeld en gekwalificeerd werden. Op basis van de hoge kwaliteit studies werd geconcludeerd dat het gebruik van enterale medische voeding als onderdeel van het ZGO management vanuit een gezondheidseconomisch oogpunt efficiënt kan zijn, in de meeste gevallen leidend tot kostenbesparingen (Hoofdstuk 5).

Hoofdstuk 6 doet verslag van een internationale expert workshop die werd georganiseerd, waarin de geschikte gezondheidseconomische evaluatiemethoden 
onderzocht en bediscussieerd werden voor medische voeding in het ZGO management. Vraagstukken in de evaluatie van zowel de validiteit als de betrouwbaarheid van bewijs werden onder de loep genomen aan de hand van stellingen. Er werd geconcludeerd, dat ondanks het gegeven dat de algemene beginselen van gezondheidseconomische evaluaties van toepassing kunnen zijn op alle vormen van levenswetenschappelijke technologiën, de specifieke kenmerken van medische voeding toch consequenties hebben betreffende de kwaliteit van het voorhande zijnde bewijs om een geldige gezondheidseconomische evaluatie te kunnen uitvoeren. Om de besluitvorming betreffende het ZGO management te kunnen verbeteren ten behoeve van zowel de patiënt als de gezondheidszorg, is het nodig dat er consensus bereikt wordt over de wijze waarop de methodologische kwesties in de gezondheidseconomische evaluatie van medische voeding aangepakt moeten worden, gevolgd door het binnen de wetenschap bekend maken daarvan. Vervolgens zouden er voedingseconomische richtlijnen voor medische voeding ontwikkeld kunnen worden om economische data van hogere kwaliteit te kunnen leveren die op een consistente wijze verkregen zijn.

De algemene discussie in Hoofdstuk 7 beschrijft de belangrijkste bevindingen van dit proefschrift, resultaten worden besproken en methodologische uitdagingen en de daarop volgende aanbevelingen voor de praktijk en toekomstig onderzoek zijn op een rij gezet:

- Het kan wenselijk zijn om consensus te bereiken over een internationale definitie van ondervoeding, waarin ook een classificatie gegeven wordt op basis van de betreffende oorzaak, om het type/syndroom van ondervoeding te kunnen bepalen, alsmede dat er een bijpassend gevalideerd screeningsinstrument gegeven wordt. Bijvoorbeeld, het lichaam verandert van een metabole toestand in een katabole toestand door metabole veranderingen die ontstaan als gevolg van een metabole stress situatie, zoals ziekte, een operatie of trauma. Als er vervolgens niet voorzien wordt in de dan ontstane verhoogde behoefte aan voedingsstoffen kan ondervoeding ontstaan, zijnde ZGO. Wanneer onder- of overvoeding wordt veroorzaakt door socio-economische aspecten, kan het nuttig zijn om dit type als socio-economische ondervoeding te betitelen.

- Het kan nuttig zijn om ook overeenstemming te bereiken over een eenduidige rekenmethode betreffende de kosten-van-ziekte voor ZGO, om de omvang van dit probleem in de gezondheidszorg in verschillende instellingen en landen met elkaar te kunnen vergelijken.

- Om een meer precieze berekening te kunnen maken van de Nederlandse ZGO kosten, is verder onderzoek nodig naar concrete cijfers over zowel het toegenomen gebruik van gezondheidszorgvoorzieningen buiten het ziekenhuis als ook data over de indirecte gezondheidszorgkosten en de prevalentie van ZGO in de Nederlandse extramurale zorg. 
- Om de resultaten van economische evaluaties van interventies in het ZGO management beter met elkaar te kunenn vergelijken, zou het kunnen helpen om ook daarvoor een eenduidige methode te hanteren.

- Gezondheidseconomische analyses waarin de kosteneffectiviteit van het handelen volgens de richtlijn 'Screening en behandeling van ondervoeding' berekend is, kan nuttig zijn voor zorgverleners vanwege de toenemende druk op budgetten in een tijdperk van concurrerende gezondheidszorgfinanciering.

- Er zijn nog geen evaluaties beschikbaar die de gezondheidseconomische waarde van medische voeding berekenen bij kinderen met ZGO en deze worden derhalve aanbevolen om uit te voeren.

- Ons gevisualiseerde overzicht van de centrale rol van gezondheidseconomie (figuur 1 in Hoofdstuk 6) kan helpen bij de verdere ontwikkeling van de nieuwe specifieke gebieden binnen de gezondheidseconomie, zijnde hulpmiddelen-economie en voedingseconomie. De gepubliceerde discussies over de bestaande uitdagingen in de gezondheidseconomie voor hulpmiddelen, medische voeding en andere voedingsinterventies kunnen gebruikt worden als basis voor het ontwikkelen van meer gedetailleerde economische richtlijnen voor deze specifieke nieuwe gebieden binnen de gezondheidseconomie.

- In de strijd tegen ZGO is het van essentieel belang om bestaand bewijs om te zetten in volksgezondheidsacties om deze meestal onzichtbare ondervoeding in tegenstelling tot overvoeding, succesvol te kunnen aanpakken zoals gedaan wordt in de strijd tegen het toenemende probleem van overgewicht in onze samenleving. Hiervoor zijn openbare-particuliere samenwerkingsverbanden nodig, waarbij de overheid, universiteiten, zorginstellingen, de burgermaatschappij en de particuliere sector betrokken zullen moeten zijn, aangezien deze groepen een belangrijke rol hebben in het verstrekken van de nodige oplossingen inzake voeding. Op overheidsniveau zou ZGO erkenning kunnen krijgen door het waarborgen van vergoeding van kosteneffectieve voedingsinterventies en door de invoering van meer verplichte prestatie-indicatoren betreffende het ZGO management in alle zorginstellingen. Zorgverleners kunnen geholpen worden in hun erkenning van dit enorme probleem binnen de gezondheidszorg, door via onderwijs en het ontwikkelen en/of implementeren van evidence-based richtlijnen te helpen bij de herkenning en het managen van patiënten met (risico op) ZGO.

- $\quad$ Aangezien de kosten van ZGO vooral aanzienlijk zijn bij oudere patiënten bovenop een vergrijzende bevolking, zou vanuit een gezondheidseconomisch oogpunt prioriteit gegeven kunnen worden aan het management van het ZGO probleem bij deze oudere patiënten.

- Voordat er meer voedingseconomische studies geïnitieerd worden, is het verstandig om eerst consensus te bereiken binnen een groep van deskundigen over de wijze waarop specifieke methodologische kwesties in de totale evaluatie van medische voeding aangepakt moeten worden, gevolgd door het binnen de 
wetenschap bekend maken daarvan (hoofdstuk 6). Eenduidige kosteneffectiviteitsdata van hoge kwaliteit zal dan naar alle waarschijnlijkheid verkregen kunnen worden, hetgeen de bewustwording zal vergroten inzake de waarde van een optimaal ZGO management, inclusief medische voeding, in het voordeel van zowel de patiënt als van de gezondheidszorg. 
Dankwoord 


\section{Dankwoord}

Hoe het allemaal begon... ik weet het nog heel goed....In de zomer van 2010, tijdens een overleg met leden van de LPZ (Landelijke Prevalentiemeting Zorgproblemen) projectgroep, vroeg Prof. Dr. Jos Schols aan mij of ik weleens gedacht had aan promoveren. Deze vraag kwam voor mij als een complete verassing, aangezien ik promoveren nog nooit overwogen had. Ik voelde mij zeer gevleid aangezien Prof. Dr. Jos Schols mij deze vraag stelde naar aanleiding van mijn toelichting op de door mij gemaakte overzichten van health economics data betreffende medische voeding. Vanaf dat moment ben ik me gaan verdiepen in mijn mogelijkheden om naast mijn full-time baan te kunnen promoveren. Na enig onderzoek in de reglementen van de Maastricht Universiteit betreffende een extern PhD traject, het invullen van formulieren en enige overlegmomenten met mijn werkgever, was ik per medio november 2011 officieel ingeschreven als externe PhD kandidaat bij de School for Public Health and Primary Care (CAPHRI) van de Maastricht Universiteit. In januari 2012 ben ik vervolgens vol overgave van start gegaan met het promotietraject, waarvoor ik twee jaar de tijd had gekregen. Op 5 februari 2014 kreeg ik het mooie verlossende woord van de beoordelingscommissie dat mijn proefschrift unaniem was goedgekeurd. Daarna nog de laatste puntjes op de i, zoals dit dankwoord, en dan zal dit proefschrift in zijn volledigheid gedrukt kunnen worden; wat een overheerlijk gevoel!

Met dit dankwoord wil ik graag iedereen bedanken die heeft bijgedragen aan het tot stand komen van dit proefschrift:

Allereerst mijn promotor, Prof. dr. Jos M.G.A. Schols, die mij gevraagd heeft om bij hem te komen promoveren. Jos, zonder jou was ik nooit aan deze mooie uitdaging begonnen. Heel veel dank dat jij mogelijkheden bleef zien om dit traject aan te gaan, terwijl ik in het begin grote twijfels had om te kunnen promoveren naast mijn full-time baan en deze uitdaging bijna was misgelopen. Jouw steun door steeds weer complimenten te geven over mijn werk, hebben mij zoveel goed gedaan. Ik kreeg hierdoor vleugels en mijn zelfvertrouwen is hierdoor gegroeid. Heel veel dank voor al je steun en jouw immer blijvende vertrouwen in mij. Jos, ik hoop van harte dat we ook na dit mooie traject nog zullen samenwerken.

Mijn copromotores, Dr. Ruud J.G. Halfens, Dr. Judith M.M. Meijers en Dr. Mark J.C. Nuijten, voor al jullie steun en wijsheid, waarvan ik veel geleerd heb. Ruud en Judith op het gebied van ziektegerelateerde ondervoeding en Mark op het gebied van gezondheidseconomie. Samen met Jos waren jullie voor mij een super team! Een speciale dank aan Mark Nuijten. Mark, wij hebben elkaar leren kennen in 2008 toen ik jou had gekozen als de health economics consultant om samen een economische evaluatie uit te voeren. Sinds die tijd zijn wij goede vrienden geworden en heb jij mijn co-promotor willen zijn, hetgeen je volledig belangeloos en in je schaarse privé tijd hebt 
gedaan. Tevens heb ik via jou Irene leren kennen en hebben wij elkaar kunnen introduceren in de wereld van health economics en medische voeding, hetgeen voor ons beiden zeer waardevol gebleken is. Lieve Mark, heel veel dank dat jij dit allemaal voor mij hebt willen doen! Ik hoop nog heel lang goede vrienden te blijven!

The members of the appraisal committee: Prof. dr. S.M.A.A. Evers, Prof. dr. M. Elia (University of Southampton, United Kingdom), Prof. dr. W.N.J. Groot, Prof. dr. ir. C.P.G.M. de Groot (Wageningen University \& Research centre) and Prof. dr. A.M.W.J. Schols. Thank you all very much that you were willing to take the time to read and appraise my PhD thesis. A special thanks to Prof. dr. Elia as I am honoured that you have found the time to travel to Maastricht from the UK to be present as one of the members of the appraisal committee. Also a special thanks to Prof. dr. Silvia Evers, who I met during one of the European ISPOR (International Society for Pharmacoeconomics and Outcomes Research) congresses and who became more and more interested in nutrition when we talked about this subject during the years thereafter. Together with her, Mark Nuijten and Irene Lenoir-Wijnkoop, we have founded our ISPOR Special Interest Group (SIG) "Nutrition Economics", for which I am really proud that we succeeded in having formed this SIG. Thank you Silvia for being the chair of both the appraisal committee and the SIG.

Opponenten, Prof. Dr. Paul A.M.M. van Leeuwen en Dr. Koen F.M. Joosten. Heel veel dank dat jullie een gaatje in jullie drukke agenda wilden maken om tijdens mijn promotieplechtigheid te oponeren.

All the co-authors of my publications: thank you so very much for working with me on the manuscripts to improve the quality resulting in having the manuscripts published. I have learned a lot from you.

Irene Lenoir-Wijnkoop. Lieve Irene, we hebben elkaar leren kennen via Mark N, toen we in 2009 samen met Mark en Marten Poley voor het eerst met elkaar om de tafel gingen zitten om te brainstormen over de expert meetings -die we ook daadwerkelijk georganiseerd hebben- waarin voeding en gezondheidseconomie aan elkaar gekoppeld worden. Tijdens deze eerste meeting werd duidelijk dat we ons, beiden als voedingskundige/diëtist, sinds 2007 onafhankelijk van elkaar zijn gaan verdiepen in health economics. Jij vanuit jouw positie bij Danone Research in Frankrijk op het gebied van functional en consumer food en ik vanuit mijn functie bij Nutricia Advanced Medical Nutrition in Nederland op het gebied van medische voeding. Onze eerste expert meeting was een succes en de definitie van "Nutrition Economics" was geboren. Sindsdien hebben we veel contact en zijn we goede vriendinnen geworden en volgden er nog 2 expert meetings m.b.t. dit onderwerp. Helaas kon ik wegens omstandigheden tot mijn grote spijt geen co-auteur zijn van de eerste twee publicaties. Echter, voor het 
laatste manuscript, dat op dit moment onder review is bij een internationaal tijdschrift en hopelijk voor publicatie geaccepteerd zal worden, zijn we dan eindelijk beiden auteurs. Als 'founders' van de SIG "Nutrition Economics", samen met Mark en Silvia, zullen we gelukkig nog veel in de toekomst samenwerken om (medische) voeding nog beter op de kaart te zetten, zowel binnen als buiten de gezondheidszorg. lets waarin wij als voedingskundigen zo geloven en waarvoor we zullen blijven strijden. Irene, heel veel dank voor al je support en samenwerking. Ik ben blij dat ik je heb leren kennen en dat we samen ons doel kunnen nastreven.

Mijn dierbare familie. Lieve pap en mam, dank jullie wel voor jullie immer durende liefde en dat jullie ons als kinderen alles hebben gegeven wat we ons maar hebben kunnen wensen. Heel veel dank voor wat jullie allemaal voor ons hebben gedaan. Mede daarom ben ik gekomen waar ik nu sta. Ook wil ik nog mijn grootvader Dr. Johan Hendrik Christiaan Freyer, huisarts gepromoveerd op het onderwerp van stuitligging, noemen die altijd zo trots was op zijn familie en hopelijk op een of andere wijze ziet dat ik mijn promotie mag beleven. Mijn zusjes In en Tam - de 3 zusjes die alles met elkaar kunnen bespreken, hetgeen we ook regelmatig doen en hopelijk ook altijd zullen blijven doen! En 'last but certainly not least' mijn broertje Robin en zijn gezin. Lieve allemaal, heel veel dank voor jullie onvoorwaardelijke steun, geduld en liefde. Love you so much!

Mijn paranimfen, zijnde mijn zusje Ingrid en mijn broertje Robin. Lief zusje en broertje, dank jullie wel dat jullie mijn paranimfen willen zijn en dat ik het mooie moment van mijn promotie op deze wijze met jullie kan delen.

Al mijn vrienden. Lieve allemaal, dank jullie wel voor jullie steun en de interesse die jullie telkens weer toonden in het verloop van mijn PhD traject. Echt geweldig. Ik hoop dat we nog heel lang vrienden mogen zijn.

Geert. We kennen elkaar al sinds 2000 en na onze relatie zijn we altijd maatjes gebleven, dat hopelijk nog lang zal voortduren. Ondanks onze 'scheiding', heb jij een speciale plek in mijn hart.

De sponsors, en (ex)collega's van Nutricia Advanced Medical Nutrition in Zoetermeer en in het hoofdkantoor in WTC te Schiphol. Dank jullie wel dat ook jullie steeds interesse bleven tonen in mijn PhD traject en mij gesteund hebben op meerdere vlakken. Speciale dank aan $\mathrm{HH}$ (Hoof ;)), die het mooie gedicht aan het begin van dit proefschrift speciaal voor mij geschreven heeft. Hoof, super veel dank - je hebt talent hoor!! Jij en nog een paar anderen zijn voor mij meer dan alleen collega's!

Allen, ieder in zijn/haar eigen rol, nogmaals heel veel dank; ik ben een intens gelukkig mens dat ik met jullie steun en liefde mijn promotie heb kunnen en mogen realiseren. 
About the author 


\section{About the author}

Karen Freijer was born on $3^{\text {rd }}$ of April 1967 in Amsterdam. After finishing secondary school at the Nieuw Lyceum in Hilversum (VWO in 1985) she first got her Board Secretary licence before starting the college education in Nutrition and Dietetics at the University of Applied Sciences (HvA, Amsterdam). In 1992 she received her Bachelor in Health Science degree, with specialization into methodology. After her graduation she worked in various functions: sales representative for Pfizer BV, temporarily in charge of a private dietician practice, nutritionist in nutritional food

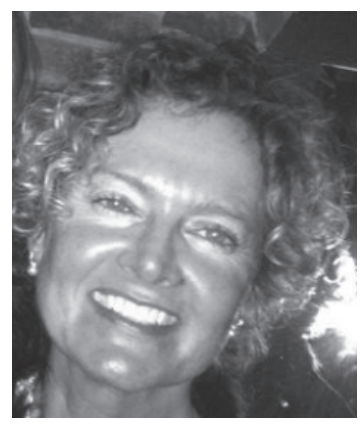
supplement companies and several functions within Nutricia Advanced Medical Nutrition (NAMN). Since 2007 she has been specializing in health economics and market access in her function as a HE/MA manager at NAMN which in the end of 2011 resulted in starting this PhD study at the University of Maastricht alongside her working career at NAMN. 
Publications 


\section{List of publications}

\section{International journal articles/abstracts}

\section{Related to PhD thesis}

Freijer K, Lenoir-Wijnkoop I, Russell CA, Koopmanschap MA, Kruizenga HM, Lhachimi SK, Norman K, Nuijten MJC, Schols JMGA. Nutrition economics - The view of international experts regarding health economics for medical nutrition in disease related malnutrition. Submitted for publication 2014.

Freijer K, Bours MJL, Nuijten MJC, Poley MJ, Meijers JMM, Halfens RJG, Schols JMGA. The economic value of enteral medical nutrition in the management of Disease Related Malnutrition: a systematic review. JAMDA 2014; 15: 17-29.

Freijer K, Tan SS, Koopmanschap MA, Meijers JMM, Halfens RJG, Nuijten MJC. The economic costs of disease related malnutrition. Clin Nutr 2013; 32: 136-141.

Freijer K, Nuijten MJ and Schols JM. The budget impact of oral nutritional supplements for disease related malnutrition in elderly in the community setting. Front. Pharmacol. 2012; 3; 78: 1-8.

Freijer K, Nuijten MJC. Analysis of the health economic impact of medical nutrition in The Netherlands. EJCN 2010; 64: 1229-1234.

Nuijten MJC, Freyer K. The Budget Impact of oral nutritional supplements in the community setting in the Netherlands. Value in Health 2010; 13; 3: A101 (abstract \& poster; Poster awarded as one of the Finalist Best Poster of ISPOR congress 2010).

Freyer K, Nuijten MJC. The Health Economic Impact of oral nutritional supplements in the community setting in the Netherlands. Value in Health 2010; 13; 3: A101 (abstract \& poster).

Nuijten MCJ, Freyer K, Green CJ. Cost-effectiveness of food for special medical purposes relative to standard care in patients undergoing abdominal surgery. Value in Health 2008; 11 (6): A632 (abstract \& poster).

\section{Other}

Freijer K, Lenoir-Wijnkoop I, Nuijten MJC, Evers SMAA. Nutrition in health care: from clinical to health economic value. Foundation of a new Special Interest Group "Nutrition Economics". Submitted for publication 2014. 
Péter $S$, Eggersdorfer $M$, van Asselt $D$, van den Berg $M$, Buskens $E$, Detzel $P$, Freijer $K$, Koletzko B, Kraemer K, Kuipers F, Neufeld L, Obeid R, Wieser S, Zittermann A, Weber P. Healthy ageing and the economic impact of inadequate nutrient intake. Submitted for publication 2014.

Freyer K, Nuijten MJC. The Health Economic Impact of oral nutritional supplements in the hospital setting in Germany. Value in Health 2010; 13; 3: A101 (abstract \& poster).

Nuijten MJC, Freyer K. The Health Economic Impact of oral nutritional supplements in residential care in Germany. Value in Health 2010; 13; 3: A102 (abstract \& poster).

Nuijten MJC, Freyer K. The Health Economic Impact of oral nutritional supplements in ambulatory setting in Germany. Value in Health 2010: 13; 3: A102 (abstract \& poster).

\section{National journal articles}

Freijer K. Behandeling ziektegerelateerde ondervoeding Noodzakelijk \& Kosteneffectief. De ondervoedingskrant - uitgave ter gelegenheid van de dag van de ondervoeding 2013; 11 december: 8.

Freijer K. Ziektegerelateerde ondervoeding bij ouderen vier keer duurder dan bij jongeren. Voeding NU 2012; nr 8/9: 6.

Freyer K. De Do's \& Don'ts van Diëten. Yes 1999; 12: 42-43.

\section{Oral presentations related to $\mathrm{PhD}$ thesis}

The health economics of (disease related) malnutrition. Symposium "Underernæring og helseøkonomi". Oslo, Norway, January $16^{\text {th }} 2013$.

The economic value of medical nutrition. Workshop "Healthy Ageing and Economic Impact of Micronutrients Intake". Groningen, The Netherlands, April $4^{\text {th }} 2013$.

Behandeling van ziektegerelateerde ondervoeding noodzakelijk \& kosteneffectief. Stuurgroep Ondervoeding ism Eerstelijns OndervoedingsInstituut (EOI) "Cursus Diagnostiek en behandeling ondervoeding - implementatie van de dieetbehandelingsrichtlijn ondervoeding". 24 mei (Houten), 7 juni (Zoetermeer), 16 september (Zwolle), 23 september (Amsterdam) 28 oktober (Tilburg), The Netherlands 2013.

The health economics of (disease related) malnutrition. NSKE (Nors Selskap for Klinisk Ernæring) Conference "Ernæringsbehandling - hvorfor og hvordan". Oslo, Norway, January $16^{\text {th }} 2014$. 
Health Economic Outcomes Associated with Nutritional Screening-assessmentintervention: Added Value We Can't Afford to Ignore. 35th Nutritional RiskUndernutrition-Support- Outcome- Cost/Effectiveness (NUSOC) Database Co-op Team Workshop. Bejing, China, April $12^{\text {th }} 2014$.

Nutrition Economics \& Disease Related Malnutrition. Danish Society of Clinical Nutrition and Metabolism “Annual meeting of Clinical Nutrition". Copenhagen, Denmark, May $9^{\text {th }}$ 2014.

Media attention in NL regarding publication Freijer $K$, Tan SS, Koopmanschap MA, Meijers JMM, Halfens RJG, Nuijten MJC. The economic costs of disease related malnutrition. Clin Nutr 2013; 32: 136-141. (Chapter 2)

De Limburger. Ondervoeding kost kapitalen. 17 juli 2012; pag 1.

http://www.foodholland.nl/nieuws/artikel.html?id=139934

http://www.spitsnieuws.nl/archives/binnenland/2012/07/ondervoede-

pati\%C3\%ABnten-kosten-miljarden

http://www.bndestem.nl/nieuws/algemeen/binnenland/11393355/Ondervoedingkost-kapitalen.ece

http://www.ed.nl/nieuws/algemeen/binnenland/11393355/Ondervoeding-kost-

kapitalen.ece

http://www.pzc.nl/nieuws/algemeen/binnenland/11393355/Ondervoeding-kost-

kapitalen.ece

http://www.dagelijksestandaard.nl/2012/07/we-zijn-kapitalen-kwijt-aan-ondervoeding http://www.nujii.nl/algemeen/ondervoeding-kost-

kapitalen.17982301.lynkx\#axzz20zfmsMm8

http://www.destentor.nl/regio/11393355/Ondervoeding-kost-kapitalen.ece

http://www.gelderlander.nl/nieuws/algemeen/binnenland/11393355/Ondervoeding-

kost-kapitalen.ece

http://www.limburg24.nl/ondervoeding-kost-kapitalen/

http://www.food-hospitality.nl/nieuws/fho-carrousel/ondervoeding-is-duurder-dan-

obesitas.172276.lynkx

http://www.voedingnu.nl/ondervoeding-is-duurder-dan-obesitas.172277.lynkx

Gooi \& Eemlander, 17th July 2012

Radio 2/Knooppunt Kranenborg on 17th of July 2012 (afternoon)

4nieuws.nl/show.php?key=407286\&amp;titel... 
Valorisation 


\section{Valorisation}

\section{Relevance}

Malnutrition, meaning under-nutrition (lack of nutrients) in health care also known as disease related malnutrition (DRM) in this thesis, is still an undervalued health problem, leading to health impairment associated with high health care costs. To be successful in tackling this mostly not visible under-nutrition in contrast to over-nutrition, it is essential to keep raising awareness about the clinical consequences as well as to show the economic impact on society. In addition, evidence on the costs-benefits relationship of its management techniques, such as medical nutrition, is crucial to be applied in health care; now more than ever. Malnutrition is not a new problem and with an ageing population DRM continues to become a major public health concern, as increasing age is associated with an increased risk of malnutrition (Chapter 1 ). This thesis provides an understanding of the problem as well as to have some insights about the economic value of medical nutrition in the total management of DRM.

\section{Target groups}

See 7.4 on page 120

\section{Activities/Products}

A practical calculation tool has been developed based on the results of this thesis which is used to compute the additional costs of DRM for individual hospitals and/or department within a hospital as well as to estimate the costs-benefits of using medical nutrition as part of the total management of DRM.

Also a Special Interest Group (SIG) within the International Society for Pharmacoeconomics and Outcomes Research (ISPOR) is founded, partly due to the conducted research and results of this thesis.

Furthermore, international Societies of Clinical Nutrition and Metabolism showed interest in the results by inviting me as a speaker during their national annual meetings of 2013 and 2014 and Chapter 2 of the thesis got a lot of Dutch media attention (see Chapter 12 on page 153).

\section{Innovation}

For pharmaceuticals and other health technologies, including devices, Health Technology Assessment (HTA) is common practice, in particular for submission of health economics data to support application for reimbursement. Reimbursement agencies in different countries have issued evaluation guidelines, resulting in a large number of published research papers on economic evaluation of health technologies. From 2009 onwards specialists have argued that specific methodological issues in the 
assessment of the evidence (effectiveness and cost-effectiveness) of medical devices are more challenging than for other pharmaceuticals. It was concluded that these issues therefore require particular attention in conducting reliable evaluations. The same applies for (medical) nutrition. To gain a better understanding of the significant influence of (medical) nutrition on health outcomes, and related economics, a multidisciplinary expert group introduced in 2010 "Nutrition Economics" as a novel discipline within Health Economics which has been defined as "a discipline dedicated to researching and characterizing health and economic outcomes in nutrition for the benefit of society" (see Chapter 1, 6 and 7).

\section{Schedule \& Implementation}

In Chapter 8 on page $129-130$ recommendations for practice and future research are given. 